\title{
Field Testing and Demonstration of the Smart Monitoring and Diagnostic System (SMDS) for Packaged Air Conditioners and Heat Pumps
}

May 2015

Prepared for the U.S. Department of Energy By:

Danny Taasevigen Michael R. Brambley Yunzhi (Lucy) Huang Robert Lutes Spencer Gilbride Pacific Northwest National Laboratory 


\section{Disclaimer}

This document was prepared as an account of work sponsored by the United States Government. While this document is believed to contain correct information, neither the United States Government nor any agency thereof, nor [report author], nor any of their employees, makes any warranty, express or implied, or assumes any legal responsibility for the accuracy, completeness, or usefulness of any information, apparatus, product, or process disclosed, or represents that its use would not infringe privately owned rights. Reference herein to any specific commercial product, process, or service by its trade name, trademark, manufacturer, or otherwise, does not constitute or imply its endorsement, recommendation, or favoring by the United States Government or any agency thereof, or Pacific Northwest National Laboratory. The views and opinions of authors expressed herein do not necessarily state or reflect those of the United States Government or any agency thereof or Pacific Northwest National Laboratory.

The work described in this report was funded by the U.S. Department of Energy under Contract No. DE-AC0576RL01830.

\section{Acknowledgements}

Demonstration facility, Pritchett Controls: Bob Carbonella, Nate Pritchett and Dan Zebroski

Demonstration facility, Greencon: José Ventura

United States Department of Energy (DOE): Charles Llenza and Amy Jiron, DOE Managers for the project Pacific Northwest National Laboratory: Linda Sandahl, Project Manager; Sriram Somasundaram, peer reviewer; Susan Arey, editorial revicew; and Joe Petersen and Ron Underhill for technical assistance and advice.

NorthWrite Inc.: David Burchfiled, Paul Bursch, Jim Erickson, Curtis Haugen, Terrence McManus, Sarah Benjamin, and Patrick O'Neil

Universal Devices: Michel Kohanim and Stuart Britton

NYSERDA: Anthony W. Abate

For more information contact:

Tech Demo Reports

Mail Stop EE-5B

US Department of Energy

1000 Independence Ave, SW

Washington, DC 20585-0121

techdemo@ee.doe.gov 


\section{Executive Summary}

Packaged air conditioners and heat pumps, commonly known as rooftop units (RTUs), serve approximately 2.1 million buildings in the U.S., serving more than 39 billion square feet of commercial-building floor space. They provide primary heating, ventilating and air conditioning for most commercial buildings with floor areas of less than $50,000 \mathrm{ft}^{2}$ and supplemental cooling for parts of larger buildings. RTUs consume an estimated 628 trillion Btu of site energy annually corresponding to 1900 trillion Btu of primary energy each year. Although RTUs provide cooling for more than $68 \%$ of cooled non-mall commercial floor space, they are ordinarily one of the most poorly maintained of all heating, ventilating and air-conditioning equipment, often operating well below their peak efficiencies.

Most buildings in the 50,000 $\mathrm{ft}^{2}$ and less size range do not have integrated building automation and control systems. As result, each RTU is generally controlled individually. Newer, high-end RTUs may have the capability for connecting to the web for monitoring specific parameters, but most RTUs in the field are aged and not high end, and provide no feedback on their condition or performance. As a result, performance deteriorates over time, and faults occur in operational practices (e.g., schedules) and in the equipment itself, resulting in sub-optimal performance, including reduced energy efficiency.

\section{Overview of the SMDS Technology}

The Smart Monitoring and Diagnostic System (SMDS), developed for the Department of Energy Building Technologies Office by Pacific Northwest National Laboratory in collaboration with NorthWrite, Inc., and Universal Devices, specifically targets maintaining peak efficiency and performance by continuously monitoring the condition of RTUs and providing meaningful information on performance degradation and its impacts on energy consumption and costs so that building owners and their staff can make informed decisions regarding when to have the equipment serviced. The SMDS is a low-cost, retrofitable technology that can be applied to new and existing RTUs. It detects performance degradation (and improvement) of RTUs and quantifies it as increases in the cost of operation. The SMDS also automatically detects several common operation faults (e.g., conditioning an unoccupied building, a supply fan that operates continuously, and short-cycling of RTU compressors). When a unit is serviced, the SMDS shows whether degradation is eliminated. If not entirely eliminated, the SMDS shows how successful the servicing was in eliminating the degradation and its cost impacts, enabling building management to distinguish between successful servicing and unsuccessful servicing. The SMDS detects these issues and alerts building owners, staff, and authorized maintenance providers to them through a web-based graphical user interface. Authorized users can then access information about their RTUs from any computing device with a web connection--personal computer, tablet, or smart phone.

The costs of the SMDS are very low (less than $\$ 600$ to the end user) because only two sensors (for outdoor-air temperature at the building and the total power consumption of each RTU) are used to derive important condition and performance information, which limits both the initial capital cost and the cost and complexity of installing the SMDS. Furthermore, producing such a solution was in direct response to comments from commercial HVAC service providers who tested a much more complex, 15-sensor version of the technology, even though it provided more detailed diagnostics. Their comment was that they did not need all the diagnostic information prior to on-site servicing. They instead wanted a system that was much lower in cost, less complex, easier to install, and provided only critical information — that performance has degraded and how much it is costing the building owner (the customer).

Two versions of the prototype SMDS have been field tested. The Hardware SMDS consists of a hardware package that is installed on each RTU. This package provides sensor data collection, processing that provides detection of performance degradation and operational faults, and local wireless communication to a wireless gateway that then transmits results via cellular data service to a network operations center. At the network operations center, the results 
are stored and made available to users on web pages. One gateway can serve the SMDS hardware packages on many RTUs. The other version is the Cloud SMDS. It uses off-the-shelf components for sensing and data collection and a commercially available cell modem to transmit the raw sensor measurements to a Cloud service. The data are stored and managed in the Cloud, where the SMDS algorithms process the data, and a web server makes the results available to the authorized users.

No competing system is on the market for monitoring the condition of RTUs in this way with potential for a very low cost. The feedback provided by the SMDS can keep users informed on the condition of RTUs and the quantitative impact of faults and degradation, including the energy cost impacts for space conditioning. Without this capability, building owners have no feedback on the performance of RTUs until the units either do not provide air that feels conditioned or the unit fails to operate at all. Significant unneeded expenditures on energy often have occurred by that time, and the equipment may have been damaged by operating under impaired conditions.

\section{Study Design and Objectives}

The study documented in this report focuses on testing the field performance of two different prototype implementations of the SMDS, the Hardware SMDS and the Cloud SMDS. The study represents the first time that the SMDS was tested on operating RTUs under field conditions. The tests are exploratory compared to demonstrations and tests of new commercial products, which are ready for or are already sold commercially. The SMDS units tested were installed in the field and tested for the first time. The objectives of this study are to:

- Characterize the performance of the SMDS technology,

- Estimate the savings-to-cost ratio for demonstration units,

- Characterize the usability of the SMDS based on feedback from the installers and users.

- Discover and document issues with field deployment and use of the prototypes that should be corrected during the next phase of product development.

The Hardware SMDS was tested on six RTUs, three in the moist and mixed U.S. climate zone 4A of Beltsville, MD, and three in the very hot and moist climate zone 1A of San Juan, Puerto Rico. The three Maryland units were packaged air conditioners with capacities of 6.5 to 12.5 tons of refrigeration with gas heat on a $22,000 \mathrm{ft}^{2}$ small office building. The three San Juan units were packaged air conditioners (without heat) with capacities of 5 to 10 tons on a restaurant. The Cloud SMDS was tested offline using data collected in a collaborative effort with a project focused on commissioning of existing small to medium commercial buildings (led by NorthWrite, Inc.), which was funded by the New York State Energy Research and Development Administration. Data were collected using wireless communications and the data were processed in the Cloud as described previously; however, the data were not directly input into the SMDS Cloud database in real time. Instead, the data were moved from a NorthWrite database to the PNNL Cloud SMDS database and processed later. The data were obtained from three RTUs on a 15,000- $\mathrm{ft}^{2}$ hardware store in the cold and moist climate zone 6A conditions of Rome, NY, and from three RTUs on a 3500-ft ${ }^{2}$ fast food restaurant in the cool and moist climate zone 5A conditions of Suffern, NY. All the RTUs are packaged air conditioners with capacities of 5 to 10 tons, with gas heat.

\section{Project Results/Findings}

Performance degradation was detected for 2 of the 12 RTUs on which the SMDS systems were tested. Degradation was found by the Hardware SMDS on one RTU in Maryland. The estimated cumulative electricity cost impact of the degradation was $\$ 456(3650 \mathrm{kWh})$ for a blended electric rate of $\$ 0.125 / \mathrm{kWh}$ from the time of detection on May 31 until the end of October when data collection was ended. This impact, however, did not include additional electricity 
costs for 10 weeks from June 19 until September 3, which includes weeks that are generally the hottest in the summer. Therefore, the actual additional cost for electricity resulting from the degradation is likely to have been much greater than the value we report.

Degradation was detected on a second unit by the Cloud SMDS, an RTU on the hardware store in Rome, NY. It had an estimated additional energy cost impact of $\$ 55(550 \mathrm{kWh})$ for a blended electric rate of $\$ 0.10 / \mathrm{kWh}$ for the period from September 8 through October 20, near the end of the cooling season. The Hardware SMDS also detected improved performance on an RTU in Puerto Rico for which the estimated energy savings are $\$ 68$ over a period of 3 weeks. Ordinarily, savings would result from servicing the RTU, but service records for the RTUs were not provided and, therefore, the cause of these estimated savings could not be verified.

No degradation was detected for 10 of the 12 RTUs to which the SMDS was applied. This is not surprising because degradation often occurs gradually over time and fault occurrence is stochastic. Therefore, monitoring for a longer time and/or a much larger sample of units would be required to understand the rate of fault occurrence and the success of the SMDS in detecting performance degradation and faults.

The SMDS identified four of the five faults the system detects: the RTU not providing ventilation when it is not cooling, the RTU off all 24 hours in a day, the fan alone on all 24 hours of the day, and the RTU cycling too frequently (short cycling). These faults were detected in multiple RTUs. The last fault for the compressor running all day was detected on only a single day for one RTU.

\section{Conclusions}

The SMDS prototypes successfully identified both degradation and operational faults and quantified the additional electricity use associated with the performance degradation. The findings revealed that obtaining a reliable estimate for the savings-to-cost ratio will require estimates of both the rate at which degredation is detected across RTUs and the average energy cost impact of the degredations detected, which can only be obtained from a much larger sample of RTUs monitored for several months. Installers of the Hardware SMDS at the sites reported that the installation was somewhat lengthy and difficult. These comments need to be taken in context and are not unexpected because the prototype hardware and the firmware were being used in the field for the first time by the installers. As usually found in initial pilot field tests, issues were found that needed correction. This underlies the necessity and importance of field testing. As a result, the installers did not just install and walk away but were also involved in troubleshooting, installing firmware updates, uninstalling the hardware, and reinstalling hardware after offsite repairs by the technical team. Therefore, their impressions were likely affected by the protracted "installation process." The SMDS Hardware system is designed to be very simple to install and require no user input to configure the system and get it up and running. NorthWrite staff reported that the first SMDS took 1 hour to install but additional units only took 15 to 20 minutes. Evaluating the installation process at this stage in the life cycle was probably premature, and the feedback from installers should be interpreted with considerable caution; this should be studied during follow-up stages of product development. Users were given access to the user interface for the Maryland test site for a couple weeks near the end of the demo. Difficulties were found in interacting with the interface, which appeared to be related to slow response of the web server; future iterations will need to ensure fast web server response. These issues need to be resolved before the SMDS is rolled out commercially to customers. The commercial partners collaborating on this project have viewed the results as promising enough to justify continued interest and investment in SMDS product development. 


\section{Table of Contents}

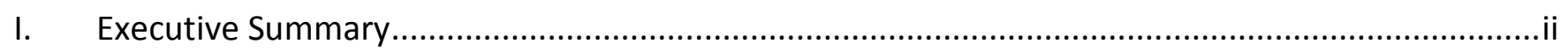

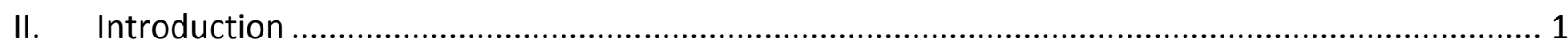

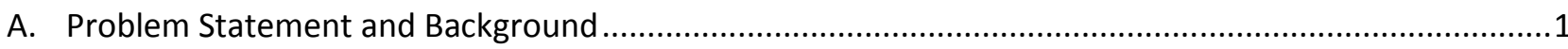

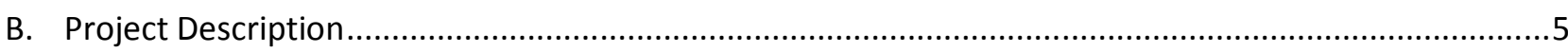

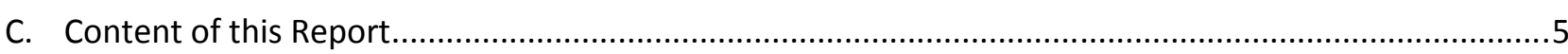

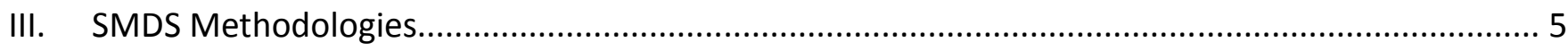

A. Performance Degradation Detection and Energy Impact Estimation.................................................. 6

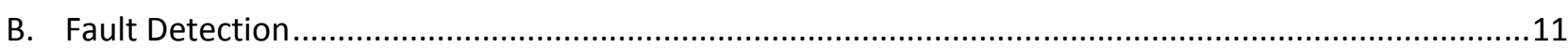

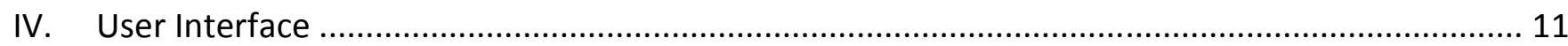

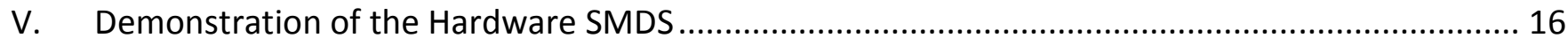

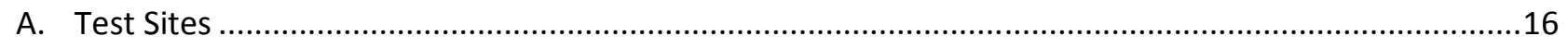

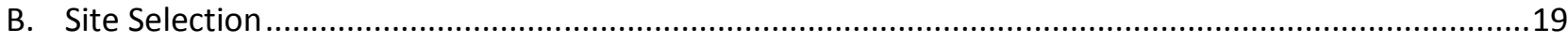

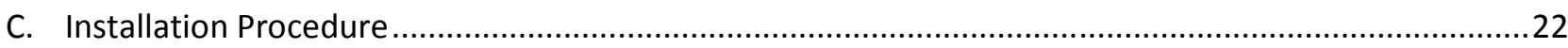

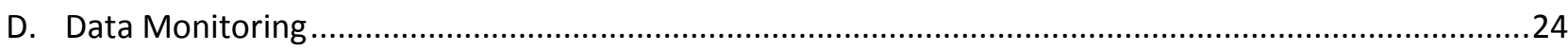

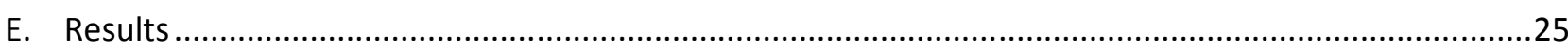

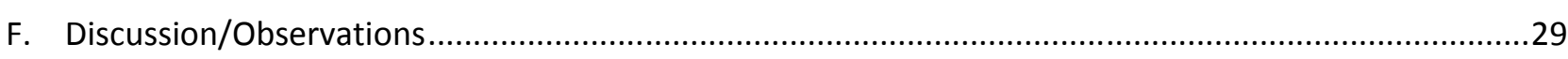

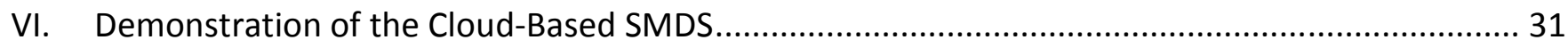

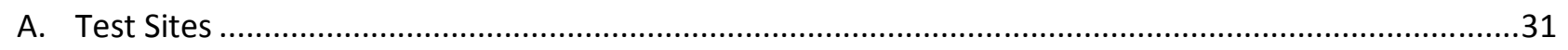

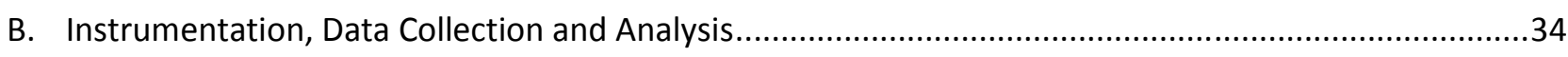

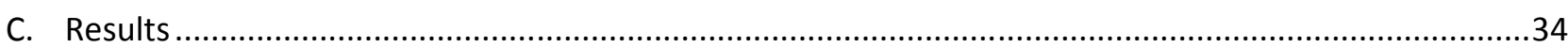

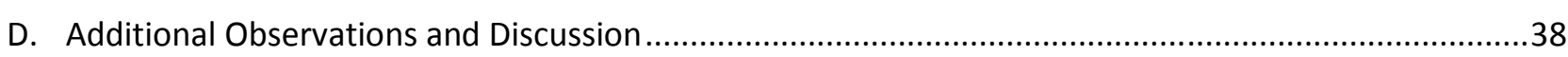

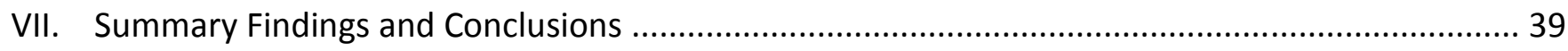

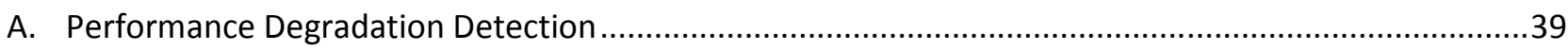

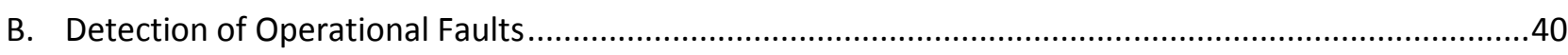

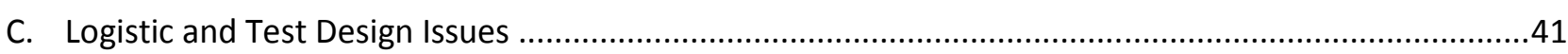

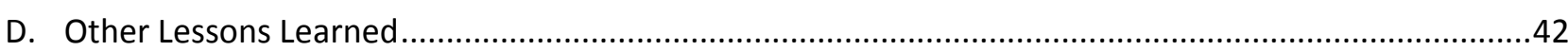

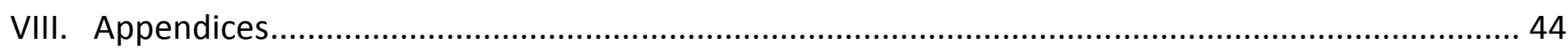

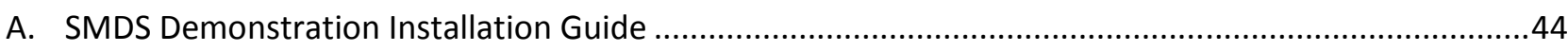

B. Degradation Detection Methodology Improvement - Use of Smaller Data Sets.................................48

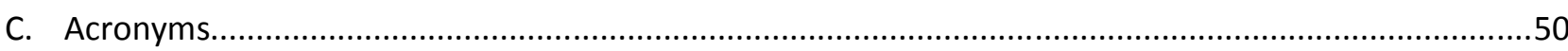

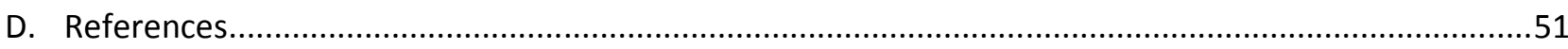




\section{II.Introduction}

\section{A. Problem Statement and Background}

Rooftop units (RTUs), both packaged air conditioners and heat pumps, serve approximately 2.1 million buildings representing over 39 billion square feet of commercial-building floor space in the U.S (over 68\% of all non-mall commercial floor space; EIA 2006). Such units commonly provide the primary heating, ventilation and air conditioning (HVAC) for smaller commercial buildings (with less than 50,000 $\mathrm{ft}^{2}$ floor area) and supplemental cooling for select parts of larger commercial buildings (with greater than 50,000 $\mathrm{ft}^{2}$ of floor area). The RTU portfolio across the U.S. contributes about 628 trillion Btu of site energy consumption annually (based on data from EIA 2006) which corresponds to 1900 trillion Btu/yr. of primary energy, and RTUs are typically the most poorly maintained of all HVAC equipment, often operating at well below peak efficiency.

Industry standards for maintenance practices on RTUs include changing filters every 3 to 6 months and having general servicing done once per year (ASHRAE 2012). General servicing includes checking the refrigerant charge and adjusting it (if needed), greasing the bearings, checking the pulleys and belts, checking the temperature drop across the condenser coil, and checking the RTU amperage draw for potential electrical problems. However, many RTUs are not provided seasonal or annual servicing but instead are run until complete failure occurs or occupant complaints lead to finding that little or no cooling or heating is provided. The lack of detailed maintenance contributes to increased mechanical degradation over time, thus causing units to perform less efficiently and consume more energy. Condition-based maintenance (CBM) based on condition monitoring can help alleviate this degradation in performance, but it requires monitoring system performance and providing parties responsible for maintenance decisions (e.g., the owner or staff working on behalf of owners) with the information required to decide when to perform maintenance. This requires information on the cost impacts of equipment condition and performance degradation, because cost is well understood by decision makers. PNNL, in collaboration with NorthWrite Inc. and Universal Devices Inc., has developed the Smart Monitoring and Diagnostics System (SMDS) to monitor RTU performance over time and automatically detect and report problems to the user on a daily basis.

The SMDS prototype, developed by Pacific Northwest National Laboratory in collaboration with NorthWrite Inc. and Universal Devices Inc., is a very low cost, retrofitable technology that meets this need. It provides continuous monitoring of RTU performance and automated detection of performance degradation (efficiency and capacity) and common operational faults (e.g., operation during times the building is unoccupied, not providing ventilation during occupied hours, RTU compressor short cycling, RTU systems never turn on during the day, compressor operates all day, RTU supply fan operates all day). When performance degradation or faults are detected, the SMDS informs owners or managers, responsible for the HVAC equipment, of the faults and the cost impacts of performance degradation through a graphic interface available from any computing device (i.e., personal computer, laptop, tablet, or cell phone) running a web browser. This enables them to make decisions regarding if and when to have units serviced. Without such as technology, little information is available to inform these decision makers about RTU condition and, as a result, these units commonly run in degraded condition until the next scheduled servicing or until failure. By informing decision makers about equipment condition and the cost impacts of degradation, the SMDS enables maintenance based on the actual equipment condition (i.e., condition-based 
maintenance, $\mathrm{CBM}$ ), which saves energy, decreases operating costs, ensures continuous maintenance of comfortable conditions for occupants, and helps minimize disruptive, unexpected catastrophic failures of RTU compressors and other components. Energy savings alone are potentially $10 \%$ to $20 \%$ of the total energy consumption of RTUs on average.

Although the Department of Energy (DOE) Building Technologies Office (BTO) actively promotes high performance RTUs (DOE 2014), replacement of most of the existing units with new units will likely take more than 20 years, given present replacement practices. Furthermore, degradation of performance occurs in all RTUs, new and existing, after they are installed, and the SMDS technology is compatible with all RTUs with two or fewer cooling stages ${ }^{1}$. The SMDS provides a unique retrofitable technology targeted at helping ensure the performance of the large inventory of RTUs.

Several methods exist for detecting and diagnosing faults in packaged air conditioners. All focus on specific faults (e.g., low or high refrigerant charge, economizer faults, and insufficient evaporator air flow), and require several sensors, many of which are not commonly installed on the packaged air conditioners and heat pump models most frequently installed. The sensors and computations required make commercial application of these methods difficult and expensive. At the same time, these fault detection and diagnostic methods provide information of little use to owners and their staff; the detailed information they provide is useful to technicians when they service equipment, but not to the decision makers. At least one hand tool exists for guiding technicians with fault detection and diagnostics based on measurements. As a hand tool that is reused many times over years, the cost of the sensors is justified because they support servicing a large number of RTUs many times. Such a tool can be used by technicians during RTU servicing to ensure the quality of the results. The first critical step, however, is to get the owner to call the technician, and the specific purpose of the low-cost SMDS is to provide the information essential for owners and their staff to make informed decisions regarding servicing. No other automated tool exists today that meets this need at a reasonable cost—only the SMDS.

The SMDS was developed to require only two sensors, those for outdoor-air temperature and total electric power draw of an RTU, which are used in the SMDS algorithms to detect when loss of RTU efficiency or capacity occurs, to quantify the energy cost impacts of the degradation, and to convey this information to decision makers via a web page. While systems with more sensors could provide additional fault detection and diagnostics, industry feedback on an earlier generation 15sensor version of the SMDS technology indicated that users wanted a system that was much lower cost, less complex, easier to install, and provided only the critical information-that performance has degraded and how much the degradation is costing the building owner (the customer). By focusing on communicating cost impacts, the SMDS provides information that is meaningful to decision markers, who can then assess whether the cost of continuing operation with the degradation present is sufficient to call a service provider to correct the problems leading to performance degradation and increased costs. After servicing, the SMDS indicates whether the degradation has been eliminated successfully.

1 The SMDS methodology could be readily extended to RTUs with more than two stages but was prototyped for units with one and two stages only.

Field Testing and Demonstration of the Smart Monitoring and Diagnostics System (SMDS) for Packaged Air Conditioners and Heat Pumps 
Although the SMDS was developed primarily for detection of RTU performance degradation and associated cost implications to inform decision makers, the two sensors it uses enable detection of specific faults at no additional cost. The additional information can be used by technicians in servicing the RTU and, for some faults, actions can be taken by building staff to decrease energy consumption and costs by simply adjusting RTU schedules to condition building spaces to comfortable temperatures only when they are occupied.

Two prototype versions of the SMDS have been developed and were tested in the project presented in this report. The first, which is referred to in this report as the Hardware Version, is based on a hardware module that is installed on each RTU. The hardware module includes sensors for outdoor-air temperature and total RTU power that are connected to circuit boards that provide signal conditioning, data processing, and wireless communication of results, using the Zigbee protocol ${ }^{2}$. The power is measured with a set of three pre-wired current transducers (CTs) and voltage taps that must be installed on each phase of power from the RTU power supply, while the outdoor-air temperature sensor is already wired and pre-installed at the bottom of the enclosure with shielding(shown at the bottom of Figure 2). The SMDS hardware can measure power from single phase, split phase, or three-phase power supplies, and can handle 120 Volt, 120/240 Volt, and 480 Volt configurations. The SMDS RTU module comes with a mounting bracket and screws, to mount the system on or close by the RTU. Once the system is mounted, wired properly and all connections are secured, the SMDS automatically begins recording measurements when the RTU is powered on (for safety, the RTU must be powered down during installation).

The SMDS algorithms for performance degradation and fault detection run on the processor, producing findings, which are communicated wirelessly to a rooftop SMDS gateway. The gateway and cellular modem must be installed indoors, as close to the RTUs as possible (e.g., on the top floor if the building is multi-story) to maximize signal strength. It stores the results from multiple units and periodically transmits the results via a cellular data network to a network operations center (NOC). At the NOC, the results are stored and made available to authorized users via a web page. Users have access only to the web page and data for RTUs at their facilities. The process is shown graphically in Figure 1 with the SMDS hardware module mounted on each RTU circled in red. A photo of this module is shown in Figure 2 with the enclosure door open to reveal the main components.

${ }^{2}$ Zigbee Alliance, What is Zigbee? web page at http://zigbee.org/what-is-zigbee/; last accessed on January 13, 2015.

Field Testing and Demonstration of the Smart Monitoring and Diagnostics System (SMDS) for Packaged Air Conditioners and Heat Pumps 


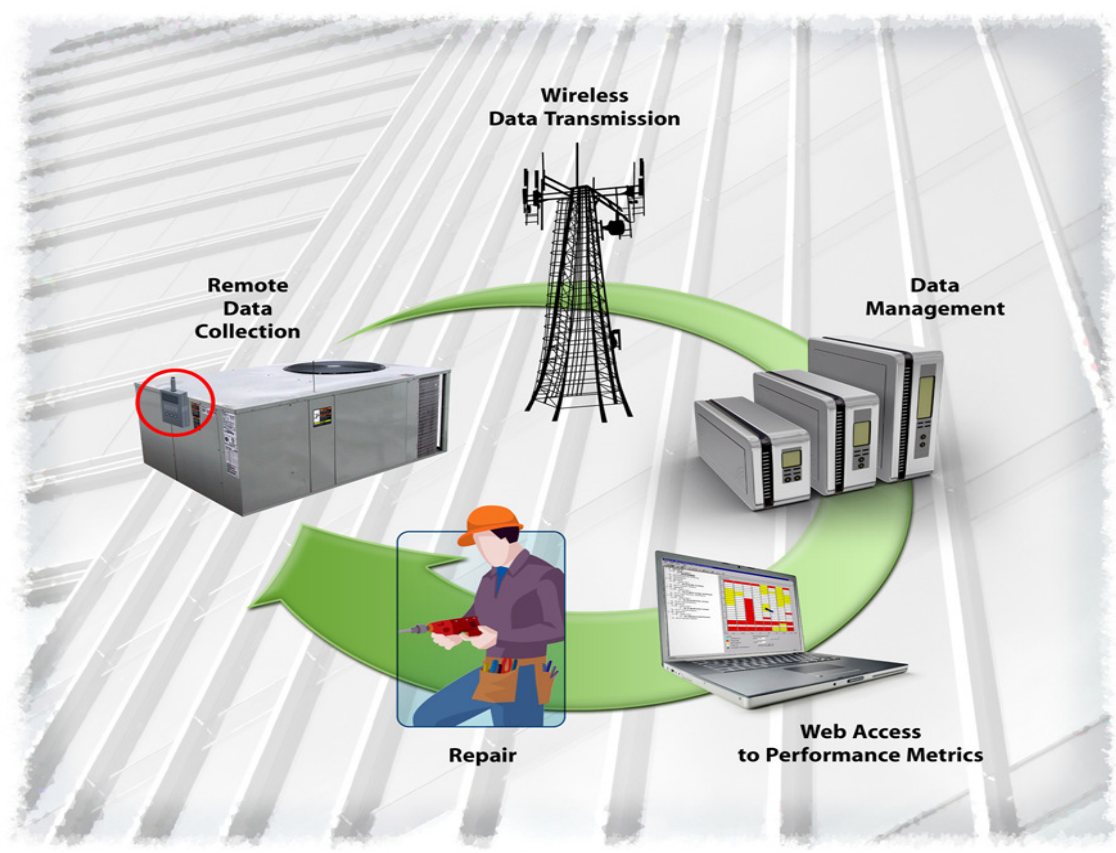

Figure 1. Diagram of the process flow for use of the Hardware SMDS Prototype

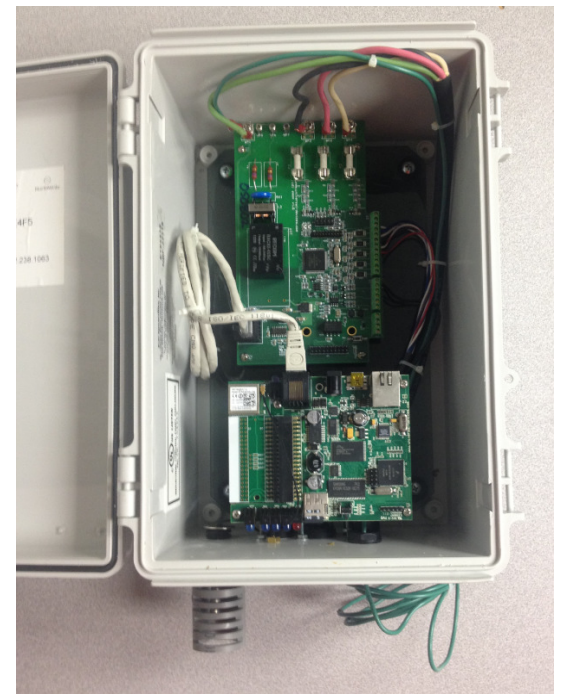

Figure 2. The SMDS module that is mounted on each RTU, which includes sensor signal processing, data processing using the SMDS algorithms, and wireless Zigbee communications

The second version, the Cloud SMDS prototype, differs in that the fault and performancedegradation detection processes are run in the Cloud rather than on hardware at the building site. For this version, only the sensors and a cellular modem need to be installed at the site. The SMDS hardware module mounted on each RTU is eliminated. Raw data are sent by wireless cellular data network to the Cloud on which the SMDS Cloud Version is installed. This approach reduces hardware cost in exchange for a considerably increased volume of data that must be sent on the cellular data network. The data are stored in a database in the Cloud, and the web server that 
provides the user interface also resides in the Cloud. The cost of cellular data communication has decreased substantially over the last few years, and the Cloud version is now likely to have a lower total cost. Ultimately, however, the relative costs of these two SMDS versions will depend on the business models for their delivery. Packaging the SMDS with other services could affect which version is more cost effective for a specific business model.

\section{B. Project Description}

This project focuses on testing and demonstrating both the hardware and Cloud versions of the SMDS under field conditions. The objectives for testing and demonstrating the hardware are to 1) characterize the performance of the SMDS technology, 2) estimate the savings-to-cost ratio for demonstration units, and 3) characterize the usability of the SMDS including ease of installation and use. The SMDS provides information to the user, but to realize savings, actions must be taken by the user. The hardware demonstrations seek to discover how effective information is in influencing actions, including which faults generate the most servicing actions by the user.

These field demonstrations are of prototype SMDS units, which have not yet completed the product development process. These early demonstration projects are critical to understanding SMDS performance in the field and to gaining a better understanding of the potential performance or user interface enhancements needed in the next generation SMDS units. Conclusions related to the larger commercial building market, such as the incidence of performance degradation and specific faults and the energy savings resulting from addressing them are beyond the scope of this study and not compatible with the current stage of SMDS development.

The demonstration was performed separately for the hardware and Cloud versions of the SMDS. Both demonstrations involved selecting buildings, installing the required hardware (although it requires less hardware, the Cloud version requires sensors and cell modems), collecting and processing data, and viewing and tabulating results. Details of the procedures are presented later in this report.

\section{Content of this Report}

The remainder of this report provides additional information on the SMDS prototype technology, the demonstration project, and findings from it. Overviews of the performance-degradation and fault detection methodologies are presented in Section III. A description of the user interface follows in Section IV and descriptions of the field testing/demonstration of the Hardware SMDS and the Cloud SMDS in Sections V and VI, respectively. Key findings are summarized and conclusions provided in Section VII with suggestions for future work presented in Section VIII. Appendices follow and include the Hardware SMDS installation guide, other research details, references, and a glossary.

\section{SMDS Methodologies}

The SMDS methodologies for detecting performance degradation (Section A) and specific operation faults (Section B) are described briefly in this section. The two SMDS versions use the same methodologies; they are just implemented in a different infrastructure. 


\section{A. Performance Degradation Detection and Energy Impact Estimation}

The SMDS detects performance degradation of an RTU by identifying when a change in the power (P) versus outdoor-air temperature (OAT) performance curve occurs for at least one stage of mechanical cooling. RTUs can have a single stage, two stages, or more than two. A cooling stage usually corresponds to each compressor in an RTU, although some larger RTUs run multiple compressors in unison so that the number of stages is fewer than the number of compressors. The current SMDS implementation of performance degradation detection applies only to RTUs with one or two stages, which covers most RTUs with cooling capacities of 15 tons and less. Larger units often have more than two stages. Although the current SMDS only applies to RTUs with one or two stages, the algorithms and software code could be extended to cover RTUs with more mechanical cooling stages.

The method is implemented using a monitoring period of 3 consecutive weeks (30,240 minutes) to create a performance curve. During this time period, total RTU power use and OAT are measured at 1-minute intervals. Data for shorter time periods might be used, but further testing would be required before doing so. Figure 3 shows examples of representative raw data from 3-week monitoring periods for a) an RTU with one cooling stage and b) an RTU with two cooling stages.

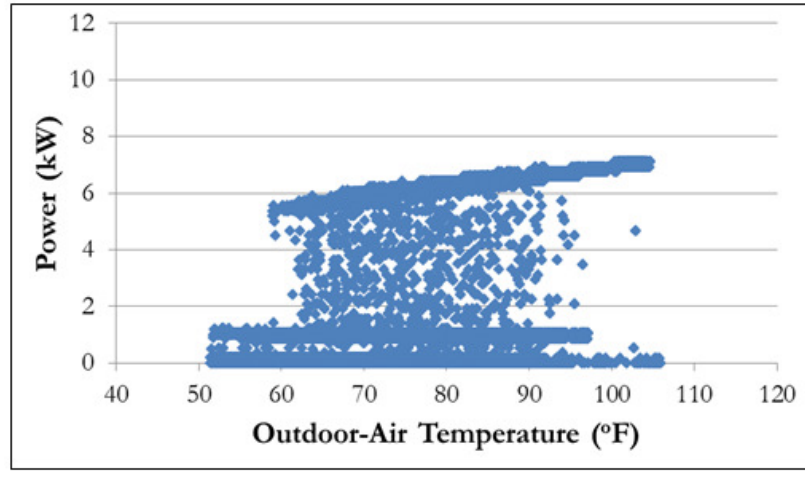

(a)

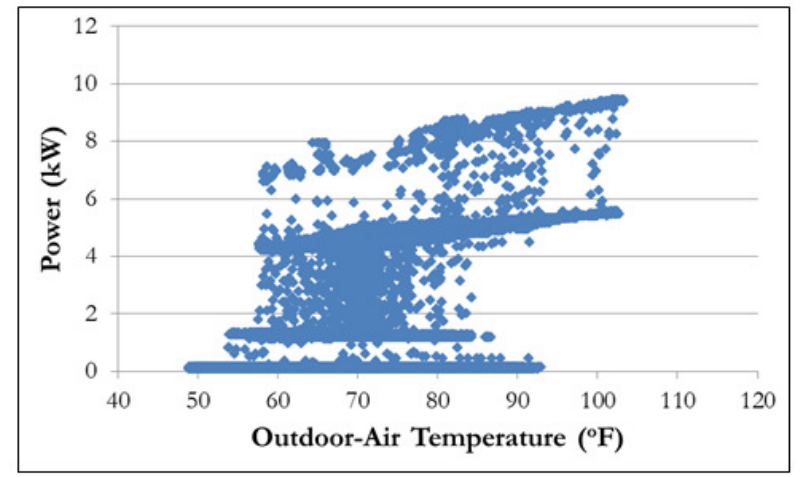

(b)

Figure 3. Total RTU power and outdoor-air temperature data measured at 1-minute time intervals for a) a single-stage RTU and b) a two-stage RTU

The SMDS filters out points that are not part of steady-state cycles, filters out cycles corresponding to only the supply fan operating and the unit entirely off, and divides cycles longer than 10 minutes into 10 minute segments plus a segment for the remaining minutes, if any. It then assigns values of $\mathrm{P}$ and OAT to each cycle, creating a (P, OAT) point. Figure 4 shows examples of steady-state data points (P, OAT) after one 3-week monitoring period for a) an RTU with one cooling stage and b) an RTU with two cooling stages. A straight line is fit to the steady-state data of each stage, using the least-squared errors criterion. This line represents the P-OAT performance curve for an RTU stage. This approach is possible because the RTU steady-state power consumption is not affected by changes in cooling loads (e.g., from changes in thermostat settings).

To successfully detect changes in the steady-state power versus OAT relationship over time, a baseline performance curve for each RTU cooling stage must be established. Ideally, the baseline performance would represent the RTU's optimal cooling performance. However; because the SMDS technology applies to both new and existing equipment, RTUs that are not new (e.g., 
installed and operating for 5 years or more) should be commissioned by a qualified HVAC technician prior to retrofitting with the SMDS technology. The SMDS, however, can be applied without commissioning, in which case it will detect degradation relative to its baseline performance, which may correspond to less than peak performance.

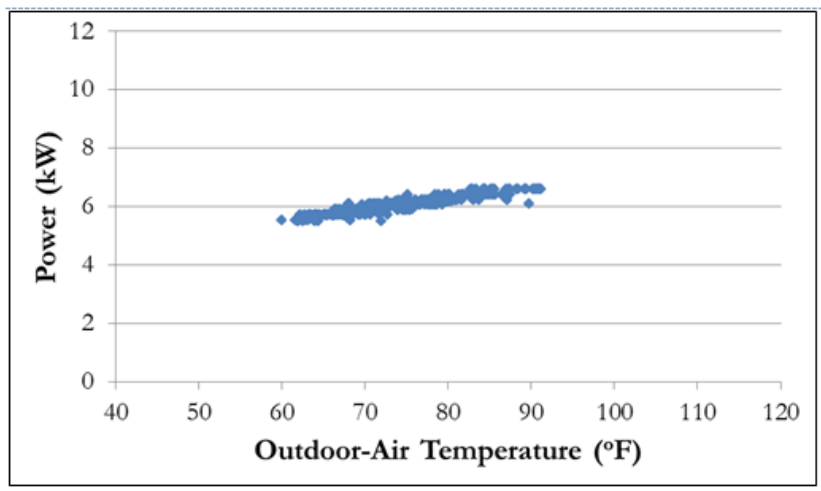

(a)

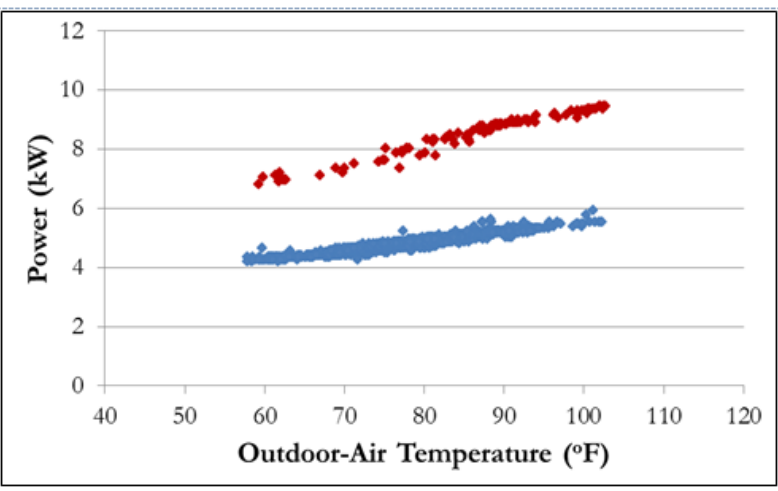

(b)

Figure 4. Steady-state power and average outdoor-air temperature data for a) a single-stage RTU and b) a two-stage RTU

After installation, the SMDS begins collecting data over the first monitoring period (i.e., the first 3 weeks) to establish the baseline performance of the RTU cooling stages. To ensure that the performance of the RTU is accurately characterized, criteria are established that require a minimum number of cooling cycle points over a specified minimum range of outdoor-air temperatures be used to develop performance curves. These criteria help ensure that the P-OAT line is adequately defined by the data points. Figure 5 shows 3 weeks of steady-state power and average outdoor-airtemperature cycle points for development of a baseline for a single-stage RTU. Before establishing the baseline performance curve, the temperature range $\left(T_{\max }-T_{\min }\right)$ must be greater than or equal to $20^{\circ} \mathrm{F}$, and the number of points representing steady-state cycles $\left(\mathrm{N}_{\text {cycles }}\right)$ must be greater than 50 . If both criteria are not satisfied, the SMDS continues to collect data for another week ${ }^{3}$ before processing the data to determine the baseline performance curve.

Once the criteria are satisfied, as in Figure 6, the SMDS establishes baseline performance curves for RTUs with up to two stages of mechanical cooling. Figure 6 shows example baseline performance curves for a) an RTU with one cooling stage and b) an RTU with two cooling stages.

After the baseline performance curves have been established (see Figure 6 in which the first and second cooling stages are represented by the blue and red performance curves, respectively), the SMDS begins collecting data for a new monitoring period (i.e., the subsequent 3 weeks). At the conclusion of this monitoring period, the SMDS first determines whether both criteria for adequate data are satisfied; if they are not, the SMDS continues to collect data, testing periodically (e.g., weekly) to determine whether the criteria are satisfied. When the data criteria are met, the first

${ }^{3}$ The specification of an additional week is somewhat arbitrary. Data collection could be continued for some other time period, e.g., a day, and the criteria evaluated to see whether the data available satisfy them.

Field Testing and Demonstration of the Smart Monitoring and Diagnostics System (SMDS) for Packaged Air Conditioners and Heat Pumps 


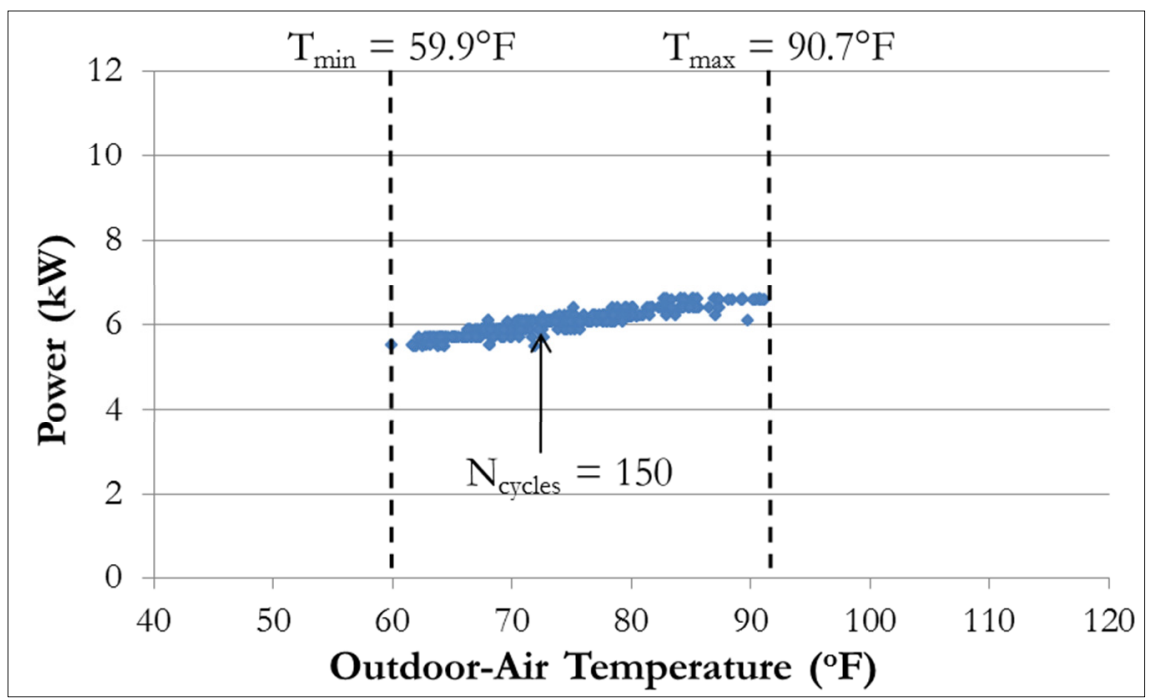

Figure 5. Steady-state power and corresponding outdoor-air temperature points for a single-stage RTU during establishment of a baseline

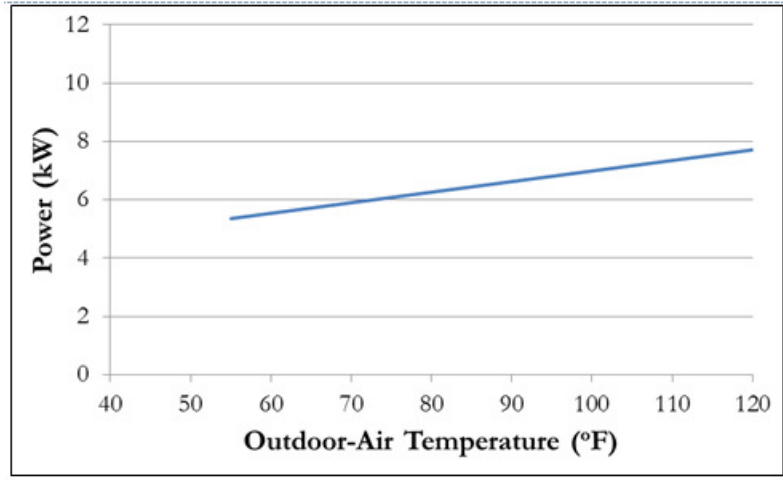

(a)

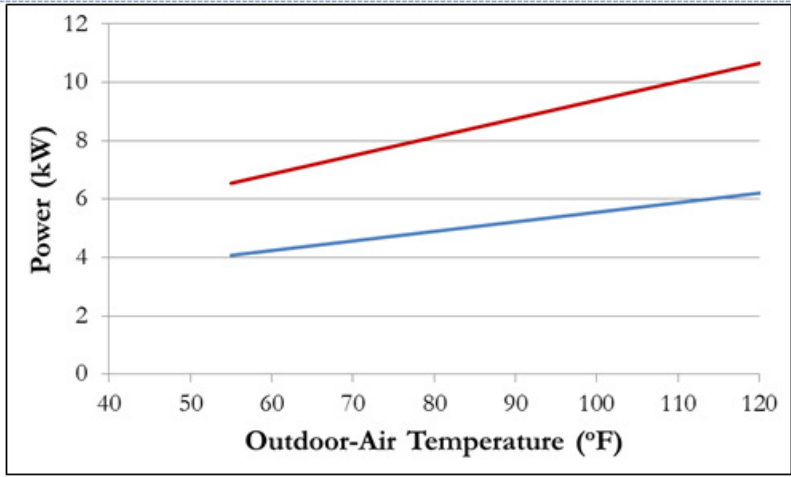

(b)

Figure 6. Baseline performance curves for a) a single-stage RTU and b) a two-stage RTU

post-baseline performance curves are empirically determined for comparison with the baseline performance curves.

After the baseline and first post-baseline performance curves are developed for at least one stage of mechanical cooling, they are compared to determine whether degradation has occurred between the time periods corresponding to the two curves. The SMDS concludes that performance degradation has occurred when the difference in power between the two curves at the midpoint temperature of the data sets exceeds a threshold (e.g., 5\%), which we refer to as being significant. The threshold can be adjusted to tune the SMDS, but this is not a user option in the current prototype software. Figure 7 compares post-baseline performance curves (green lines) to baseline curves (blue lines) for a single-stage RTU for two cases: a) when the change in the performance curve is not significant (no degradation detected) and b) when the change is significant (degradation is detected). 


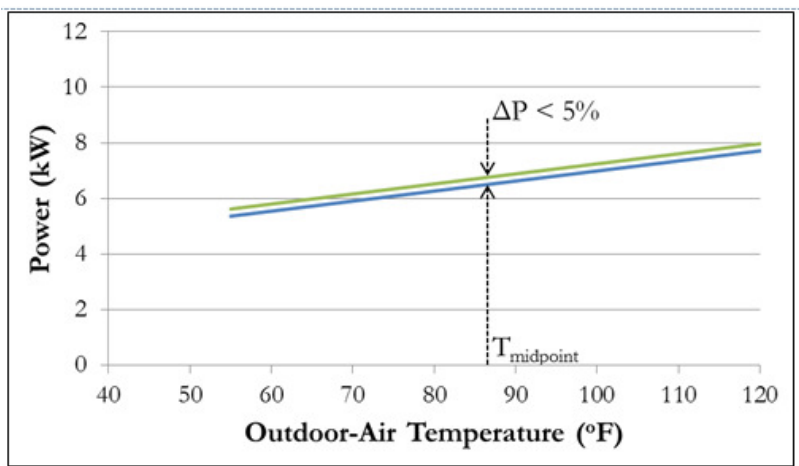

(a)

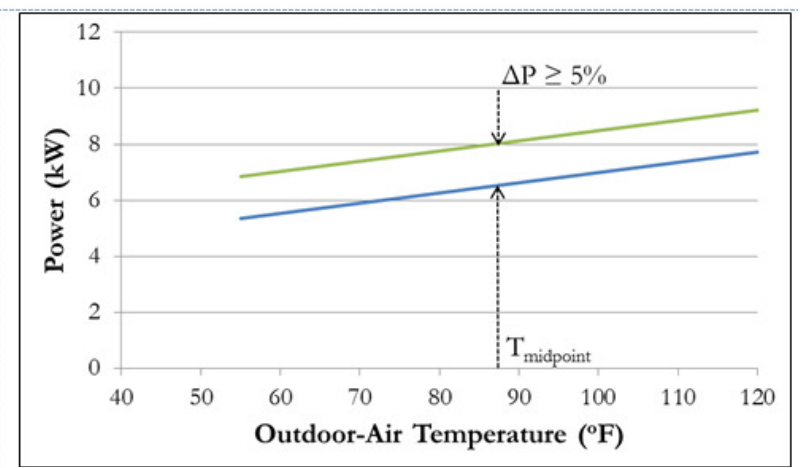

(b)

Figure 7. Baseline and post-baseline performance curves for a single-stage RTU when a) changes in performance are insignificant (no degradation) and b) changes in performance are significant (degradation occurred)

A single-stage RTU has one performance curve. A two-stage RTU has two performance curves, one for each stage. The SMDS determines the performance curves for each stage of cooling independently, and the data collection time periods for the different stages of mechanical cooling often do not coincide with one another.

After the SMDS establishes the first set of post-baseline performance curves for the RTU, and the difference between them is analyzed for degradation, additional data are collected in 1-week increments, and the post-baseline period for the data set becomes a moving 3-week time window moving 1 week at a time. This time period could be shortened, but except for cases of sudden significant degradation, little change in performance curves will occur over shorter time periods. Hence, if the baseline performance curves are determined after weeks 1 through 3 of data collection, and the first set of post-baseline performance curves are determined after weeks 4 through 6 of data collection, then the second set of post-baseline performance curves will be determined using data collected during weeks 4 through 7, i.e., the SMDS detects changes in performance weekly after the first 6 weeks of initial data collection. Although the SMDS currently requires a minimum of 3 weeks of 1 -minute data (30,240 data points) to define a performance curve, initial evaluation of shorter time periods for defining performance curves has shown that 2 weeks of data (20,160 points) should be sufficient and for many RTUs even shorter time periods may be sufficient.

When degradation ${ }^{4}$ in performance is detected, the SMDS estimates the energy impact of the degradation, which is made available on the user interface along with other SMDS results. Curves of energy use as functions of outdoor-air temperature are developed for the RTU in both baseline and post-baseline operating conditions. These curves are determined using all raw data points of power and corresponding outdoor-air temperature, not just steady-state data.

${ }^{4}$ Although the term used throughout this explanation is "degradation," the actual change in performance can be either degradation, which corresponds to a decrease in RTU efficiency, capacity or both, or an improvement in performance. Because spontaneous improvements in performance would be extraordinarily rare without human intervention, improvements in performance should only be expected after proper servicing of an RTU.

Field Testing and Demonstration of the Smart Monitoring and Diagnostics System (SMDS) for Packaged Air Conditioners and Heat Pumps 
By analyzing the RTU power consumption at each minute, the SMDS assigns each RTU power and associated outdoor-air temperature measurement to one of three operating conditions, off, ventilation only, or mechanical cooling. The data are aggregated to determine the hourly operating condition of the RTU for each hour in the data set. The values of energy consumption for each minute (in $\mathrm{kW}$-min per minute) are summed over all minutes in each state separately and then divided by the number of minutes in that the unit is in the corresponding state during the hour to obtain the energy consumption associated with each state during the hour. An average temperature associated with each operating state is obtained by averaging the temperatures for all minutes in that state during the hour. The (hourly energy consumption $(\mathrm{kWh} / \mathrm{h})$, hourly average outdoor-air temperature) points data are then binned into one of the following categories corresponding to an operating state: 1) occupied, which we define as the RTU ventilating and/or mechanically cooling for 50 minutes or more during the hour; 2) off, which we define as the RTU ventilating and/or mechanically cooling 5 minutes or less during the hour; and 3) cycling, which corresponds to the supply fan running only when the RTU mechanically cools (i.e., the compressor operates). The results are used to develop an average hourly schedule for the post-baseline period.

The SMDS also automatically develops an empirical relationship between the hourly energy consumption and the hourly average outdoor-air temperature for the occupied state and for the cycling state from the data points assigned to each operating state. No relationship is needed for the off state because it makes no contribution to the energy use. Separate sets of the two empirical relationships are developed for the baseline and the relevant post-baseline period.

The energy impact of the degradation (which equals the energy savings that would occur if the degradation were eliminated by servicing the RTU) is estimated for the most recent week as the difference between the energy consumption for the week determined using the empirical hourly energy use relationships and the schedule and the hourly average temperatures for the last week. For each hour of the week, the schedule determines the operating state and, therefore, the empirical relationship that is used to estimate the energy consumption assigned to the hour. The sum of the energy use estimates for the hours of the week gives an estimate for the total energy consumption during the week. By using the post-baseline set of empirical relationships, this process yields an estimate of the actual energy consumption for the last week but for the idealized hourly schedule of operating states for the week. When the baseline set of empirical relationships is used, the process yields an estimate of the energy use that would have occurred during the last week, if the RTU performance had not degraded. The difference between the values of energy consumption estimated from the baseline relationships and the post-baseline relationships is an estimate of the energy impact of the degradation (and potential savings from correcting the degradation).

Each time (i.e., week) for which performance degradation is detected, the energy impact is estimated. After an initial estimate of the energy impact, the SMDS accumulates the energy impacts and provides a graph on its user interface showing the cumulative energy impacts over time after degradation is first detected, until the unit is service. By multiplying the energy impact by a blended electric rate (specific to the SMDS user's location) an estimate of the energy cost impact of degradation is obtained, which is also reported as part of the cumulative energy cost over time on the SMDS web-based user interface. This information enables the user (building owner, building maintenance personnel, etc.) to make the decision on when to service each RTU based on the cumulative energy cost of its degradation. No similar feedback is available for RTUs today and, as a result, RTU maintenance is often neglected and units operate at degraded performance for 
extended time periods. When a unit is serviced, the SMDS shows whether continued degradation is eliminated. If not entirely eliminated, the SMDS will show how successful the servicing was in eliminating the degradation and its cost impacts. This information will help users distinguish between good, successful servicing and poor, unsuccessful servicing.

\section{B. Fault Detection}

In addition to the performance degradation and cumulative energy cost increases detected and reported over time, the SMDS also monitors, detects and diagnoses the several operational system faults on a daily basis. By analyzing each minute of RTU power consumption data, the SMDS can use the categorized RTU operating condition data described above (i.e., off, ventilation or mechanical cooling mode) to detect and diagnose these operational faults. The faults are all listed here with brief descriptions, and are discussed more in Section IV.

- RTU not providing ventilation: this fault is generated when the RTU supply fan only operates during times in which mechanical cooling is active during a day.

- RTU systems off all day: this fault is generated when the RTU is found to be off for an entire day. The SMDS acknowledges that there may be days when the RTU should be off; however, the user should double check to make sure it makes sense to have the RTU off for that day.

- RTU compressor operating all day: this fault is generated when the RTU compressor operates for an entire day.

- RTU supply fan operating all day: this fault is generated when the RTU supply fan never turns off during the day.

- RTU compressor short cycling: compressor short cycling is determined by looking at the time (in minutes) for each compressor cycle ("ON" cycle) and the time between consecutive compressor cycles ("OFF" cycle). If either the compressor "ON" or "OFF" time is shorter than a defined minimum time, then this qualifies as a short cycle. If the daily number of RTU short cycles exceeds the acceptable threshold, this fault is generated.

\section{User Interface}

A common user interface, which is described in this section, is used by the Hardware SMDS and the Cloud SMDS. All raw data and diagnostic results from the SMDS are sent to the network operations center on a server where the data are managed and displayed on a user interface (UI) made available by a web server. The UI, web-accessible with login credentials, is customized for each test site so the building owner/manager can login and periodically check the performance degradation and fault detection results for the RTUs monitored during the field test. The UI home screen is shown in Figure 8. The home screen shows operational fault and performance degradation status updates for each RTU monitored in the field test. The home screen, by default, shows the status updates for the current day, but the user has the ability to go back to any day since installing the SMDS, to track performance degradation or operational faults over time, by utilizing the built-in calendar shown in the upper lefthand corner of Figure 8.

If no performance degradation is detected for the current day, then the "Performance Degradation" message will display "No Degradation Detected, System is Running OK" (as shown in Figure 8 for RTU2 and RTU3). However, if performance degradation is detected (similar to what is displayed in 
Figure 8 for RTU1), the cumulative cost of the degradation is displayed for the user, and they are advised to click on the highlighted orange box for more details. The cumulative cost of degradation is calculated using the increase in $\mathrm{kWh}$ from the baseline performance of the RTU to the current performance of the RTU, multiplied by a site-specific blended utility rate ( $\$ / \mathrm{kWh})$.

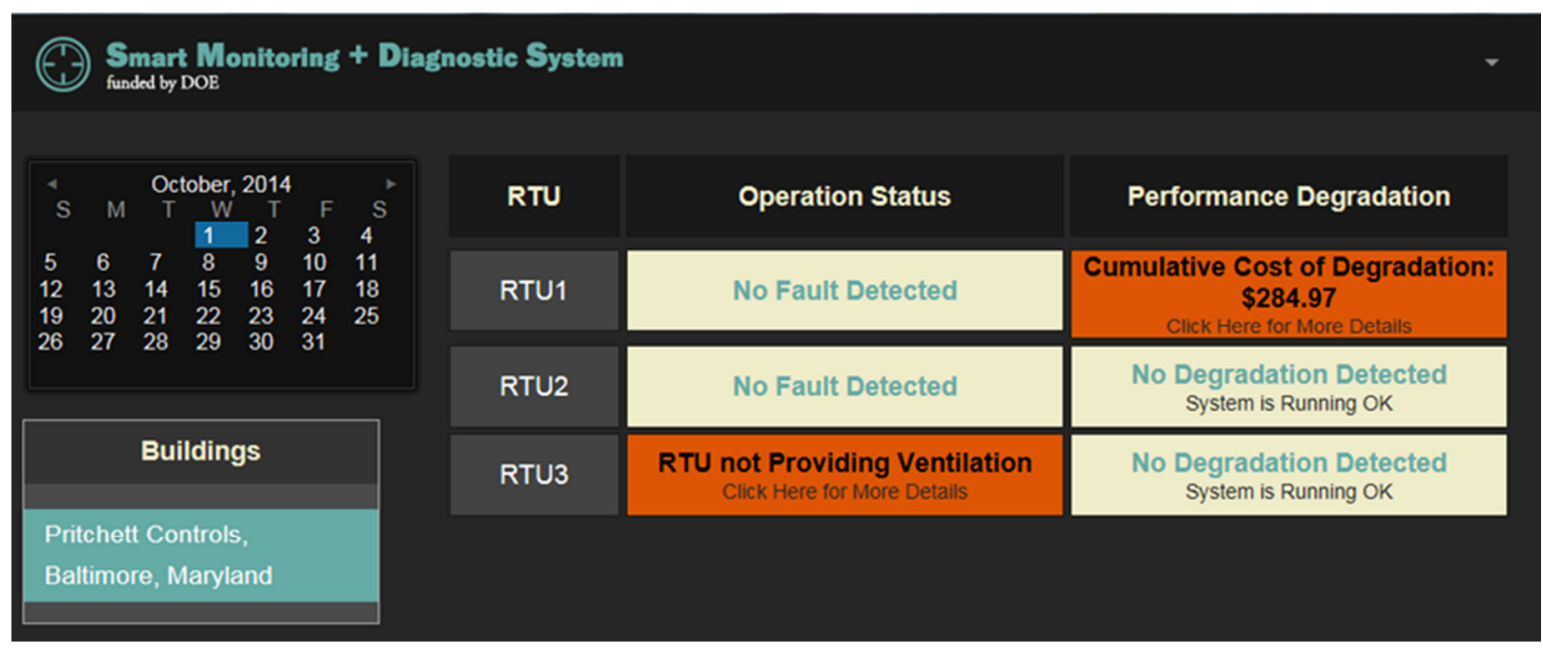

Figure 8. Sample SMDS user interface home screen showing representative results

The performance degradation details screen (Figure 9) displays a graph of the cumulative energy cost impacts from degradation over time, beginning with initial detection of degradation and continuing through the selected date. The top of the page lists the RTU, the date for which results are displayed, the data analysis date range (3-week period), and the corresponding cumulative energy cost impact. The cumulative cost includes all energy cost from the current and previously detected performance degradation. During times when the slope of the line is zero (i.e., constant energy cost over time), the SMDS has not detected further degradation. For example, the display date is October 1, 2014, and the cumulative energy cost is about $\$ 285$. However, the cumulative energy cost line is constant dating back to June 20, 2014. This indicates that the cumulative cost from degradation has not increased since June 20, but the degradation message is still displayed to the user so they are aware that degradation has been detected. They can then track that degradation over time, and decide if and when servicing is required.

Similar to the performance degradation message, the "Operation Status" message displays "No Fault Detected" when the SMDS does not detect any faults for the day (e.g., RTU1 and RTU2 in Figure 8). However, when a fault is detected (see RTU3 in Figure 8), the fault is identified in an orange box for that RTU, and the user is advised to click in the box for more details. Figure 10 shows an example operation status fault details screens. The display provides the RTU number, the date of the fault, a description of the fault, possible causes of the fault, and the fault's impact on RTU performance.

By periodically logging into the UI and reviewing the performance degradation and fault detection results for each RTU, the building owner or manager for the building can use actual performance information to plan servicing of RTUs and mitigate costly degradation impacts.

Table 1 shows all faults that the SMDS can detect with a brief description of the impacts on RTU performance for each.

Field Testing and Demonstration of the Smart Monitoring and Diagnostics System (SMDS) for Packaged Air Conditioners and Heat Pumps 


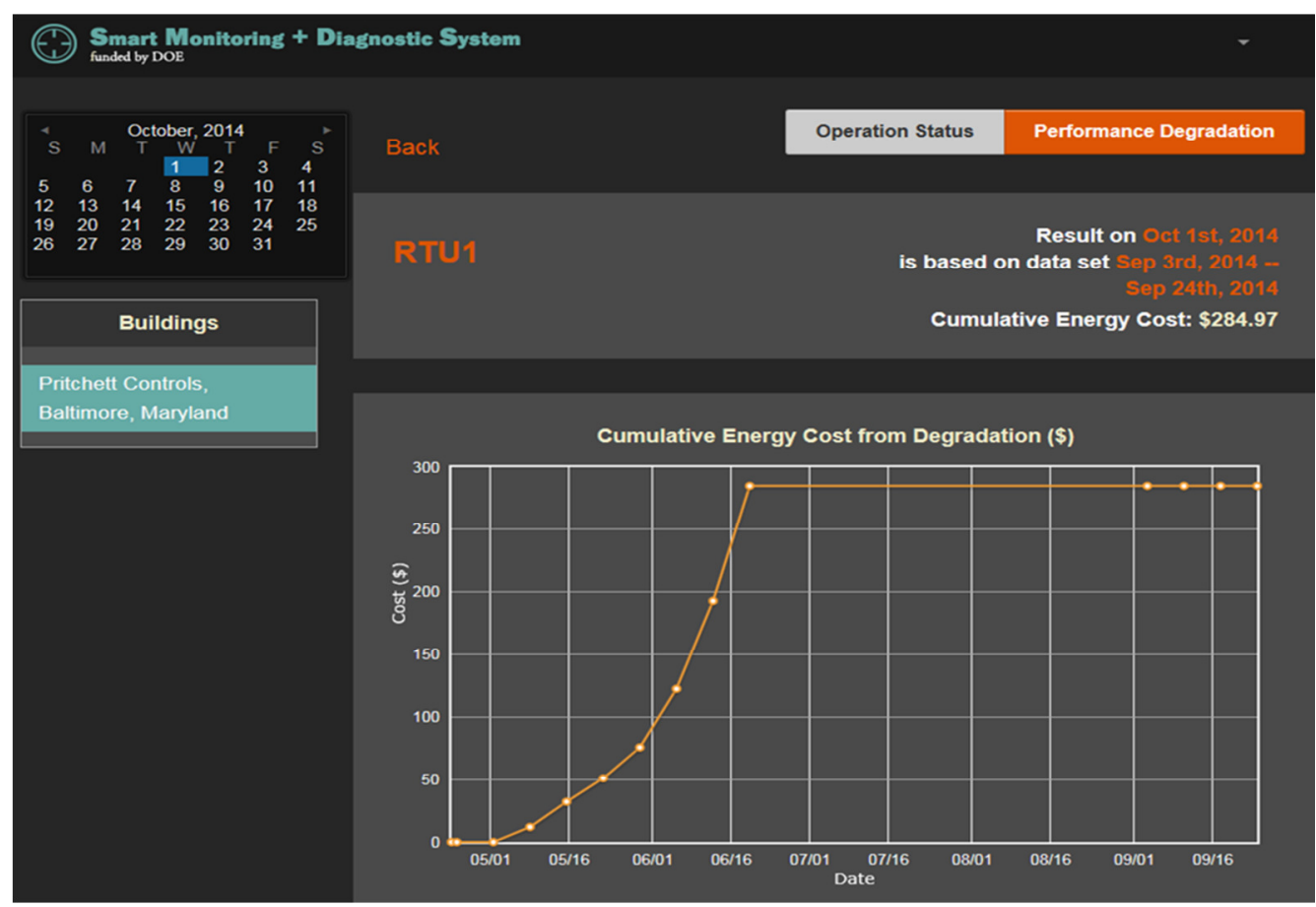

Figure 9. Sample user interface screen showing performance degradation details

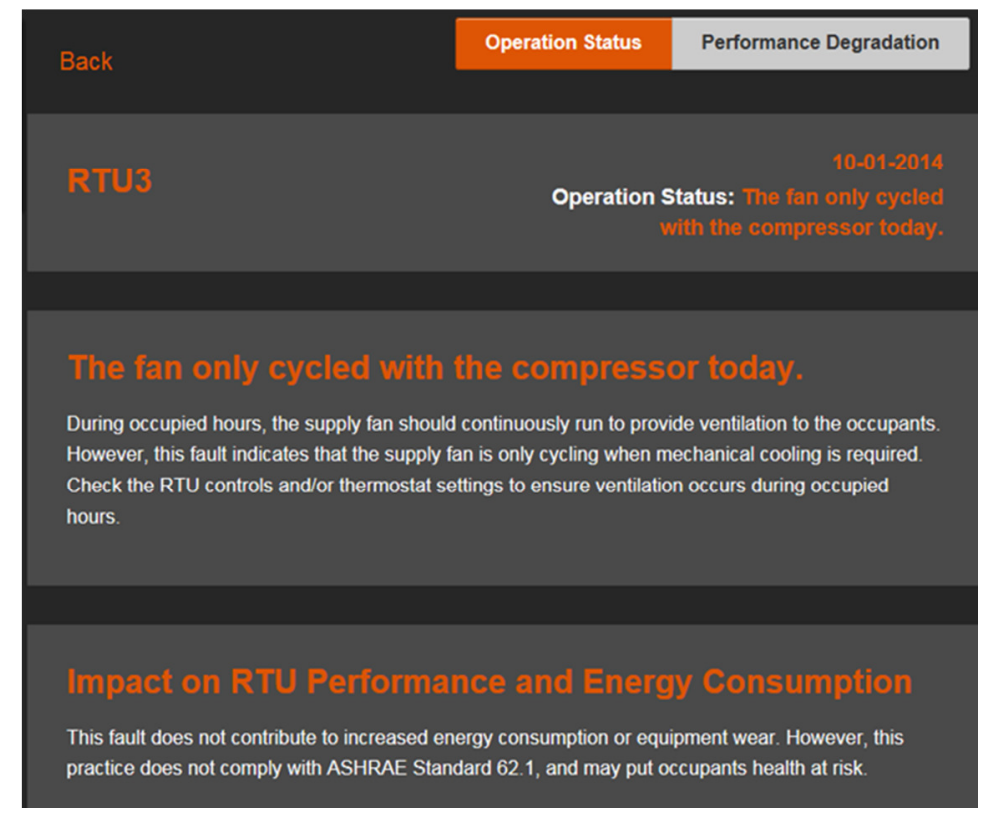

Figure 10. Sample SMDS user interface screen for a fault reported as the operational status and explanations of the fault and its impacts

By periodically logging into the UI and reviewing the performance degradation and fault detection results for each RTU, the building owner or manager for the building can use actual performance information to plan servicing of RTUs and mitigate costly degradation impacts.

Field Testing and Demonstration of the Smart Monitoring and Diagnostics System (SMDS)

for Packaged Air Conditioners and Heat Pumps 
Table 1. Descriptions of operational faults detected by the SMDS and the impacts on RTU performance

\begin{tabular}{|c|c|c|c|}
\hline Operation Status & $\begin{array}{c}\text { Fault Description } \\
\text { Title } \\
\end{array}$ & Fault Description & $\begin{array}{c}\text { Impact on RTU } \\
\text { Performance }\end{array}$ \\
\hline $\begin{array}{l}\text { RTU not Providing } \\
\text { Ventilation }\end{array}$ & $\begin{array}{l}\text { The fan only cycled } \\
\text { with the } \\
\text { compressor today }\end{array}$ & $\begin{array}{l}\text { During occupied hours, the } \\
\text { supply fan should } \\
\text { continuously run to } \\
\text { provide ventilation to the } \\
\text { occupants. However, this } \\
\text { fault indicates the supply } \\
\text { fan is only cycling when } \\
\text { mechanical cooling is } \\
\text { required. Check the RTU } \\
\text { controls and/or thermostat } \\
\text { settings to ensure } \\
\text { ventilation occurs during } \\
\text { occupied hours. }\end{array}$ & $\begin{array}{l}\text { This fault does not } \\
\text { contribute to } \\
\text { increased energy } \\
\text { consumption or } \\
\text { equipment wear. } \\
\text { However, this } \\
\text { practice does not } \\
\text { comply with } \\
\text { ASHRAE Standard } \\
62.1 \text {, and may put } \\
\text { the health of } \\
\text { occupants at risk. }\end{array}$ \\
\hline System off all Day & $\begin{array}{l}\text { The system did not } \\
\text { turn on today }\end{array}$ & $\begin{array}{l}\text { The RTU did not turn on } \\
\text { today. This may be } \\
\text { attributable to the building } \\
\text { being unoccupied, } \\
\text { equipment failure, } \\
\text { controller failure, or a user } \\
\text { override. If the RTU } \\
\text { should be on, check the } \\
\text { thermostat to ensure } \\
\text { correct set points. In } \\
\text { addition, check to make } \\
\text { sure the system is not } \\
\text { overridden to the off } \\
\text { mode. If the system is } \\
\text { intentionally off, this } \\
\text { message can be ignored. }\end{array}$ & $\begin{array}{l}\text { If multiple RTUs } \\
\text { serve the same } \\
\text { space, then having } \\
\text { one of them off will } \\
\text { negatively affect the } \\
\text { performance of the } \\
\text { other RTUs, as they } \\
\text { must work harder to } \\
\text { maintain space set } \\
\text { points. In addition, } \\
\text { if the spaces served } \\
\text { by this RTU are } \\
\text { occupied, no } \\
\text { conditioned air will } \\
\text { be provided to the } \\
\text { occupants. In this } \\
\text { scenario, occupant } \\
\text { comfort will be } \\
\text { compromised, } \\
\text { leading to } \\
\text { complaints. }\end{array}$ \\
\hline Operation Status & $\begin{array}{c}\text { Fault Description } \\
\text { Title }\end{array}$ & Fault Description & $\begin{array}{c}\text { Impact on RTU } \\
\text { Performance }\end{array}$ \\
\hline
\end{tabular}

Field Testing and Demonstration of the Smart Monitoring and Diagnostics System (SMDS) for Packaged Air Conditioners and Heat Pumps 


\begin{tabular}{|c|c|c|c|}
\hline Compressor on all Day & $\begin{array}{l}\text { The compressor } \\
\text { operated all day } \\
\text { today }\end{array}$ & $\begin{array}{l}\text { The RTU compressors ran } \\
\text { continuously today. This } \\
\text { fault may be caused by a } \\
\text { controller failure, unusual } \\
\text { thermostat settings, supply } \\
\text { fan failures, leaky } \\
\text { ductwork, refrigerant } \\
\text { charge issues, or an } \\
\text { undersized system. It is } \\
\text { also possible that the } \\
\text { spaces served by the RTU } \\
\text { reached extreme } \\
\text { temperatures during the } \\
\text { previous unoccupied } \\
\text { period. If this fault } \\
\text { continues, the RTU should } \\
\text { be serviced by a } \\
\text { professional. In addition, } \\
\text { make sure that the } \\
\text { occupied and unoccupied } \\
\text { temperature set points are } \\
\text { reasonable for the spaces } \\
\text { served by this RTU. }\end{array}$ & $\begin{array}{l}\text { When an RTU } \\
\text { compressor runs for } \\
\text { an extended period } \\
\text { of time, the RTU } \\
\text { will perform less } \\
\text { efficiently and } \\
\text { consume more } \\
\text { energy. This } \\
\text { message indicates } \\
\text { that the RTU is } \\
\text { operating during } \\
\text { both occupied and } \\
\text { unoccupied hours, } \\
\text { which is not } \\
\text { recommended. If } \\
\text { this fault continues, } \\
\text { it will negatively } \\
\text { impact the RTU } \\
\text { performance, } \\
\text { decrease the } \\
\text { equipment life, and } \\
\text { increase } \\
\text { expenditures on } \\
\text { energy. }\end{array}$ \\
\hline Fan on all Day & $\begin{array}{l}\text { The RTU supply } \\
\text { fan was on all day } \\
\text { today }\end{array}$ & $\begin{array}{l}\text { The RTU supply fan ran } \\
\text { continuously today. This } \\
\text { fault may be caused by a } \\
\text { controller failure, unusual } \\
\text { thermostat settings, } \\
\text { equipment failure, or a user } \\
\text { override. Check the } \\
\text { thermostat and make sure } \\
\text { the fan is set to "auto." In } \\
\text { addition, make sure that } \\
\text { the RTU controller is still } \\
\text { functional, and that no } \\
\text { overrides are in place. If } \\
\text { the fault persists, the RTU } \\
\text { should be serviced by a } \\
\text { professional. }\end{array}$ & $\begin{array}{l}\text { The supply fan } \\
\text { should only operate } \\
\text { during occupied } \\
\text { hours and during } \\
\text { unoccupied times } \\
\text { when the RTU air } \\
\text { conditions so the } \\
\text { compressor runs. } \\
\text { Excessive fan run } \\
\text { time leads to } \\
\text { increased energy } \\
\text { consumption and } \\
\text { decreases the } \\
\text { lifetime of the } \\
\text { supply fan motor. In } \\
\text { addition, excessive } \\
\text { fan run time will } \\
\text { contribute to } \\
\text { frequent belt and } \\
\text { filter replacements. }\end{array}$ \\
\hline
\end{tabular}

Field Testing and Demonstration of the Smart Monitoring and Diagnostics System (SMDS) for Packaged Air Conditioners and Heat Pumps 


\begin{tabular}{|c|c|c|c|}
\hline Operation Status & $\begin{array}{c}\text { Fault Description } \\
\text { Title }\end{array}$ & Fault Description & $\begin{array}{l}\text { Impact on RTU } \\
\text { Performance }\end{array}$ \\
\hline RTU Short Cycling & Short Cycling & $\begin{array}{l}\text { This fault occurs whenever } \\
\text { the compressor cycles } \\
\text { (turns on and off) } \\
\text { excessively during the day. } \\
\text { This may be caused by } \\
\text { refrigerant charge issues, } \\
\text { equipment faults, an } \\
\text { oversized RTU, or a very } \\
\text { tight thermostat dead- } \\
\text { band. If short cycling } \\
\text { persists, consider having } \\
\text { the RTU serviced by a } \\
\text { professional. }\end{array}$ & $\begin{array}{l}\text { When an RTU } \\
\text { cycles excessively, } \\
\text { this negatively } \\
\text { impacts the } \\
\text { equipment operating } \\
\text { efficiency and } \\
\text { lifetime, thus leading } \\
\text { to an increase in } \\
\text { energy consumption } \\
\text { and costs. }\end{array}$ \\
\hline
\end{tabular}

\section{Demonstration of the Prototype Hardware SMDS}

The SMDS hardware demonstration was led by PNNL, with collaboration from NorthWrite Inc. and Universal Devices Inc. The performance degradation and fault detection algorithms, described in Chapter III and developed by PNNL, were embedded in Universal Device's patented EM3 commercial grade energy monitors, which measured, processed, and communicated data with their ISY994i Series Gateway. NorthWrite Inc. hosted the data and results at their Network Operations Center, and created a user interface to display the diagnostic results to the end user. The test sites, installation procedures, data monitoring and results of the hardware demonstration will be discussed in the remaining sections of this chapter.

This section describes the demonstration of the Hardware SMDS and presents results characterizing the SMDS findings and performance.

\section{A. Test Sites}

The SMDS technology was demonstrated at two locations in FY14; Beltsville, Maryland (Test Site A, Figure 11) and San Juan, Puerto Rico (Test Site B, Figure 12). Test Site A is a 22,145 square foot single-story office building and Test Site B is a 6,000 square foot Restaurant. The SMDS was installed on three RTUs at each test site. Their capacities range from 5 tons to 12.5 tons. More information about the test sites is given in Table 2 .

Of the six RTUs on which the SMDS technology was demonstrated across the two sites, three of them had two stages of mechanical cooling, and three of them had a single stage of mechanical cooling. The three RTUs at Test Site A were packaged air-conditioning units equipped with natural gas for the heating season. The three RTUs at Test Site B, however, were cooling only packaged air-conditioning units. Figure 13 shows a 12.5-ton two-stage RTU at Test Site A, after installation of the SMDS technology (highlighted in red). In addition to the unit shown in Figure 13, another 12.5-ton two-stage RTU and a 6-ton single-stage RTU were used to demonstrate the SMDS technology at Test Site A. Figure 14 shows all three RTUs at Test Site B, after installing the SMDS technology. Two of the RTUs were 5-ton, single-stage units while the other was a 10-ton, two-stage unit. 


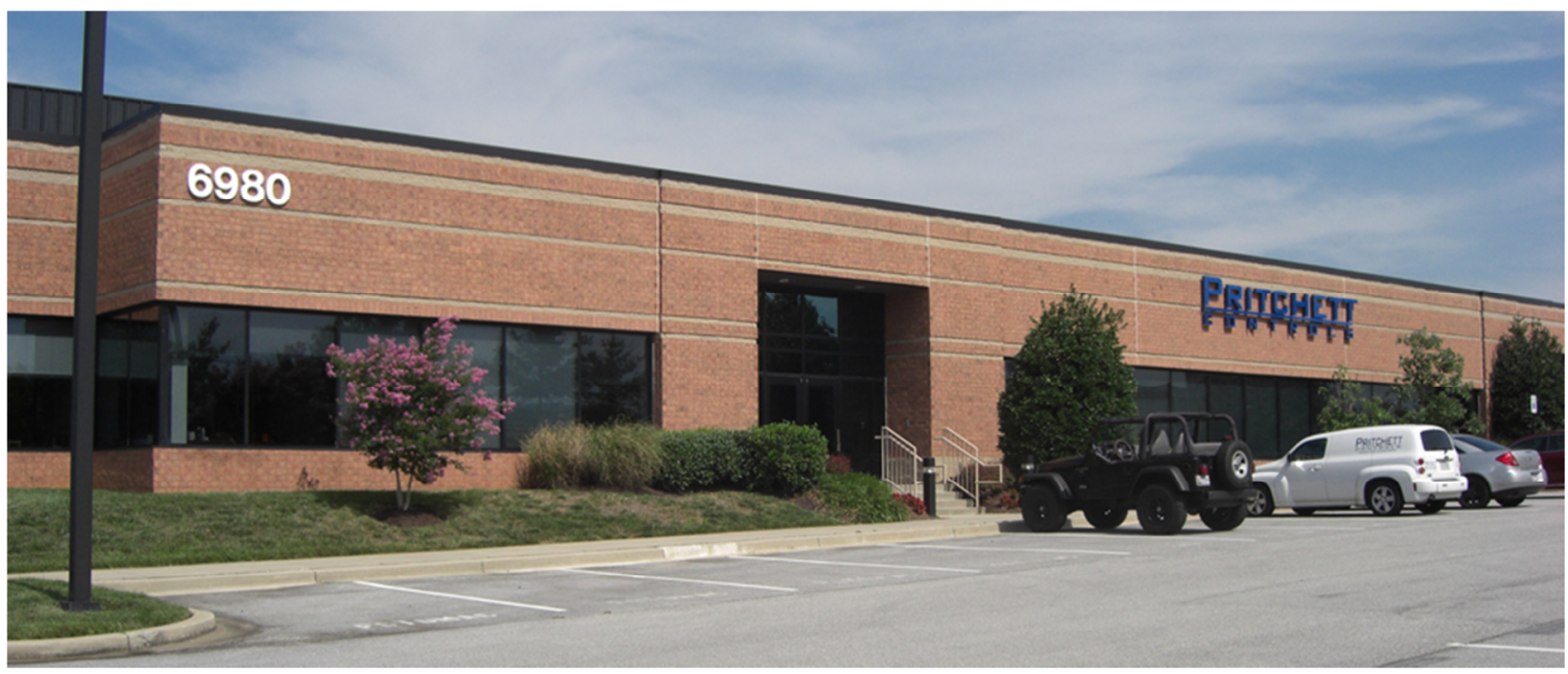

Figure 11. Test Site A building

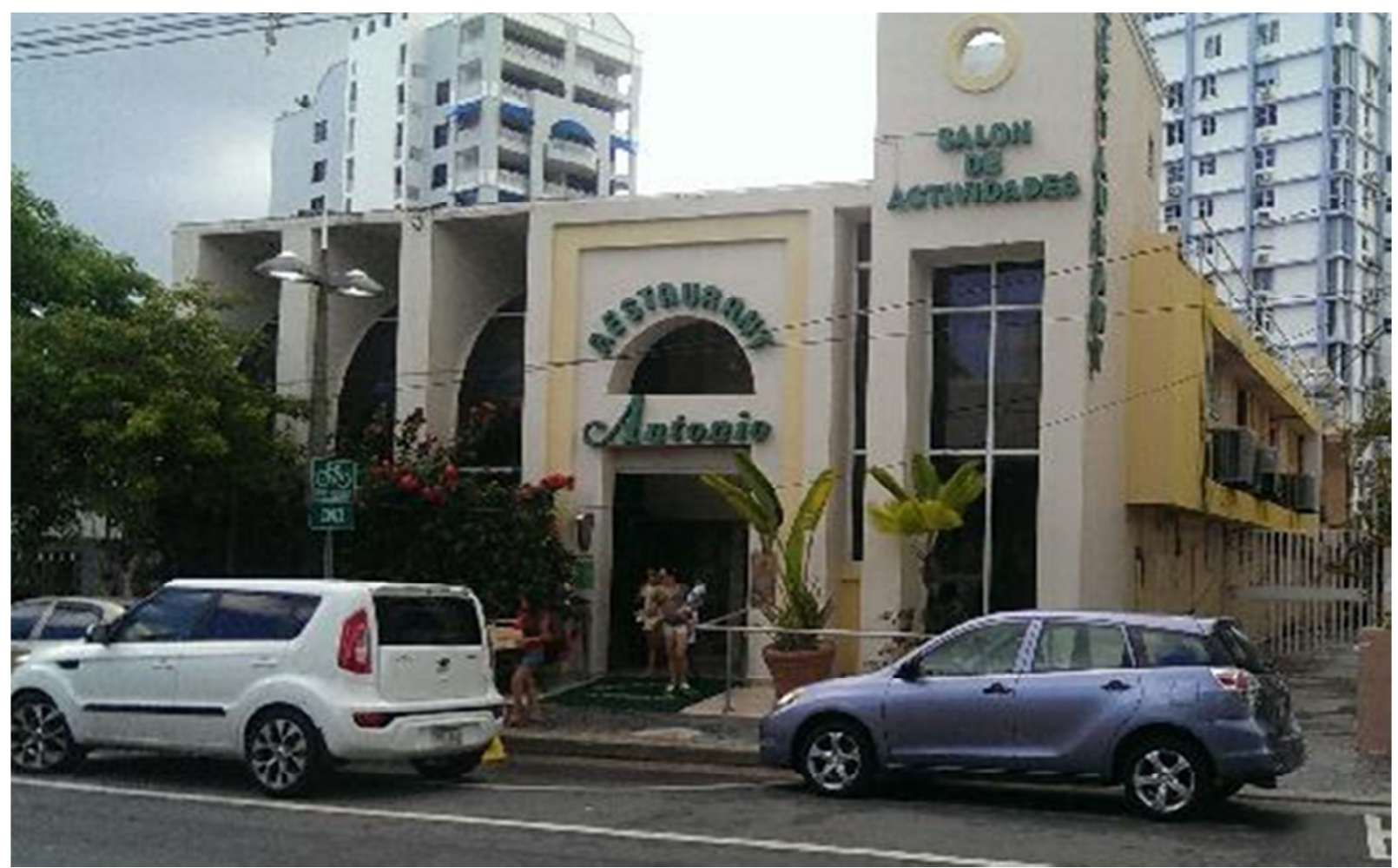

Figure 12. Test Site B building

Table 2. Characteristics of the sites for testing the Hardware SMDS

Field Testing and Demonstration of the Smart Monitoring and Diagnostics System (SMDS) for Packaged Air Conditioners and Heat Pumps 


\begin{tabular}{|c|l|c|c|c|c|c|c|}
\hline $\begin{array}{c}\text { Test } \\
\text { Site }\end{array}$ & $\begin{array}{c}\text { Location/Climate } \\
\text { Zone }\end{array}$ & $\begin{array}{c}\text { Building } \\
\text { Type }\end{array}$ & $\begin{array}{c}\text { Building } \\
\text { Size (ft }{ }^{2} \text { ) }\end{array}$ & $\begin{array}{c}\text { Total } \\
\text { Number } \\
\text { of RTUs }\end{array}$ & $\begin{array}{c}\text { Number of } \\
\text { RTUs Used in } \\
\text { Demonstration }\end{array}$ & $\begin{array}{c}\text { RTU } \\
\text { Capacity } \\
\text { Range } \\
\text { (tons) }\end{array}$ & $\begin{array}{c}\text { Types of } \\
\text { RTUs }\end{array}$ \\
\hline A & $\begin{array}{l}\text { Beltsville, MD } \\
\text { 4A, Mixed and } \\
\text { Moist }\end{array}$ & Office & 22,135 & 10 & 3 & 6.5 to 12.5 & $\begin{array}{l}\text { Air } \\
\text { Conditioners } \\
\text { with Gas } \\
\text { Heat }\end{array}$ \\
\hline B & $\begin{array}{l}\text { San Juan, PR } \\
\text { 1A, Very Hot and } \\
\text { Moist }\end{array}$ & Restaurant & 6,000 & 5 & 3 & 5 to 10 & $\begin{array}{l}\text { Air } \\
\text { Conditioners }\end{array}$ \\
\hline
\end{tabular}

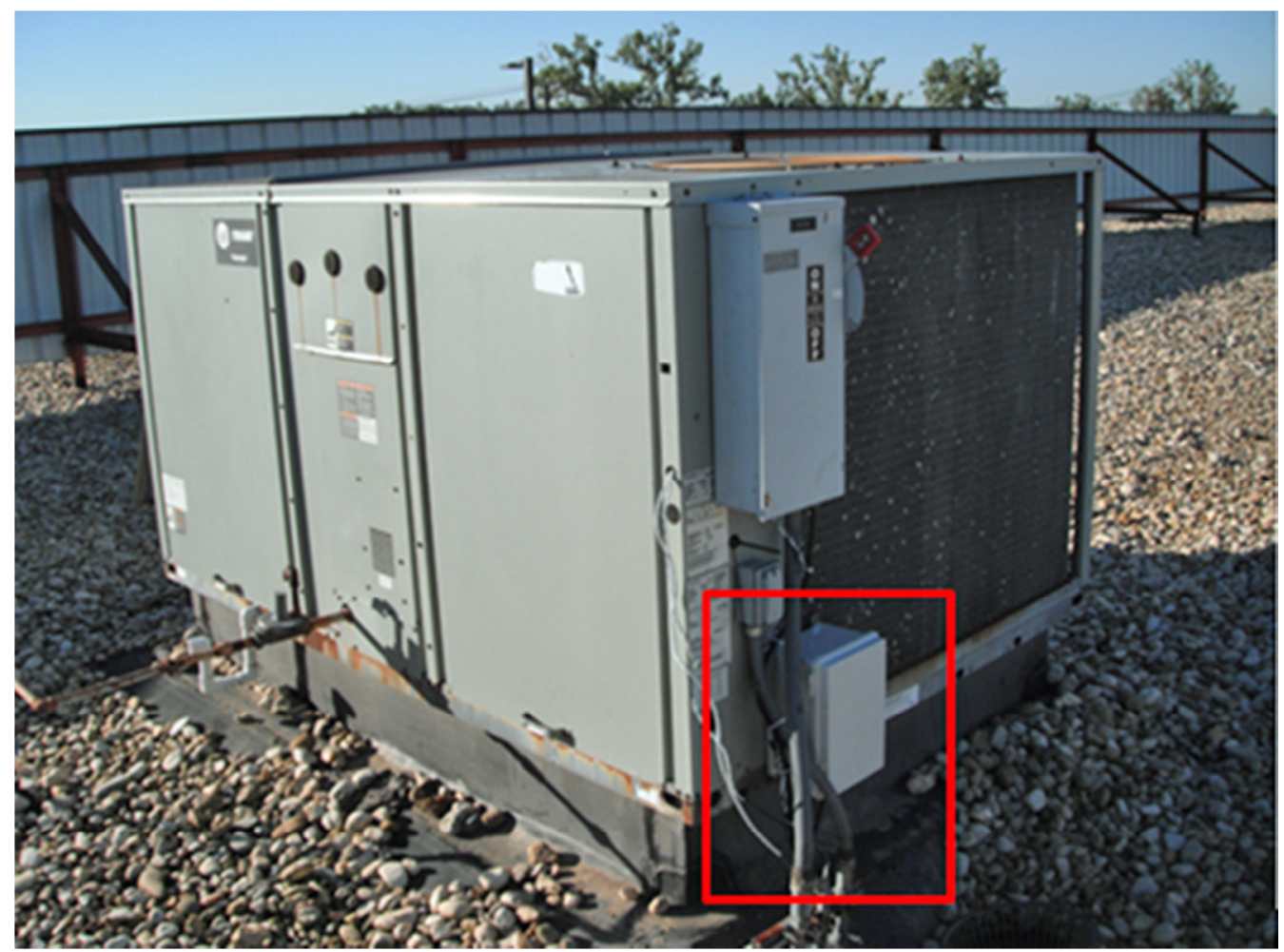

Figure 13. 12.5-ton, two-stage RTU at Test Site A, after installing the Hardware SMDS 


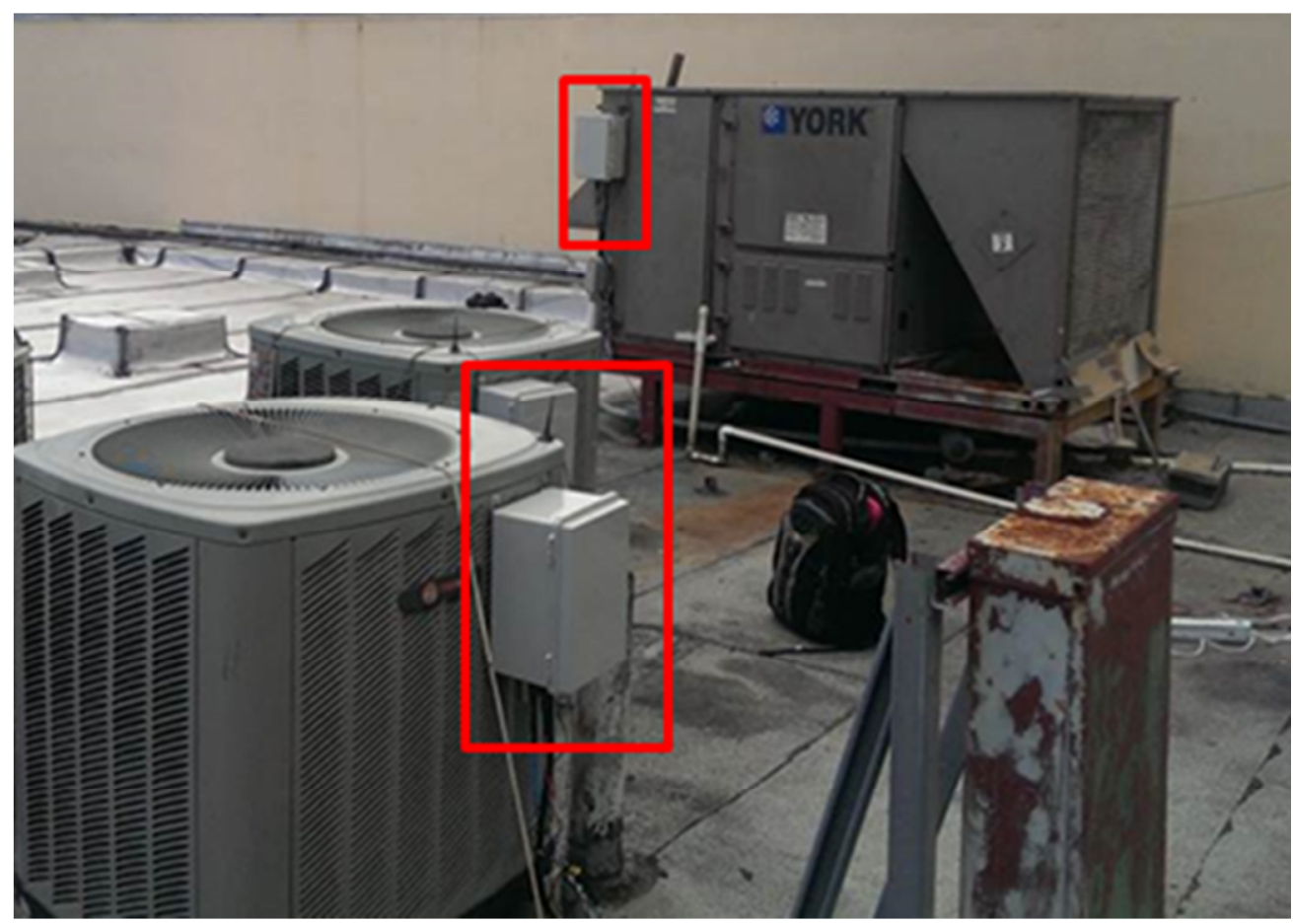

Figure 14. Three RTUs at Test Site B after installing the Hardware SMDS

\section{B. Site Selection}

Sites for demonstrating the SMDS technology were originally to be selected to ensure an adequate distribution across U.S. climate zones, to enable the field test data to provide energy performance data across six to eight climate zones making significant contributions to U.S. air-conditioning energy consumption. Based on these criteria, PNNL relied on NorthWrite Inc. to identify demonstration sites from their network of product resellers across the U.S. Once identified, the technology was to be demonstrated on two to three RTUs at each test site. Figure 15 shows a U.S. climate zone map, with the originally selected demonstration sites highlighted.

Initially, seven locations were chosen to demonstrate the technology, representing six different climate zones across the U.S. These locations were selected by NorthWrite Inc., based on their network of product resellers and a pre-installation survey that consisted of building information (i.e., square footage, building address, point-of-contact information, etc.), communications information (internet protocol), and RTU information (including pictures of nameplates). Of the seven buildings initially chosen for the demonstration, two were restaurants, two were small retail, two were mixed office/warehouse, and one was a typical office building. All of the buildings were less than 25,000 square feet. 


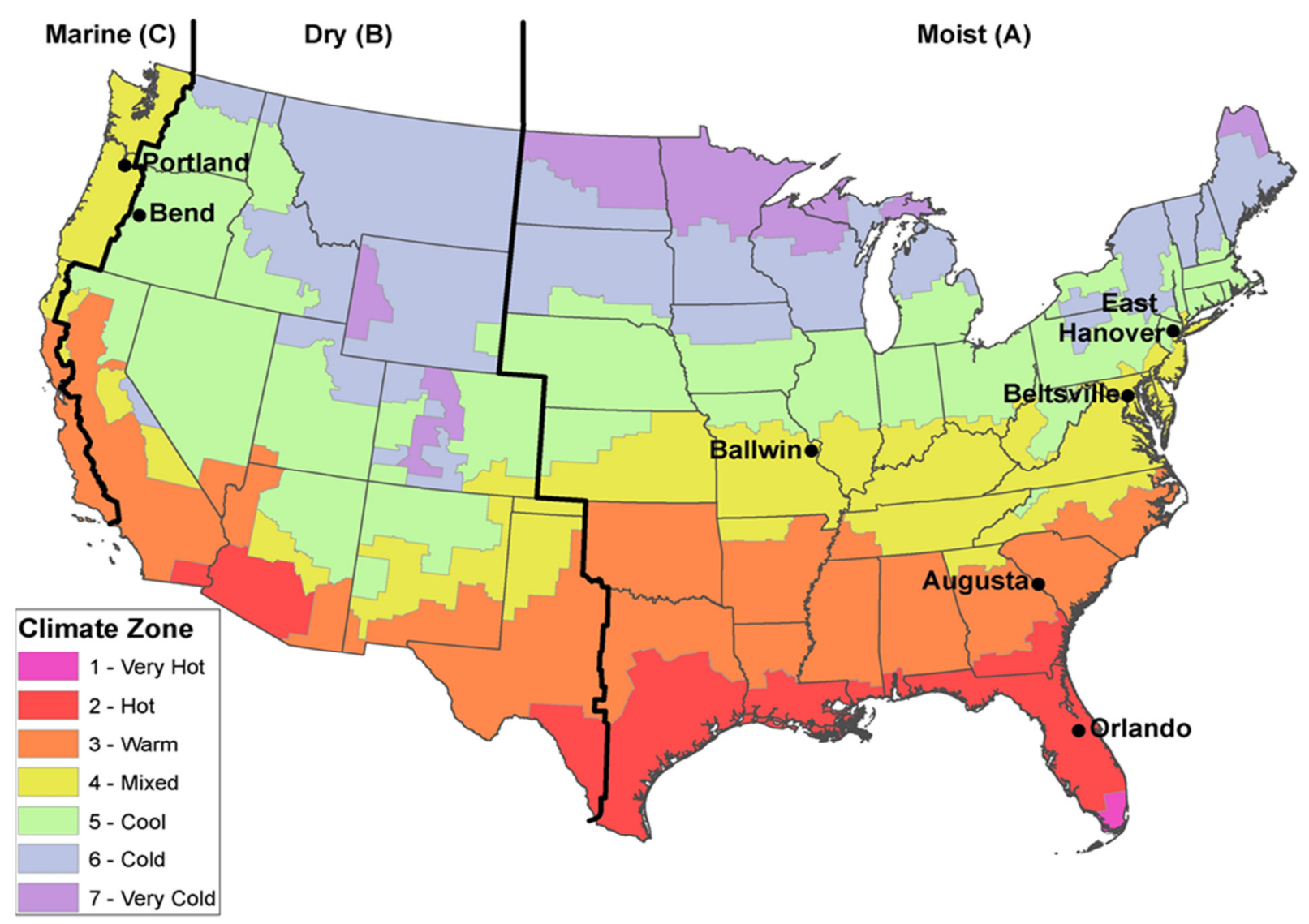

Figure 15. U.S. climate zone map with initial SMDS demonstration sites identified

Two to three SMDS units were shipped to each of the seven locations between July 2013 and August 2013 for installation. NorthWrite Inc. assisted each site with installation. At the conclusion of the first two installations, live data collected and reported to the network operations center revealed inconsistent phase power readings across several RTUs. Some power readings were negative, while others were consistently zero, indicating an issue with the power measurement equipment. Troubleshooting the $\mathrm{CT}$ placement and measurement techniques during the installation did not correct the problem, which prompted delaying all remaining installations while further testing was performed.

Testing of the power measurement equipment revealed that the CTs were wired incorrectly to the connector pins. These connections are shown in Figure 16 and Figure 17. The error resulted in cancelling all remaining installations and shipping the hardware to PNNL for further testing before deployment into the field. As a result, the demonstrations at the original locations identified by NorthWrite and shown in Figure 15 were cancelled, with the exception of the site in Beltsville, Maryland (Test Site A), because of a lack of time and project resources. PNNL, with guidance from DOE, determined that six SMDS units would be tested and validated for the demonstration and that two test sites would be used. 


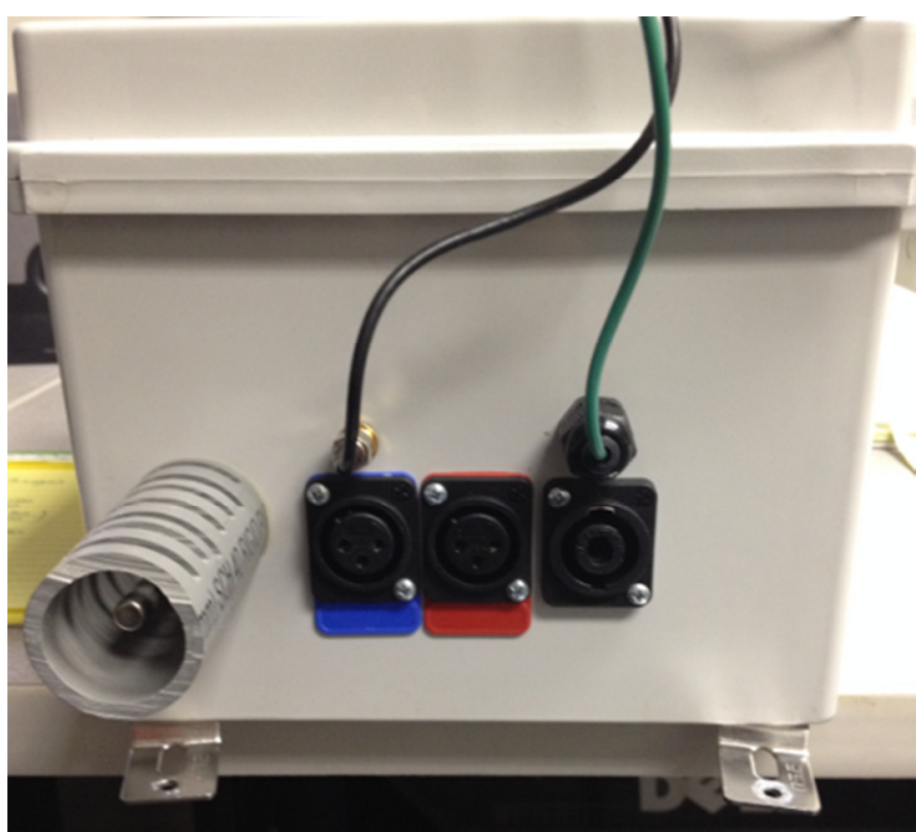

Figure 16. Bottom-view of SMDS hardware, with red and blue CT connector ports

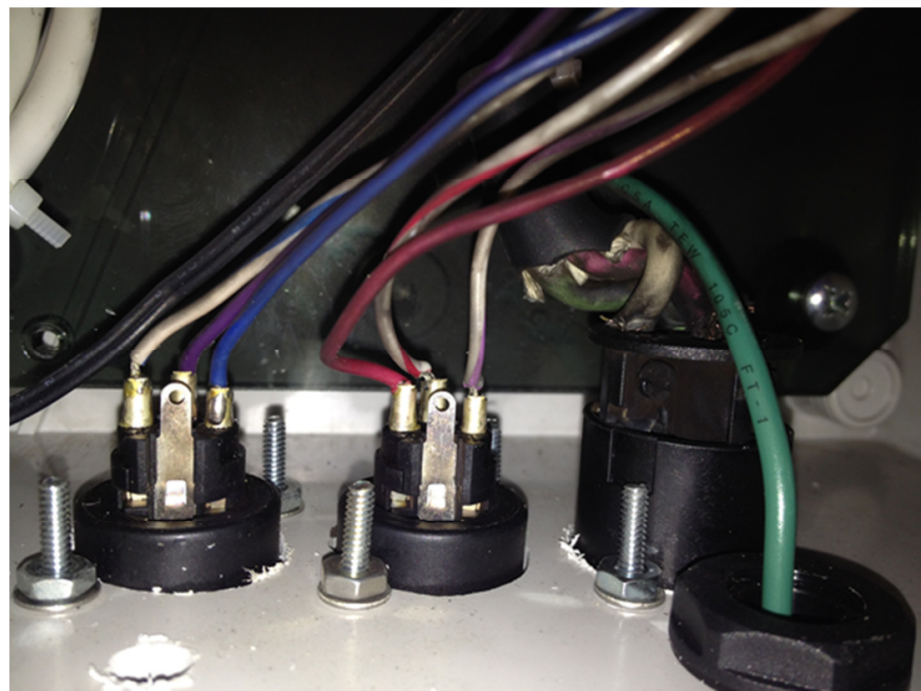

Figure 17. Interior-view of SMDS hardware with incorrectly soldered CT wires

Test Site A was kept in the demonstration because PNNL, NorthWrite and Universal Devices had established a good working relationship during the initial installation in August 2013, and it was determined that Test Site A would prove to be a beneficial demonstration partner as future developments occurred. In addition to Test Site A, NorthWrite identified another test site in San Juan, Puerto Rico (Test Site B) selected because of level of interest, a well-established working relationship, willingness to quickly install the equipment upon delivery, and its long cooling season. Figure 18 shows a climate zone map with the final two demonstration sites. 


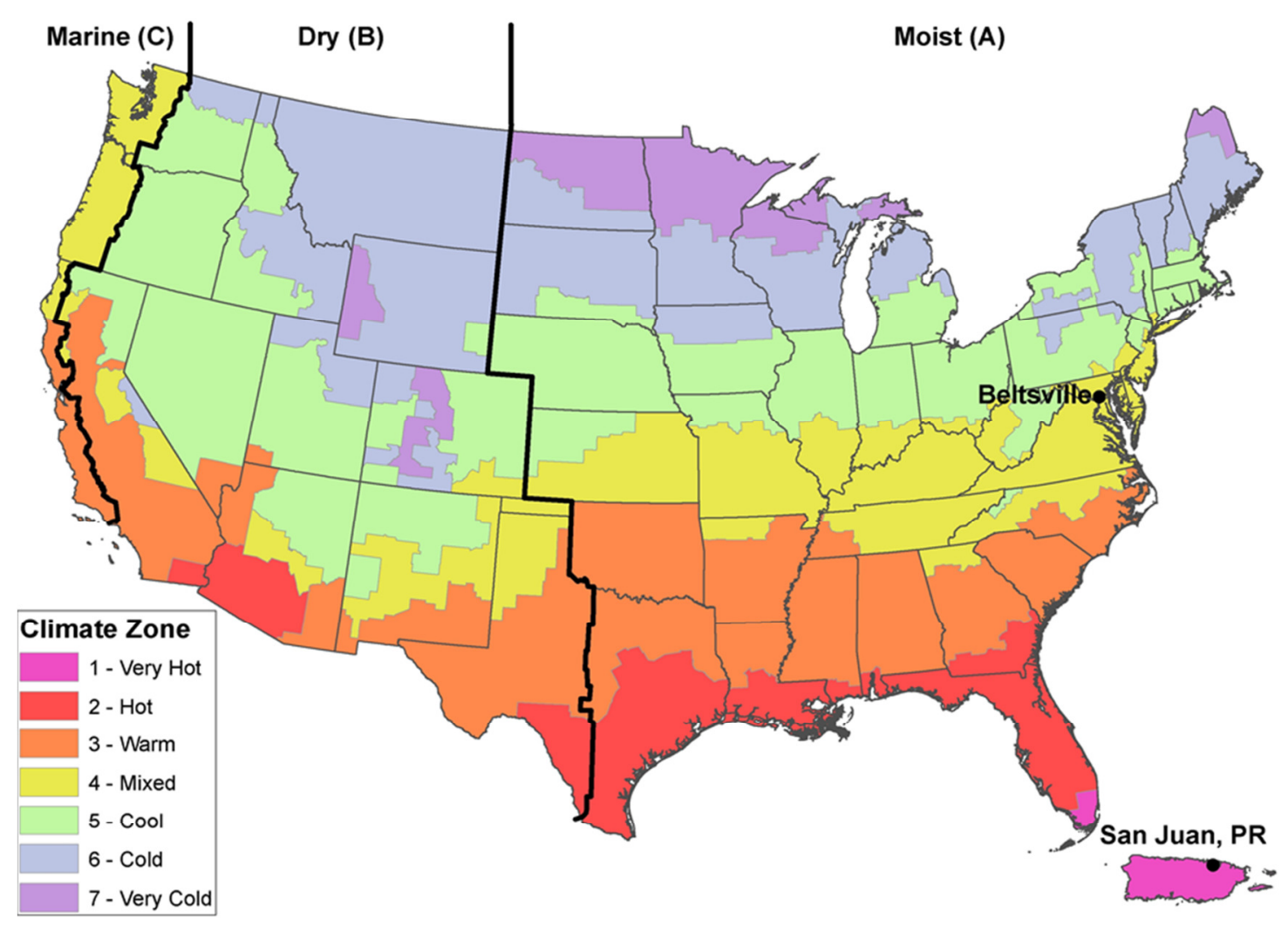

Figure 18. U.S. climate-zone map with final two SMDS demonstration sites for the Hardware SMDS identified

\section{Installation Procedure}

The installations at Test Site A and Test Site B were conducted by NorthWrite, with assistance from PNNL. An installation guide was prepared by NorthWrite, and reviewed by PNNL prior to sending to the sites with all necessary hardware components. The installation guide, in its entirety, can be found in Appendix A of this report.

The hardware sent to each site included three SMDS monitors (one per RTU), three sets of CTs wired to multi connectors, one pre-wired 4-wire power cable, one gateway with power supply, one Ethernet cable, one Zigbee repeater and one cellular modem with Sprint SIM.

PNNL shipped the equipment and installation guide to the test sites, and coordinated with NorthWrite, Universal Devices and the test site to schedule a date and time for installing the SMDS. The site was responsible to install the equipment, following the detailed instructions provided in the installation guide. During the installation, NorthWrite was available via call-in conference phone line to answer any questions and offer installation support. In addition, Universal Devices was available to provide any technical support required regarding the SMDS monitoring software and Gateway communication protocols.

Throughout the installation process, the site was responsible for taking pictures of the RTUs, the gateway, and the Sprint modem, documenting their respective locations. At the conclusion of the 
installation, NorthWrite was responsible for making sure the equipment was communicating with the NOC, and that data was being received. NorthWrite worked with the site and Universal Devices in cases where there were any difficulties with the communications protocol, until all equipment was reporting successfully to the NOC. To validate communications, NorthWrite 1) Connected to the gateway at each test site through the Universal Devices Administrative Console software and validated data measurements and 2) Connected to the NOC to validate data reporting. The Universal Devices Administrative Console is shown in Figure 19 for Test Site A, accessible by web address with login credentials. NorthWrite verified that each phase (or channel) was reporting the appropriate magnitude and sign (positive or negative) of electric power, and then checked the sampling frequency to ensure data was being collected in 1-minute intervals.

To validate data being received at the NOC, NorthWrite and PNNL connected via web address with login credentials, and used a built-in charting option to quickly identify OAT and total unit electric power consumption data transmitting successfully to the NOC. Figure 20 shows a sample screenshot from the NOC of outdoor-air temperature data at Test Site A in April 2014.

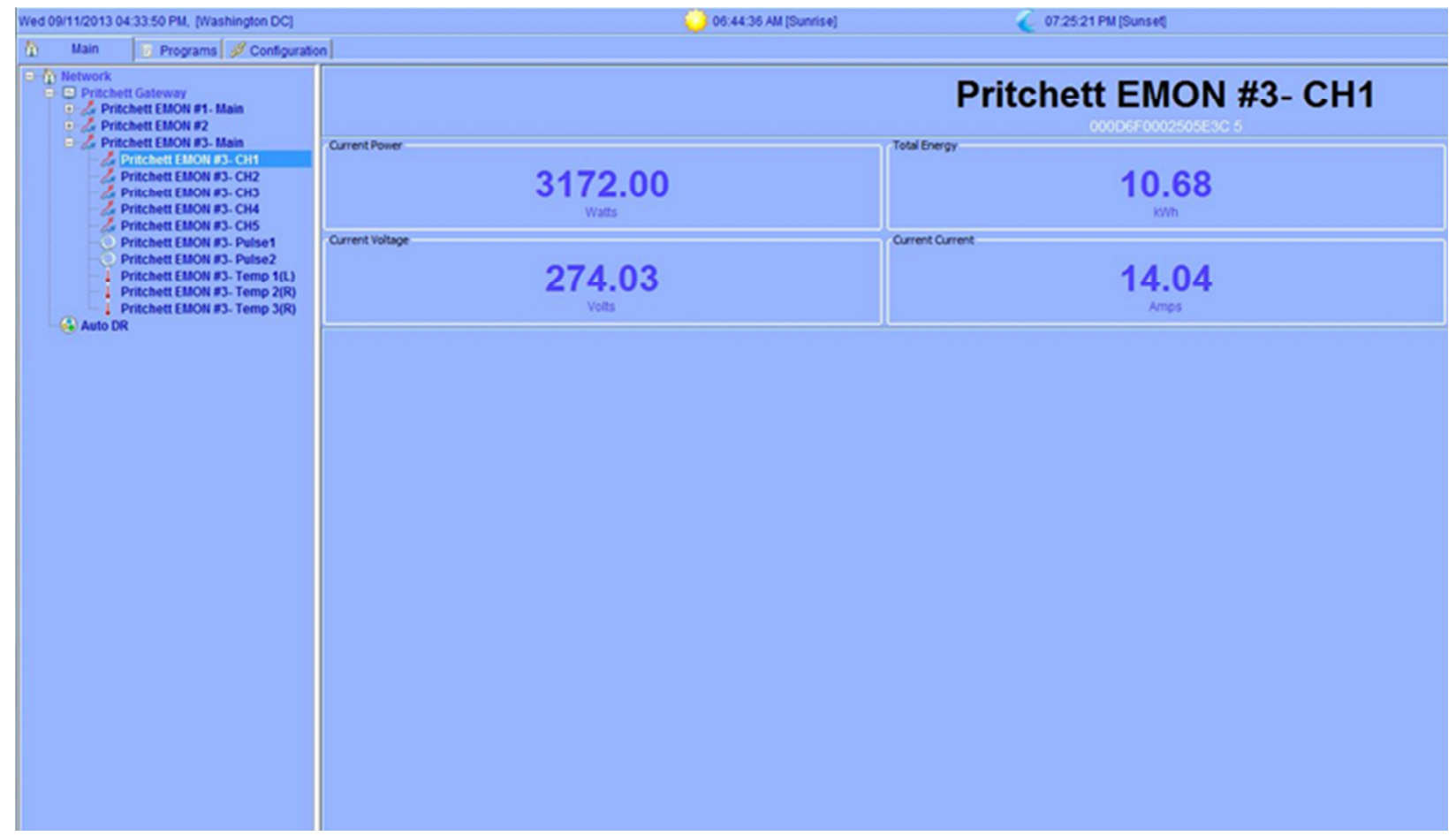

Figure 19. The user interface of the Universal Devices administrative console software for the gateway at Test Site $A$ at the conclusion of the installation 


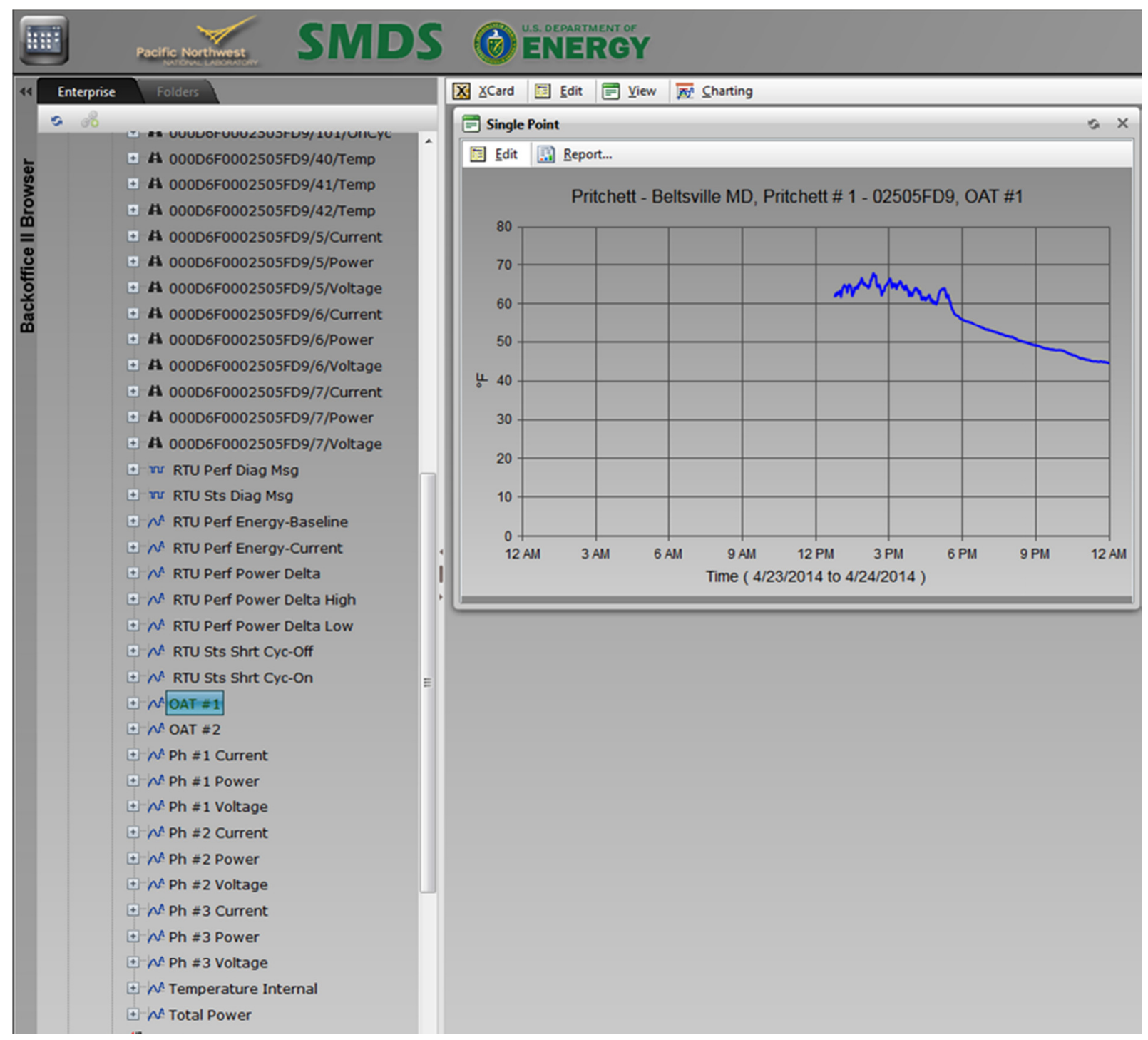

Figure 20. Outdoor-air temperature chart at the NOC for Test Site A

\section{Data Monitoring}

During the field test, the SMDS requirements were to report all raw data to the NOC at 1-minute intervals, along with the performance degradation and fault diagnostic results. This was required so that PNNL could access the raw data and run analysis and diagnostics in the event that the hardware reported results that required investigation or validation.

Upon completion of the installation, 1-minute OAT and total unit electric power consumption data began reporting to the NOC for each RTU that was retrofit with the SMDS technology. PNNL downloaded and analyzed the data two times per week, primarily looking for gaps in the data (i.e., missing timestamps) over extended periods of time for both Test Site A and Test Site B. Gaps in the data have three potential causes: 1) intermittent communications losses between the SMDS, gateway, and NOC; 2) permanent communications losses between the SMDS, gateway, and NOC; 
and 3) loss of power to the SMDS, via power outage, RTU servicing etc. The latter two causes of data gaps required communications between PNNL and the demonstration site, with consultation from NorthWrite and/or Universal Devices as necessary to diagnose and correct the problem. The solutions ranged from cycling the power to the gateway to updating the firmware at the gateway and/or energy monitors, which will be discussed in more detail in Section E.

\section{E. Results}

The installations for Test Site A and Test Site B occurred on April 23, 2014 and July 18, 2014, respectively. The nearly 3-month delay between installations occurred because 1) Test Site B was newly identified by NorthWrite, so the site staff were not familiar with the technology or the installation procedure; 2) the shipping and receiving in Puerto Rico took longer than anticipated; and 3) severe weather and contractor availability delayed installation.

This section presents two types of results: 1) information on the magnitude of data loss compared to the number of data points expected during the monitoring periods for each unit on which the Hardware SMDS was applied and 2) detections of performance degradation and specific operational faults.

Data collection for both test sites began when the installations were completed and continued through October 31, 2014, 11:59 p.m. Table 3 shows the amount of data collected at the NOC for the RTUs at each test site, and the amount of missing data points (i.e., data expected but not successfully transmitted to the NOC). The data expected for each RTU differs because several periods of time existed during the monitoring period for each test site when data were not expected at the NOC. These include power outages (which were prevalent at Test Site B), RTU servicing, and SMDS hardware and software revisions.

As shown in Table 3, when data was expected at the NOC, the SMDS technology lost less than $1.6 \%$ of measurements for all RTUs, with a total loss of $1.1 \%$ for all data collected during the field tests. This small data loss validates the reliability of the SMDS technology to transmit highresolution data.

Table 4 summarizes the performance degradation results for all RTUs used in the field test of the Hardware SMDS. Of the six RTUs in the field test, the SMDS detected performance degradation in three (see Table 4). Two of the RTUs were located at Test Site A, while the other RTU was located at Test Site B. Once performance degradation is detected, the SMDS estimates the energy impact for the most recent week of collected data. If the energy impact is greater than a userdefined threshold ( $\$ 50$ used in the field studies), the energy and cumulative cost impacts of degradation are presented on the user interface. Of the three RTUs that demonstrated performance degradation during the field test, only RTU1 at Test Site A exceeded the threshold required for reporting the degradation to the user. The cumulative cost impacts of degradation over time are shown in Figure 21. The degradation was initially detected in May 2014 and persisted for 6 consecutive weeks, accumulating increased energy costs of $\$ 285$. The SMDS for this RTU was offline for 10 weeks from June 19 until August 28; therefore, no degradation was detected during this time (dashed line segment in Figure 21). However, when the unit reestablished connection to the NOC, degradation continued throughout the monitoring period, ending with a cumulative increase in energy cost of $\$ 456$ by the end of the field test. 
Table 3. SMDS raw data collected and missing at the NOC for both test sites

\begin{tabular}{|c|c|c|c|c|c|c|}
\hline Location & Data Collection Period & \multicolumn{2}{|c|}{$\begin{array}{c}\text { RTU } \\
\text { Measurement }\end{array}$} & $\begin{array}{l}\text { Data Points } \\
\text { Collected at } \\
\text { NOC } \\
\text { (minutes) }\end{array}$ & $\begin{array}{c}\text { Data } \\
\text { Points } \\
\text { Missing at } \\
\text { NOC } \\
\text { (minutes) }\end{array}$ & $\begin{array}{l}\text { Data Points } \\
\text { Missing at } \\
\text { NOC (\%) }\end{array}$ \\
\hline \multirow{6}{*}{$\begin{array}{c}\text { Test Site } \\
\text { A }\end{array}$} & \multirow{6}{*}{$\begin{array}{l}\text { 4/23/2014 12:48 PM } \\
\text { to } \\
\text { 10/31/2014 11:59 PM }\end{array}$} & \multirow{2}{*}{ RTU1 } & Power & 193,857 & 3,093 & 1.6 \\
\hline & & & OAT & 193,857 & 3,007 & 1.6 \\
\hline & & \multirow{2}{*}{ RTU2 } & Power & 274,978 & 2,148 & 0.8 \\
\hline & & & OAT & 274,978 & 2,176 & 0.8 \\
\hline & & \multirow{2}{*}{ RTU3 } & Power & 239,099 & 3,280 & 1.4 \\
\hline & & & OAT & 239,099 & 3,255 & 1.4 \\
\hline \multirow{6}{*}{$\begin{array}{c}\text { Test Site } \\
\text { B }\end{array}$} & \multirow{6}{*}{$\begin{array}{l}\text { 7/18/2014 5:30 PM } \\
\text { to } \\
\text { 10/31/2014 11:59 PM }\end{array}$} & \multirow{2}{*}{ RTU1 } & Power & 107,924 & 978 & 0.9 \\
\hline & & & OAT & 107,924 & 978 & 0.9 \\
\hline & & \multirow{2}{*}{ RTU2 } & Power & 123,766 & 1,306 & 1.1 \\
\hline & & & OAT & 123,766 & 1,292 & 1.0 \\
\hline & & \multirow{2}{*}{ RTU3 } & Power & 112,690 & 978 & 0.9 \\
\hline & & & OAT & 112,690 & 998 & 0.9 \\
\hline
\end{tabular}

Table 4. SMDS performance degradation results for all RTUs in the field test

\begin{tabular}{|c|c|c|c|c|c|c|}
\hline Location & RTU & $\begin{array}{c}\text { Baseline } \\
\text { Performance } \\
\text { Curves } \\
\text { Established } \\
\text { (Yes/No) } \\
\end{array}$ & $\begin{array}{l}\text { Total Number } \\
\text { of Weeks after } \\
\text { Baseline } \\
\text { Establishment }\end{array}$ & $\begin{array}{c}\text { Degradation } \\
\text { Detected } \\
(\text { Yes/No) }\end{array}$ & $\begin{array}{l}\text { Fraction of } \\
\text { Weeks with } \\
\text { Detected } \\
\text { Degradation }\end{array}$ & $\begin{array}{c}\text { Estimated } \\
\text { Cumulative } \\
\text { Cost of } \\
\text { Degradation } \\
(\$) \\
\end{array}$ \\
\hline \multirow{3}{*}{$\begin{array}{c}\text { Test Site } \\
\text { A }\end{array}$} & RTU1 & Yes & 16 & Yes & $15 / 16$ & $\$ 456$ \\
\hline & RTU2 & Yes & 20 & No & $0 / 20$ & ---- \\
\hline & RTU3 & Yes & 12 & Yes & $3 / 12$ & $-\$ 3$ \\
\hline \multirow{3}{*}{$\begin{array}{c}\text { Test Site } \\
\text { B }\end{array}$} & RTU1 & Yes & 5 & Yes & $3 / 5$ & $-\$ 68$ \\
\hline & RTU2 & $\mathrm{No}$ & $\mathrm{N} / \mathrm{A}^{*}$ & $\mathrm{~N} / \mathrm{A} *$ & $\mathrm{~N} / \mathrm{A}^{*}$ & $\mathrm{~N} / \mathrm{A}^{*}$ \\
\hline & RTU3 & No & $\mathrm{N} / \mathrm{A}^{*}$ & $\mathrm{~N} / \mathrm{A}^{*}$ & $\mathrm{~N} / \mathrm{A}^{*}$ & $\mathrm{~N} / \mathrm{A}^{*}$ \\
\hline
\end{tabular}

$* \mathrm{~N} / \mathrm{A}=$ Not Applicable: the SMDS cannot detect degradation because baseline performance curves were not established for the RTU. 


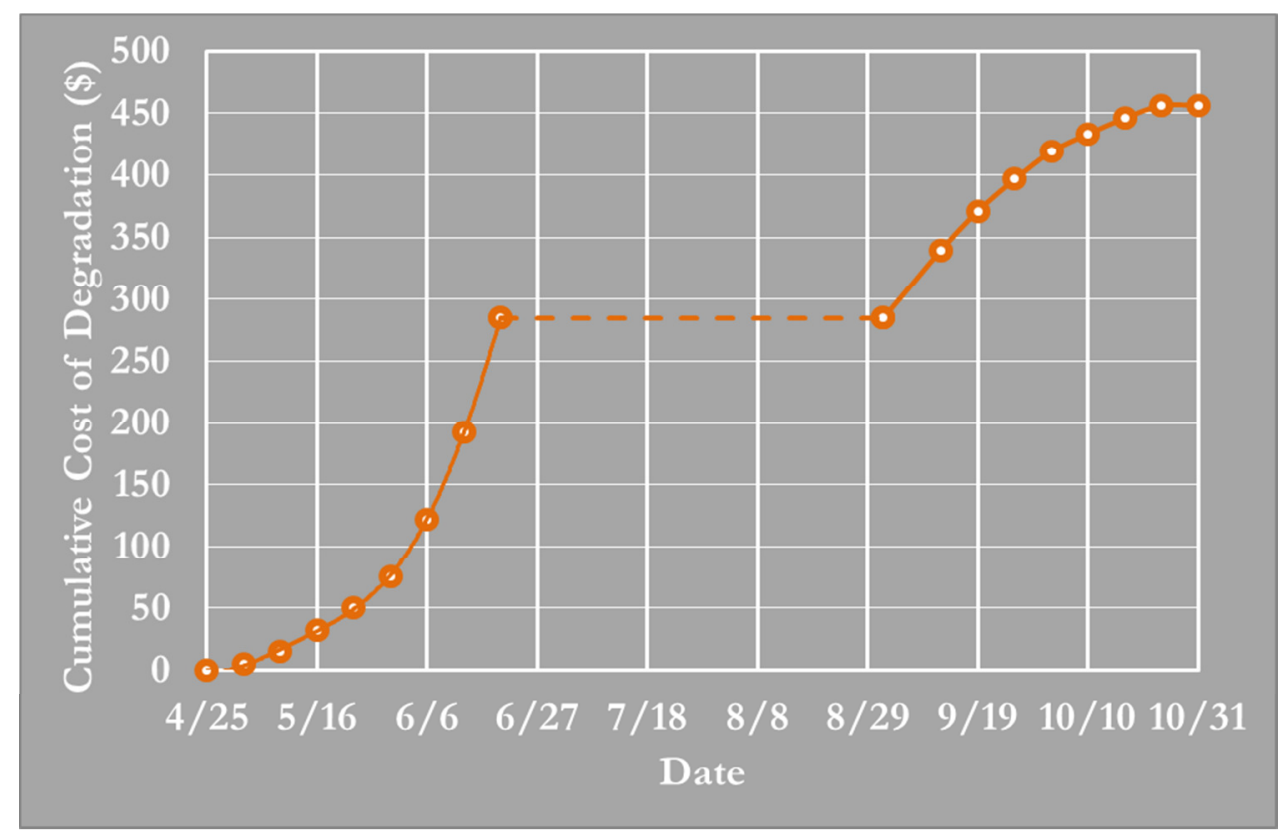

Figure 21. Cumulative energy cost from degradation for RTU1 at Test Site A

Baseline performance curves were established for all three RTUs at Test Site A, but only for RTU1 at Test Site B. Further investigation into the data revealed that RTU2 at Test Site A, while having several cooling cycles over the monitoring period, did not have enough cycles over the required outdoor-air temperature conditions to establish a performance baseline for the unit. RTU3 at Test Site $\mathrm{B}$, on the other hand, did not have enough cooling cycles over the monitoring period to establish a performance baseline because it operated in ventilation-only mode during most of its run time.

Table 4 also shows the fraction of weeks during the monitoring period that degradation was detected. For degradation to be detected, baseline performance curves must be established. Therefore, RTU2 and RTU3 at Test Site B do not have any reported degradation. RTU1 at Test Site B, however, did report degradation 3 out of the 5 weeks after baseline performance curves were established.

For Test Site A, the SMDS on RTU1 detected degradation 15 out of the 16 weeks following the baseline performance curve establishment, for an estimated cumulative cost of degradation of \$456 (see Table 4). The SMDS on RTU2, which had 20 weeks of monitored data after baseline performance curves were established, did not detect any degradation. This indicates that RTU2 did not experience any performance changes from the baseline operating condition throughout the monitoring period. RTU3, in contrast, reported degradation 3 out of the 12 weeks following establishment of the performance baseline. Both RTU3 at Test Site A and RTU1 at Test Site B had cumulative costs of degradation during the field test that were negative, indicating improved performance from the baseline operating condition.

In addition to performance degradation, the SMDS also detects the operational faults described in By periodically logging into the UI and reviewing the performance degradation and fault detection results for each RTU, the building owner or manager for the building can use actual performance information to plan servicing of RTUs and mitigate costly degradation impacts. 
Table 1 and displays results daily. Table 5 lists indicators for each of these faults, which are used in Table 6 and Table 7 to identify the rate of occurrence of each type of fault for each RTU.

Table 5. Operational status fault indices

\begin{tabular}{|l|c|}
\hline \multicolumn{1}{|c|}{ Operation Status } & $\begin{array}{c}\text { Fault } \\
\text { Indicator }\end{array}$ \\
\hline RTU not Providing Ventilation & 1 \\
\hline System off all Day & 2 \\
\hline Compressor on all Day & 3 \\
\hline Fan on all Day & 4 \\
\hline RTU Short Cycling & 5 \\
\hline
\end{tabular}

Table 6. Operational fault summary for both sites in the field tests of the Hardware SMDS

\begin{tabular}{|c|c|c|c|c|c|c|c|}
\hline \multirow{2}{*}{ Location } & \multirow{2}{*}{ RTU } & \multirow{2}{*}{$\begin{array}{l}\text { Number of } \\
\text { Days in } \\
\text { Field Test }\end{array}$} & \multicolumn{5}{|c|}{ Number of Days with Operational Fault: } \\
\hline & & & Fault 1 & Fault 2 & Fault 3 & Fault 4 & Fault 5 \\
\hline \multirow{3}{*}{$\begin{array}{c}\text { Test Site } \\
\text { A }\end{array}$} & RTU1 & 132 & 15 & 22 & 1 & 2 & 0 \\
\hline & RTU2 & 187 & 0 & 75 & 0 & 0 & 0 \\
\hline & RTU3 & 163 & 24 & 45 & 0 & 0 & 5 \\
\hline \multirow{3}{*}{$\begin{array}{c}\text { Test Site } \\
\text { B }\end{array}$} & RTU1 & 73 & 34 & 26 & 0 & 0 & 1 \\
\hline & RTU2 & 81 & 70 & 11 & 0 & 0 & 1 \\
\hline & RTU3 & 76 & 0 & 10 & 0 & 0 & 0 \\
\hline Field Test & $\begin{array}{c}\text { All } \\
\text { RTUs }\end{array}$ & 712 & 143 & 189 & 1 & 2 & 7 \\
\hline
\end{tabular}

Table 7. Fractions of total days in the field tests of the Hardware SMDS with each specific fault

\begin{tabular}{|c|c|c|c|c|c|c|c|}
\hline \multirow{4}{*}{ Location } & \multirow{2}{*}{ RTU } & \multirow{2}{*}{$\begin{array}{c}\text { Number of } \\
\text { Days in } \\
\text { Field Test }\end{array}$} & \multicolumn{4}{|c|}{ Fraction of Days (\%) with Operational Fault: } \\
\cline { 4 - 9 } & & Fault 1 & Fault 2 & Fault 3 & Fault 4 & Fault 5 \\
\hline \multirow{2}{*}{$\begin{array}{c}\text { Test Site } \\
\text { A }\end{array}$} & RTU1 & 132 & 11 & 17 & 1 & 2 & 0 \\
\cline { 2 - 8 } & RTU2 & 187 & 0 & 40 & 0 & 0 & 0 \\
\cline { 2 - 8 } & RTU3 & 163 & 15 & 28 & 0 & 0 & 3 \\
\hline \multirow{2}{*}{$\begin{array}{c}\text { Test Site } \\
\text { B }\end{array}$} & RTU1 & 73 & 47 & 36 & 0 & 0 & 1 \\
\cline { 2 - 8 } & RTU2 & 81 & 86 & 14 & 0 & 0 & 1 \\
\cline { 2 - 8 } & RTU3 & 76 & 0 & 13 & 0 & 0 & 0 \\
\hline \multirow{2}{*}{ Field Test } & $\begin{array}{c}\text { All } \\
\text { RTUs }\end{array}$ & 712 & 20 & 27 & 0 & 0 & 1 \\
\hline
\end{tabular}


The two most prominent faults reported at both test sites were 1) RTU not Providing Ventilation (Fault 1) and 2) System off all Day (Fault 2). Fault 1 is flagged by the SMDS during days in which the RTU supply fan only turns on when mechanical cooling is activated. This is a fault because building occupants are required to be provided with a minimum amount of fresh air ventilation during occupied hours (ASHRAE 2010a). Fault 2 is flagged by the SMDS during days that the RTU systems do not turn on. If the building is unoccupied for the day, then the user is advised that this fault can be ignored. However, if the building is occupied and the RTU is off, the thermal space(s) served by the RTU may not be getting the required amount of conditioned air, which can lead to occupant discomfort. More details on each of the faults identified at the test sites can be found in By periodically logging into the UI and reviewing the performance degradation and fault detection results for each RTU, the building owner or manager for the building can use actual performance information to plan servicing of RTUs and mitigate costly degradation impacts.

\section{Table 1.}

Fault 3 and Fault 4 were only discovered in RTU1 at Test Site A for 1 and 2 days during the monitoring period, respectively. RTU short cycling (Fault 5) was only observed 1 day in RTU1 and RTU2 at Test Site B and 5 days in RTU3 at Test Site A, representing between 1\% and 3\% fault occurrence. Table 7 shows the fault occurrences for each fault, along with the totals for all RTUs in the field test. Fault 2 (System off all Day) was the highest recurring fault at $27 \%$ of days during the Hardware SMDS field test, and Fault 1(RTU not Providing Ventilation) occurred $20 \%$ of the days during the field test.

\section{F. Discussion/Observations}

The SMDS provides actionable fault detection and diagnostic information to building owners and managers for their packaged RTU operations, along with estimated cumulative energy cost increases when RTU performance changes significantly over time. During the hardware-based SMDS demonstration, feedback was obtained from both test sites regarding the installation procedure and UI interaction for the technology.

User feedback for the installation procedure included:

- Installation took too long;

- Installation needed to be done during unoccupied hours to meet safety requirements; and

- NorthWrite's technical assistance was required throughout installation.

User feedback for the UI:

- It looks great, but tends to drop out when switching screens. If you try to go back it goes to a blank screen, and it is unsure if something should be there;

- The cumulative cost of degradation seems to stay constant at times; and

- Getting into the website was not easy, there were some security issues on the users system.

Field Testing and Demonstration of the Smart Monitoring and Diagnostics System (SMDS) for Packaged Air Conditioners and Heat Pumps 
Overall, the users were very pleased with the demonstration and information that is generated from the SMDS, but they were not always clear on the information presented at the UI. Understanding the information is critical to shift the paradigm of RTU maintenance practices from preventative to condition-based. This requires very clear, concise information that can quickly educate users what problem exists and if/when they should invest resources to correct the problem. The hardware installation became an issue for the users because they had to schedule times when their staff could work outside of typical building occupancy hours to follow safety requirements when installing the SMDS. In addition, they had to rely on NorthWrite throughout the installation to ensure proper setup of the equipment. Ideally, this process should be more intuitive and take less time and resources.

In addition to the installation and UI comments listed above, there were several times during the monitoring period when PNNL noticed that the SMDS units had quit communicating with the NOC. This was expected during times in which the power supply to the RTUs (and hence the SMDS) was disconnected (e.g., power outages and RTU scheduled servicing). However, interaction with the users during these periods revealed that, even during times when power had been restored, the SMDS units were still not communicating with the NOC. This required the user's manual reset of the gateway. Upon reset, all raw data was lost (for times when the power was restored but the gateway was not responding), but the operational fault and performance degradation results were still reported. Future testing of the hardware-based SMDS should be conducted to identify and eliminate these instances where manual reset is required.

The SMDS uses measurements of total RTU power and outdoor-air temperature at 1-minute intervals. The outdoor-air temperature sensor is attached to the bottom of the SMDS enclosure and shielded by a slotted gray polyvinyl chloride (PVC) tube (see Figure 16). However, analysis of the collected outdoor-air temperature data for two SMDS units at Test Site B showed some inconsistencies between measurements. Figure 22 shows outdoor-air temperature measurements for RTU1 and RTU2 at Test Site B for July 15, 2014. The outdoor-air temperature measurements differ by as much as $6^{\circ} \mathrm{F}$ during the day. This may be attributable to the outdoor-air temperature measured by the sensor being increased by solar heating at times (e.g., approximately 9:40 a.m. to 11:00 a.m.). Sunlight impinging directly on the sensor or the gray tube surrounding the temperature probe could affect the measured temperature. The sensor needs to be installed in a position where it is shaded at all times, and the tube surrounding the sensor should be a highly reflective white to minimize solar absorption. 


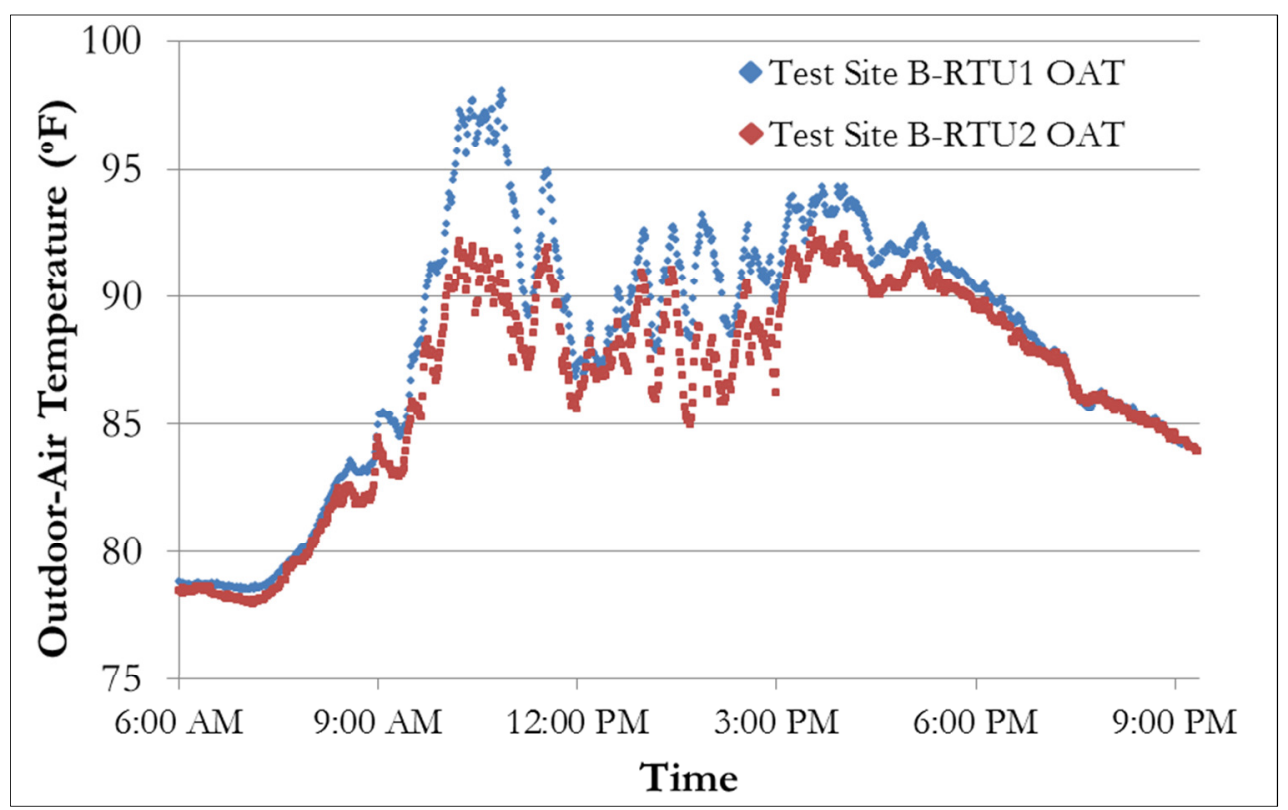

Figure 22. Outdoor-air temperature measurements by two SMDS units at Test Site B for 1 day in July 2014

\section{Demonstration of the Prototype Cloud-Based SMDS}

The section describes the demonstration of the Cloud SMDS and presents results characterizing the SMDS findings and performance. This part of the SMDS demonstration was cost shared by DOE and the New York Energy Research Development Administration (NYSERDA) as part of a project performed by NorthWrite Inc. under contract to NYSERDA.

\section{A. Test Sites}

The Cloud version of the SMDS was tested on data from three small commercial buildings located in the State of New York. Characteristics of these buildings are shown in Table 8. Photos of the test buildings are shown in Figure 23 through 25.

SMDS sensors were also installed on a soon-to-be-occupied $3000-\mathrm{ft}^{2}$ mixed-use office building, which would have represented a fourth test site, but as of October 31, 2014, this building was still unoccupied and, therefore, could not be used in the demonstration. All buildings were selected using basic guidance from PNNL on the characteristics of appropriate buildings and RTUs. NorthWrite made the selections from a list of potential buildings provided by Greenview Energy Systems as part of the NYSERDA project under which the field work for testing the Cloud SMDS was performed. 
Table 8. Characteristics of the sites for testing the Cloud-Based SMDS

\begin{tabular}{|c|l|l|c|c|c|c|l|}
\hline $\begin{array}{c}\text { Test } \\
\text { Site }\end{array}$ & $\begin{array}{c}\text { Location/ } \\
\text { Climate } \\
\text { Zone }\end{array}$ & $\begin{array}{c}\text { Building } \\
\text { Type }\end{array}$ & $\begin{array}{c}\text { Building } \\
\text { Size } \\
\mathbf{f f t}^{2} \mathbf{)}\end{array}$ & $\begin{array}{c}\text { Total } \\
\text { Number } \\
\text { of RTUs }\end{array}$ & $\begin{array}{c}\text { Number of } \\
\text { RTUs Used in } \\
\text { Demonstration }\end{array}$ & $\begin{array}{c}\text { RTU } \\
\text { Capacity } \\
\text { Range } \\
\text { (tons) }\end{array}$ & \multicolumn{1}{|c|}{$\begin{array}{c}\text { Types of } \\
\text { RTUs }\end{array}$} \\
\hline A & $\begin{array}{l}\text { Rome, NY } \\
\text { 6A, Cold and } \\
\text { Moist }\end{array}$ & $\begin{array}{l}\text { Ace } \\
\text { Hardware } \\
\text { Store }\end{array}$ & 15,000 & 4 & 3 & 5 & $\begin{array}{l}\text { Air } \\
\text { Conditioners } \\
\text { with Gas Heat }\end{array}$ \\
\hline B & $\begin{array}{l}\text { Rome, NY } \\
\text { 6A, Cold and } \\
\text { Moist }\end{array}$ & $\begin{array}{l}\text { Philipson's } \\
\text { Outdoor } \\
\text { Supply Store }\end{array}$ & 45,000 & 7 & 3 & 7.5 to 20 2 & $\begin{array}{l}\text { Air } \\
\text { Conditioners } \\
\text { with Gas Heat }\end{array}$ \\
\hline C & $\begin{array}{l}\text { Suffern, NY } \\
5 \mathrm{~A}, \text { Cool and } \\
\text { Moist }\end{array}$ & $\begin{array}{l}\text { McDonald's } \\
\text { Fast Food } \\
\text { Restaurant }\end{array}$ & 3,500 & 4 & 3 & 7.5 to 10 10 & $\begin{array}{l}\text { Air } \\
\text { Conditioners } \\
\text { with Gas Heat }\end{array}$ \\
\hline
\end{tabular}

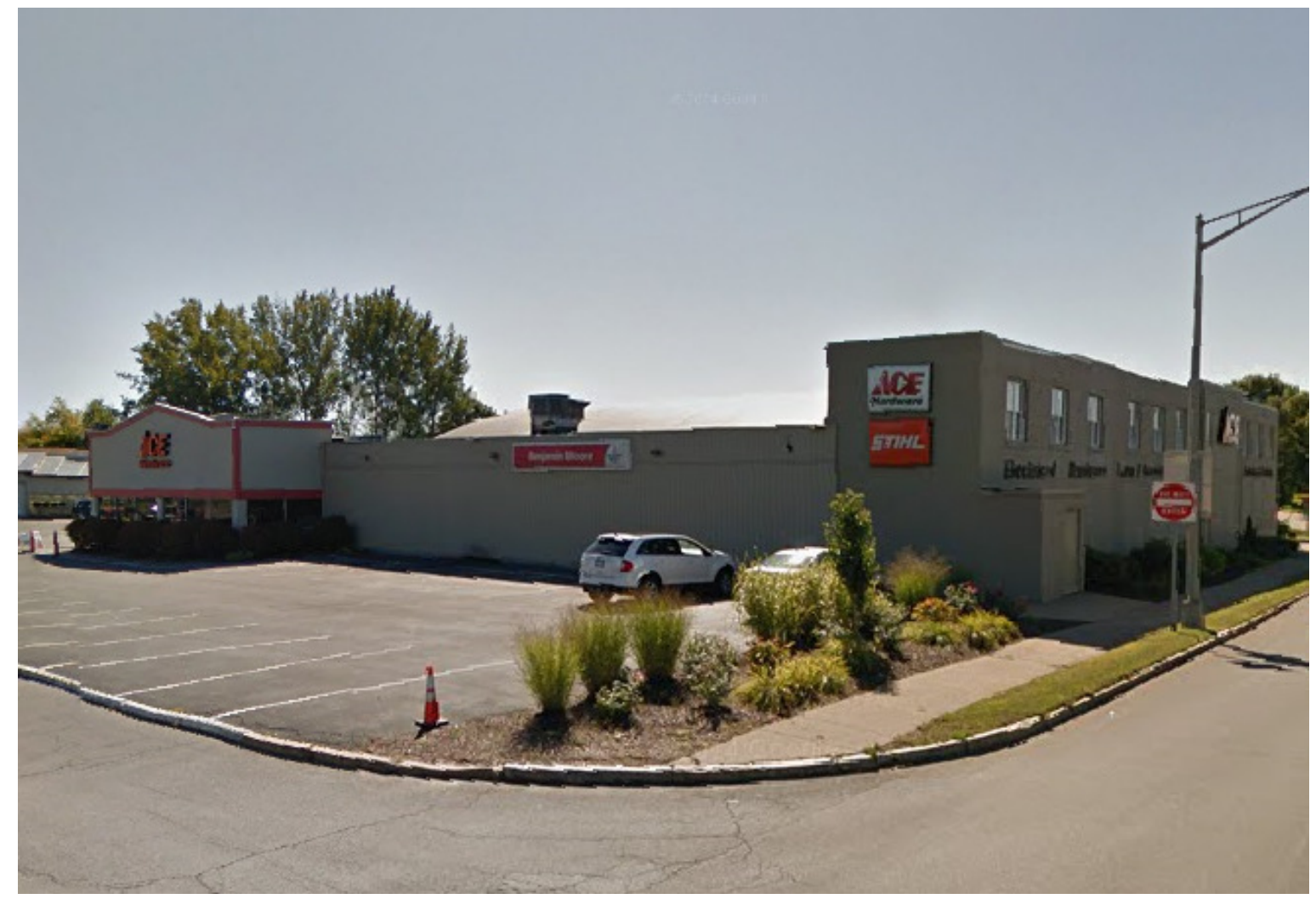

Figure 23. Test Site A for Cloud SMDS 


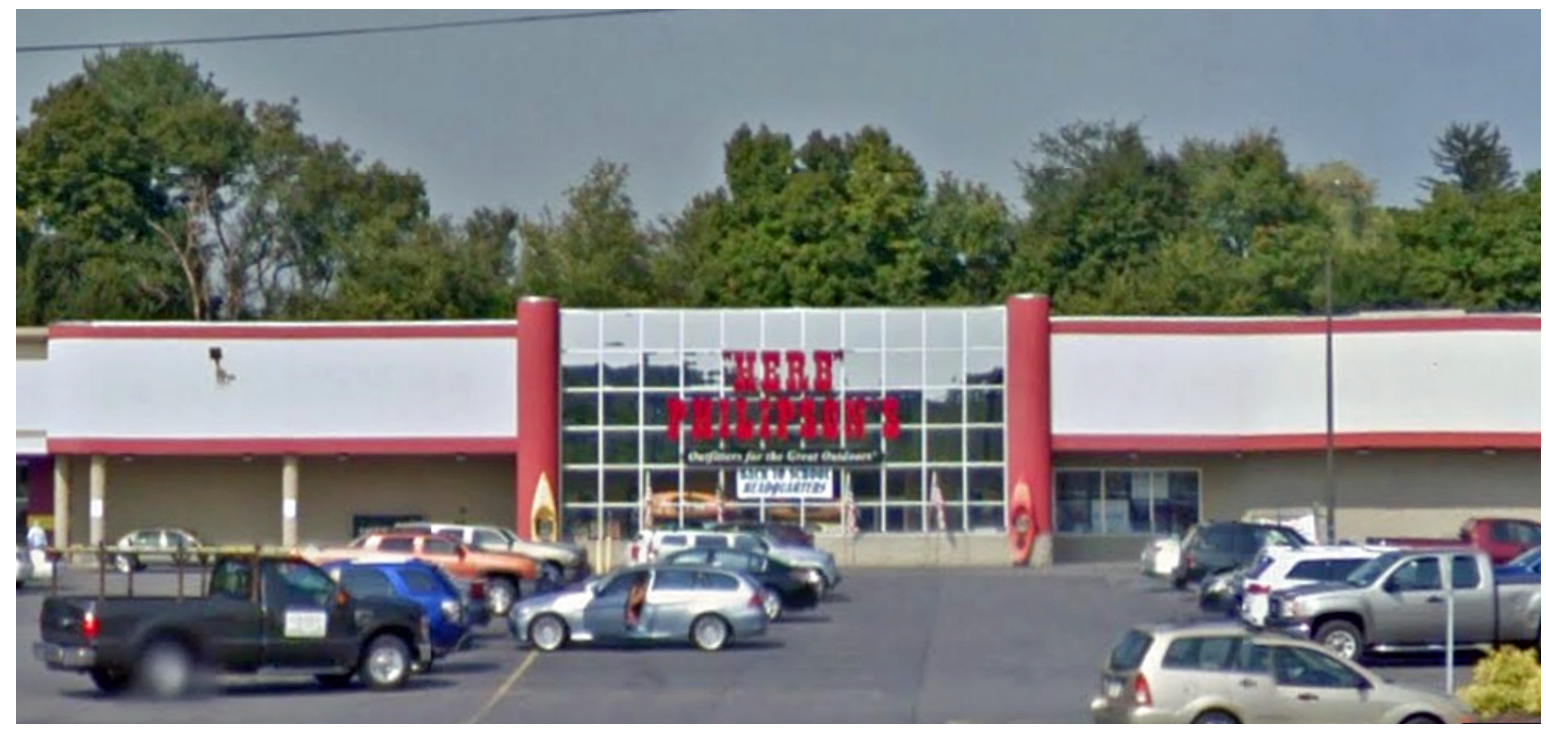

Figure 24. Test Site B for Cloud SMDS

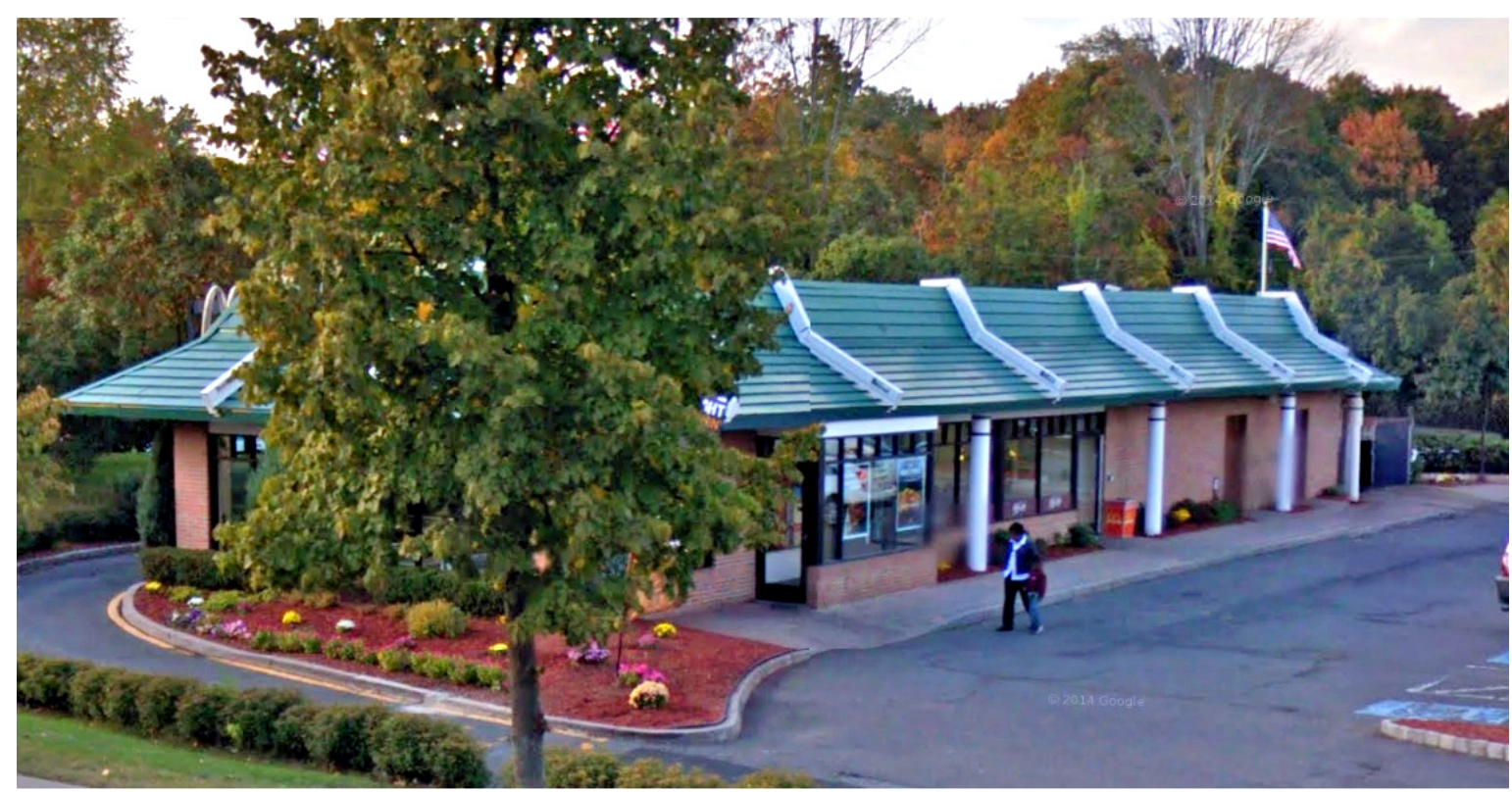

Figure 25. Test Site $\mathrm{C}$ for Cloud SMDS

Three RTUs were selected for the SMDS tests at each of the three test sites. All three of the RTUs at Test Site A for which data were collected for application of the SMDS have cooling capacities of 5 tons. For Test Site B, each RTU on which SMDS instrumentation was installed has four compressors and a capacity of 20 tons. Ordinarily the number of compressors indicates the potential to operate in four vapor compression stages, although in some installations multiple compressors are operated identically so that the effective number of stages can be less than the number of compressors. The SMDS, as prototyped, is limited in application to RTUs having one or two stages (although with enhancements to the software code, it could be extended to more stages). 
The PNNL team verified, by visual inspection of the plots of the power data versus OAT, that the three selected RTUs at Test Site B all operate as four-stage units and, therefore, are not compatible with the SMDS. At Test Site C, two of the three RTUs to which the SMDS was applied have cooling capacities of 7.5 tons, and the third RTU, which serves the kitchen, has a capacity of 10 tons; all are compatible with the SMDS. The mismatch between the SMDS requirements on maximum number of compressor stages and the units for which data were collected at Test Site B, left only six RTUs for testing of the Cloud SMDS instead of the nine originally planned.

\section{B. Instrumentation, Data Collection and Analysis}

Measurement instrumentation at each site included one outdoor-air temperature sensor and a threephase power meter on each monitored RTU. All measurements were made at 1-minute intervals. At each site the outdoor-air temperature was measured using a Veris ${ }^{5}$ TODR00 10,000-ohm thermistor weather resistant outdoor-air temperature probe (one per site). Three-phase total power consumption for each RTU was measured using a Dent Instruments ${ }^{6}$ Power Scout 3 with three Rogowski coil CTs. Data were communicated to the NorthWrite Cloud-based NOC using the Cloudgate $3 \mathrm{~g}$ modem of Option ${ }^{7}$ and the Sprint $3 \mathrm{G}$ cellular service. Data were stored in the NorthWrite NOC and processed with the Cloud SMDS.

Delays in installation of instrumentation on the test site buildings until the late summer and early fall of 2014 limited the cooling data collection and prevented opening the SMDS web interface to users. Instead the site data was batched processed by the Cloud SMDS. Results of the SMDS analysis are reported in Subsection C, which follows. No user feedback is, therefore, available from these tests.

\section{Results}

This section presents two types of results: 1) information on the magnitude of data loss compared to the number of data points expected during the monitoring periods for each unit on which the Cloud SMDS was applied and 2) detections of performance degradation and specific operational faults.

Table 9 shows the number of data points collected at the NOC compared to the total number of data points expected during the collection of data for all units. For Test Site A, 1.2\% of the outdoor-air temperature measurements (1461 points) were not recorded at the NOC. The missing data points were likely lost during wireless data transmission. Only eight data points (which corresponds to less than $0.01 \%$ ) were missing for power measurements for RTU2. For each of RTU3 and RTU4, the number of points recorded at the NOC actually exceeded the number of points expected if all were received by the NOC (by eight excess points). These excess points resulted from some double reporting of measurements for a very small fraction of the minutes (in this case, less than $0.01 \%$ ). For Test Site C, 3.1\% of the outdoor-air temperature measurements

\footnotetext{
${ }^{5}$ Veris Industries, 12345 SW Leveton Drive, Tualatin, OR 97062. http://www.veris.com/Category/Temperature.aspx

${ }^{6}$ Dent Instruments, 925 SW Emkay Drive, Bend, OR 97702. http://www.dentinstruments.com/

${ }^{7}$ Option, Gaston Geenlaan, 3001 Leuven, Belgium. http://www.option.com/ and http://www.sphinxcomputer.de/produktdb/documents/3529 4616.pdf.
}

Field Testing and Demonstration of the Smart Monitoring and Diagnostics System (SMDS) for Packaged Air Conditioners and Heat Pumps 
(3271points) were not recorded at the NOC. The missing data points were likely lost during wireless data transmission. Approximately $5 \%$ of the expected power measurement data (5780 points) for RTU-D2 did not make it to the NOC. For each of RTU-K1 and RTU-K2, all power measurements expected were received by the NOC.

Of the six RTUs in the Cloud SMDS field test, the SMDS detected performance degradation in only RTU3 at Test Site A (see Table 10). The degradation resulted in an estimated cumulative increase in energy cost of $\$ 55$ over the 6 weeks between the time the degradation was detected and the end of data collection. Figure 26 shows the accumulation of excess energy costs associated with the degradation in performance detected for this unit over time. Baseline performance curves were established for the other two RTUs at Test Site A, but no performance degradation was detected during the field test.

Table 9. SMDS raw data expected and missing at the NOC for the Cloud SMDS test sites

\begin{tabular}{|c|c|c|c|c|c|}
\hline Location & $\begin{array}{c}\text { RTU } \\
\text { Measurement }\end{array}$ & $\begin{array}{l}\text { Data Collection } \\
\text { Period } \\
\text { (UTC) }\end{array}$ & $\begin{array}{l}\text { Data Points } \\
\text { Expected at } \\
\text { NOC } \\
\text { (minutes) }\end{array}$ & $\begin{array}{l}\text { Data } \\
\text { Collected } \\
\text { at NOC } \\
\text { (minutes) }\end{array}$ & $\begin{array}{c}\text { Data Points } \\
\text { Missing at } \\
\text { NOC (\%) }\end{array}$ \\
\hline \multirow{4}{*}{$\begin{array}{c}\text { Test Site } \\
\text { A }\end{array}$} & OAT & $\begin{array}{l}\text { 8/4/2014 09:46 PM } \\
\text { to } \\
\text { 10/25/2014 02:01 AM }\end{array}$ & 116,896 & 115,435 & $1.2 \%$ \\
\hline & RTU2 Power & $\begin{array}{l}\text { 8/1/2014 08:00 AM } \\
\text { to } \\
10 / 25 / 20141: 00 \mathrm{AM}\end{array}$ & 121,981 & 121,973 & $0.0 \%$ \\
\hline & RTU3 Power & $\begin{array}{l}\text { 7/31/2014 4:00 PM } \\
\text { to } \\
\text { 10/24/2014 9:45 AM }\end{array}$ & 122,026 & 122,018 & $0.0 \%$ \\
\hline & RTU4 Power & $\begin{array}{l}\text { 7/31/2014 4:00 PM } \\
\text { to } \\
\text { 10/24/2014 9:45 AM }\end{array}$ & 122,026 & 122,018 & $0.0 \%$ \\
\hline \multirow{4}{*}{$\begin{array}{l}\text { Test Site } \\
\text { C }\end{array}$} & OAT & $\begin{array}{l}\text { 8/22/2014 4:03 AM } \\
\text { to } \\
\text { 11/03/2014 8:07 AM }\end{array}$ & 105,365 & 102,094 & $3.1 \%$ \\
\hline & RTU-D2 Power & $\begin{array}{l}\text { 8/14/2014 4:00 PM } \\
\text { to } \\
\text { 11/3/2014 7:50 AM }\end{array}$ & 116,151 & 110,371 & $5.0 \%$ \\
\hline & RTU-K1 Power & $\begin{array}{l}\text { 8/14/2014 4:00 PM } \\
\text { to } \\
\text { 11/3/2014 7:50 AM }\end{array}$ & 116,151 & 116,151 & $0.0 \%$ \\
\hline & RTU-K2 Power & $\begin{array}{l}\text { 8/14/2014 4:00 PM } \\
\text { to } \\
\text { 11/3/2014 7:50 AM }\end{array}$ & 116,151 & 116,151 & $0.0 \%$ \\
\hline
\end{tabular}


Table 10. SMDS performance degradation results for all RTUs in the Cloud SMDS field test

\begin{tabular}{|c|c|c|c|c|}
\hline Location & RTU & $\begin{array}{c}\text { Baseline Performance } \\
\text { Curves Established } \\
\text { (Yes/No) }\end{array}$ & $\begin{array}{c}\text { Degradation Detected } \\
\text { (Yes/No) }\end{array}$ & $\begin{array}{c}\text { Estimated } \\
\text { Cumulative Cost } \\
\text { of Degradation (\$) }\end{array}$ \\
\hline \multirow{3}{*}{$\begin{array}{c}\text { Test Site } \\
\text { A }\end{array}$} & RTU2 & Yes & No & - \\
\hline & RTU3 & Yes & Yes & $\$ 55$ \\
\hline & RTU4 & Yes & $\mathrm{No}$ & - \\
\hline \multirow{3}{*}{$\begin{array}{l}\text { Test Site } \\
\text { C }\end{array}$} & RTU-D2 & Yes & No & - \\
\hline & RTU-K1 & No & $\mathrm{N} / \mathrm{A}^{*}$ & - \\
\hline & RTU-K2 & Yes & $\mathrm{No}$ & - \\
\hline
\end{tabular}

$* \mathrm{~N} / \mathrm{A}=$ not applicable because the SMDS cannot detect degradation because baseline performance curves were not established for the RTU.

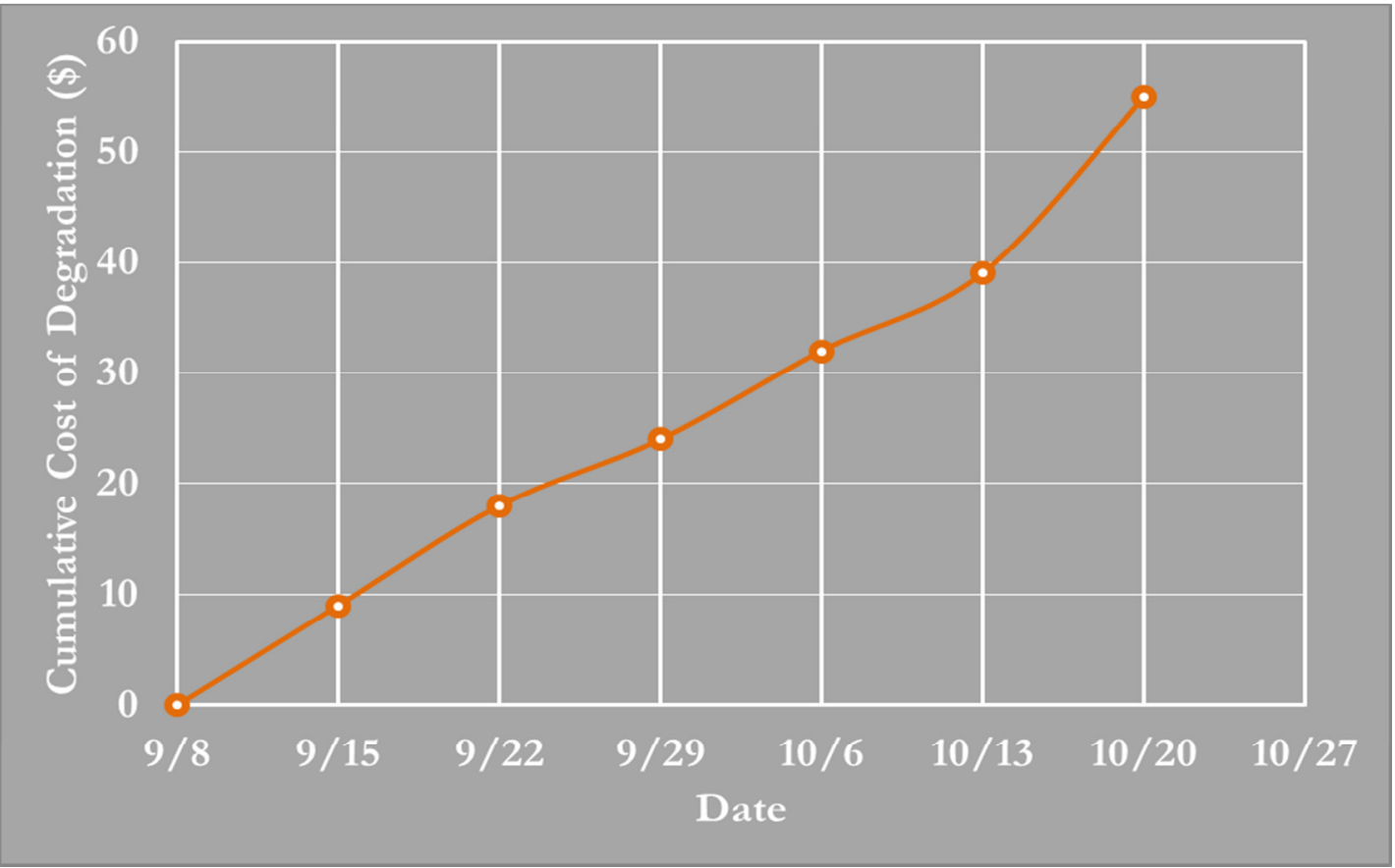

Figure 26. Cumulative energy cost from performance degradation of RTU3 at Test Site A of the Cloud SMDS field test

No degradation in performance was detected for the vapor compression systems of any of the three RTUs to which the Cloud SMDS was applied at Test Site C (see Table 10). Baseline performance curves were established for two of the RTUs--RTU-D2 and RTU-K2. A baseline was not established for RTU-K1 because operating conditions did not provide a sufficient number of cooling cycles over a sufficient outdoor-air temperature range to establish one.

As with the Hardware SMDS, besides detecting degradation in the RTU vapor compression cycle performance, the Cloud SMDS detects several operation faults (see Table 5 for the list of faults and the index for each). Summaries of the fault detection

Field Testing and Demonstration of the Smart Monitoring and Diagnostics System (SMDS) for Packaged Air Conditioners and Heat Pumps 


\section{results are shown in Table 11 and}

Table 12.

Table 11. Operational fault summary for both test sites in the field tests of the Cloud SMDS

\begin{tabular}{|c|c|c|c|c|c|c|c|}
\hline \multirow{2}{*}{ Location } & \multirow{2}{*}{ RTU } & \multirow{2}{*}{$\begin{array}{l}\text { Number } \\
\text { of Days in } \\
\text { Field Test }\end{array}$} & \multicolumn{5}{|c|}{ Number of Days with Operational Fault: } \\
\hline & & & Fault 1 & Fault 2 & Fault 3 & Fault 4 & Fault 5 \\
\hline \multirow{3}{*}{$\begin{array}{c}\text { Test Site } \\
\text { A }\end{array}$} & RTU2 & 88 & 0 & 0 & 0 & 3 & 66 \\
\hline & RTU3 & 82 & 0 & 0 & 0 & 27 & 31 \\
\hline & RTU4 & 82 & 0 & 0 & 0 & 50 & 7 \\
\hline \multirow{3}{*}{$\begin{array}{c}\text { Test Site } \\
\text { C }\end{array}$} & RTU-D2 & 74 & 0 & 14 & 0 & 15 & 22 \\
\hline & RTU-K1 & 74 & 0 & 0 & 0 & 0 & 0 \\
\hline & RTU-K2 & 74 & 0 & 0 & 0 & 31 & 1 \\
\hline $\begin{array}{c}\text { Field } \\
\text { Test }\end{array}$ & $\begin{array}{l}\text { ALL } \\
\text { RTUs }\end{array}$ & 474 & 0 & 14 & 0 & 126 & 127 \\
\hline
\end{tabular}

Table 12. Fractions of total days in the field tests of the Cloud SMDS with each specific fault

\begin{tabular}{|c|c|c|c|c|c|c|c|}
\hline \multirow{4}{*}{ Location } & \multirow{2}{*}{ RTU } & \multirow{2}{*}{\begin{tabular}{c} 
Number of \\
Days in \\
\cline { 4 - 9 }
\end{tabular}} & & \multicolumn{4}{|c|}{ Fraction of Days (\%) with Operational Fault: } \\
\cline { 5 - 9 } & Field Test & Fault 1 & Fault 2 & Fault 3 & Fault 4 & Fault 5 \\
\hline \multirow{2}{*}{$\begin{array}{c}\text { Test Site } \\
\text { A }\end{array}$} & RTU2 & 88 & 0 & 0 & 0 & 3 & 75 \\
\cline { 2 - 9 } & RTU3 & 82 & 0 & 0 & 0 & 33 & 38 \\
\cline { 2 - 9 } & RTU4 & 82 & 0 & 0 & 0 & 61 & 9 \\
\hline \multirow{2}{*}{$\begin{array}{c}\text { Test Site } \\
\text { C }\end{array}$} & RTU-D2 & 74 & 0 & 19 & 0 & 20 & 30 \\
\cline { 2 - 9 } & RTU-K1 & 74 & 0 & 0 & 0 & 0 & 0 \\
\cline { 2 - 9 } & RTU-K2 & 74 & 0 & 0 & 0 & 42 & 1 \\
\hline \multirow{2}{*}{ Field Test } & ALL & 474 & N/A & N/A & N/A & N/A & N/A \\
\hline
\end{tabular}

The two most commonly detected operational faults by far across RTUs were 1) the fan on all day (Fault 4) an 2) RTU short cycling (Fault 5). When Fault 4 is present, the supply fan operates 24 hours per day, including times when the building is not scheduled for occupancy. Supply fans generally run continuously when occupants are present to provide outdoor-air ventilation. When no occupants are present, no ventilation is generally required, and the energy used to operate the fan is wasted and unnecessarily increases energy costs. The faults can be corrected by simply scheduling the fan to run continuously during the hours when the building is scheduled for occupancy and to cycle with the RTU compressor when the building is scheduled to be unoccupied. Short cycling (Fault 5) occurs when an air-conditioning RTU begins to cool again too soon (usually less than about 4 minutes) after cooling turned off or when the unit stops cooling too soon after beginning to cool (also usually less than about 4 minutes). Short cycling both increases 
energy consumption compared to the energy use of a properly cycling unit and also increases the wear on the RTU, leading to premature failure of components and increased maintenance and repair costs.

Continuous fan operation was detected for significant fractions of the field study days for RTU3 and RTU4 (33\% and 61\%, respectively) at Test Site A and for RTU-D2 and RTU-K2 (20\% and $42 \%$, respectively) at Test Site C. The schedules for these units should be adjusted to correct for continuous fan operation. This fault was not detected for many days for RTU2 at Test Site A and RTU-K1 at Test Site C (3\% and 0\%, respectively).

Only one other fault was detected in any of the RTUs on which the Cloud SMDS was tested. RTU-D2 was detected as off (not operating at all) on 14 out of 74 days (19\%). This could be the result of manual on/off control of this unit or a combination of mild outdoor temperatures coupled with the zone served by the unit benefiting from spillover of cooling from adjacent zones cooled by other units.

\section{Additional Observations and Discussion}

The data loss by the Cloud SMDS data collection system ranged from $5 \%$ to $0 \%$ across all eight variables collected for the six RTUs. Five variables had losses of $0.0 \%$ or better. Only three measured variables had non-zero data losses, which were $1.2 \%, 3.1 \%$ and $5.0 \%$. Data loss is especially of concern when wireless data communication is being used. For purposes of RTU performance monitoring and diagnostics with the SMDS, data losses of $5 \%$ or less are entirely acceptable and will not defeat the objectives of the SMDS.

Degradation of performance was only detected by the Cloud SMDS for one of the six RTUs to which it was applied. In this one case, the degradation was detected 3 weeks after the baseline was established, and persisted for 6 weeks through October 20, the last date in the field test on which degradation detection was processed. These results for degradation performance detection should not be misinterpreted as statistically representative of the fraction of RTUs on which degradation will be detected. Degradation results from factors such as leaking of refrigerant, dirt accumulating on coils and other factors that develop over time. They also occur from discrete events such as a refrigerant charging error or sudden failure of a component. Although these discrete events do not develop over time, the probability of one occurring increases as time passes (after development of the baseline). Therefore, testing of the SMDS over longer time periods would likely have led to detection of degradation on more RTUs.

The cost impact of the degradation detected in RTU3 at Cloud SMDS Test Site A was $\$ 55$ corresponding to $550 \mathrm{kWh}$ of excess energy use. These energy and cost impacts accumulated over only 6 weeks near the end of the cooling season in New York. When degradation like this is not addressed, the impacts continue to accumulate over time. Because cooling is used less near the end of the cooling season than in the middle of summer months, if the degradation were present and had been detected earlier in the cooling season by the SMDS (if installation were completed earlier), the estimated impacts could have been significantly greater.

Concerning the detection of operational faults, only two of the five faults that the SMDS detects were detected in most of the RTUs to which the Cloud SMDS was applied. These were the fan 
running constantly 24 hours per day (Fault 4) and short cycling of the RTU (Fault 5). Fault 4 was detected on a significant fraction (from $20 \%$ to $61 \%$ ) of the days in the test periods for four of the RTUs, and Fault 5 was detected in a significant fraction (from 30\% to 75\%) of the days in the test periods for three of the units. Two units exhibited both of these faults. No RTUs had Faults 1 or 3, and only one RTU had Fault 2 (the RTU off all day) and only for $19 \%$ of the test period days. These fault detection results should not be interpreted to imply that only Faults 4 and 5 commonly occur because 1) a sample of six RTUs is extremely small and cannot be used to infer statistically meaningful conclusions about the population of all RTUs and 2) other factors also affect how well the units represent the population of all RTUs, e.g., that the six units were on only two buildings in two different climates and were maintained under the maintenance practices of two specific building owners. The comparisons of fault detection results from the tests of the Cloud SMDS and those for testing of the Hardware SMDS discussed later in Section VII show a contrast in the faults detected.

\section{Summary Findings and Conclusions}

The SMDS provides the unique capability to detect performance degradation and operational faults in packaged air conditioners and heat pumps commonly used on smaller commercial buildings (and some large commercial buildings) using only two measurements, the outdoor-air temperature and the electric power demand of each unit. As shown by the field tests of the Cloud SMDS, a single outdoor-air temperature sensor can be used for a building site. This minimal use of sensors enables fault detection at low cost especially compared to systems that detect detailed faults in the equipment but use many sensors, which results in higher capital cost and higher installation costs from increased time to install such systems. The SMDS focuses on providing information on the operating state and condition of packaged RTUs, especially the increased energy costs associated with performance degradation that owners can use to make informed decisions on whether and when to have the units serviced. No similar feedback is available for RTUs today and, as a result, RTU maintenance is often neglected and units operate at degraded performance for extended times. When a unit is serviced, the SMDS shows whether continued degradation is eliminated. If not entirely eliminated, the SMDS shows how successful the servicing was in eliminating the degradation and its cost impacts. This information will help users distinguish between good, successful servicing and poor, unsuccessful servicing. The SMDS also shows the cost savings resulting from servicing.

\section{A. Performance Degradation Detection}

Performance degradation was detected on only two RTUs, RTU 1 at Test Site A for the Hardware SMDS, and RTU3 at Test Site A for the Cloud SMDS. That corresponds to only 2 of 12 (17\%) total RTUs on which a version of the SMDS was tested. This might be considered small and tend to lead the reader to conclude that few RTUs will benefit from detection of performance degradation using the SMDS. However, except for sudden faults or failures, degradation of performance generally occurs gradually over time from leaking refrigerant, evaporators and conditioners accumulating dirt, motors wearing, and other factors. Detection of degradation relative to a baseline established in the first 3 weeks following installation of the SMDS may take months or even more than a single season. Given that all the tests for the Cloud SMDS were near the end of the cooling season when demand for cooling is less than during the summer months, 
detection of degradation in $17 \%$ of the units may not be low. Furthermore, the baselines established this season may well prove useful in detecting degradation next season or the one after.

The estimated electricity cost increase for RTU1 at Test Site A in Baltimore in the Hardware SMDS tests was $\$ 456$ over 15 weeks(see Figure 21 ) for a blended electric rate for Baltimore of $\$ 0.125 / \mathrm{kWh}$. The associated increase in energy use (and potential savings from unit servicing) is approximately $4600 \mathrm{kWh}$. The SMDS, however, was offline for repairs during 10 weeks that are generally the hottest of the summer with the greatest cooling demand. The cost impact would have been much larger had the SMDS detected continued degradation and estimated cost impacts over this time period. Servicing of this unit should yield savings equivalent to the increase in energy cost. Leaving the unit as is rather than servicing it will likely result in continued or even increased performance degradation, increasing the excess energy costs even further next season and likely eventually damaging the equipment. The estimated electricity cost increase for RTU3 at Test Site A of the Cloud SMDS tests, in contrast, was lower at $\$ 55$ over 6 weeks (see Figure 26) for an estimated rural New York blended electric rate of $\$ 0.10 / \mathrm{kWh}$. The associated increase in energy use (and potential savings from unit servicing) is $550 \mathrm{kWh}$. These increases in energy use and costs correspond to the end of the cooling season from Sept. 8 to Oct. 20. During a similar time period, the RTU with degradation in the Hardware SMDS had an estimated increase in cost over the same time period of only $\$ 150$, about $26 \%$ of the total increased energy cost of $\$ 456$ (and likely an even smaller proportion if the impacts in the hottest weeks of summer had been included in the estimated increase in energy costs). Therefore, for an entire season the degradation at the Cloud SMDS test site would likely be considerably larger.

Additional examination of the number of points used for degradation detection tends to indicate that the data collection period for each analysis could be decreased from the 3 weeks used during the demonstration to 2 weeks, which would enable the SMDS to provide results to users 2 weeks sooner (in 4 weeks rather than 6 weeks). Results for 1 week are much less encouraging. See Appendix B.

Without technology for performance degradation detection, these sorts of impacts generally go unnoticed because no feedback on equipment performance is available.

\section{B. Detection of Operational Faults}

The operational fault detection results demonstrate that the SMDS is able to detect operation faults in RTUs. Across all units, the SMDS detected four of the five operation faults that the SMDS is designed to detect. These are the primary conclusions regarding operational fault detection that can be reached from the field test results.

Different predominate faults were detected in the Hardware SMDS field tests (Faults 1 and 2) and the Cloud SMDS field tests (Faults 4 and 5). Fault 3 (compressor on all day) was detected for only 1 day for one RTU, RTU1 at Test Site A in the Hardware SMDS tests. This tends to show that the specific faults occurring may depend on the specific RTUs, their owners, geographic location, and other factors the effects of which cannot be distinguished from a study of only 12 RTUs on two buildings at two different geographic locations with different climates. A reader of the results for only one type of SMDS (Hardware or Cloud) might be tempted to conclude that only two of the faults are prevalent or that the SMDS can only detect two of the five faults. Examination of the 
fault detection results for both the Hardware SMDS and the Cloud SMDS clearly shows this is not the case. Considering both sites, the results show that four of the five faults that the SMDS can detect were detected. Furthermore, with the very small sample of RTUs (12), the conclusion should not be reached that compressors running all day (Fault 3) are rare; a much larger sample of RTUs would be required to reach such a conclusion about fault prevalence or rate of occurrence.

\section{Logistic and Test Design Issues}

Several logistic issues were encountered during the field test, the primary of which are discussed in this section.

Insufficient time was available in the field test to measure the response of building owners or management in taking corrective service actions to fix degradation and faults detected. For example, although the SMDS detected an estimated $\$ 456$ of degradation over the course of the monitoring period for RTU1 at Test Site A, there was not sufficient time at the end of the demonstration to gather information from the user on actions they took (if any) for the RTU. Ideally, the user would service the RTU, and more data would be gathered on the effect of performance degradation and RTU servicing. Advanced testing of the SMDS across more climate zones with RTU servicing actions would provide valuable information.

For similar reasons, insufficient time was available during which owner or management staff had access to the SMDS user interface to expect response to the information for the Hardware SMDS. The UI for the Cloud SMDS was not given to the buildings' staff and thus no measurement of response to the information could be measured.

The project relied on installation work and site visits to investigate and address SMDS issues for the Hardware SMDS field tests. When this work is done at no cost to the project by owners, owner staff, or service providers, it generally is given low priority and must compete with higher priority paid jobs. In the Hardware SMDS demonstration, this resulted in significant delays relative to schedule.

The SMDS prototype technology had not been field tested by actual building staff and service personnel before the tests documented in this report. The hardware technology especially may not have been ready for such testing and would have benefited from more field testing by PNNL or partner staff before moving to testing by potential end users or providers of services to them. A demonstration of early stage technology in prototype form is quite different than testing of new commercial products, which are ready for end customer use. In moving the SMDS technology to the market, end user testing, including the rates of end users taking corrective actions, and installer observations on the installation process will become increasingly important. As the technology approaches commercial-product form, collection of these responses and impressions will become more meaningful and compatible with the state of the technology. In this project, the SMDS protoytpes were still at the stage of discovering and resolving technical issues and obtaining initial measurements of its performance and behavior under field conditions.

Testing of the SMDS as it approaches commercialization (and tests and demonstration on similar technology) would benefit from the following:

Field Testing and Demonstration of the Smart Monitoring and Diagnostics System (SMDS) for Packaged Air Conditioners and Heat Pumps 
- testing on a much larger sample of RTUs to expose the SMDS to a greater variety of RTU operating conditions and changes in performance,

- testing on a larger sample of buildings with a greater variety of owners (as originally planned), and

- sampling of RTUs in the broader range of climate zones in which the SMDS would potentially be applied (as originally planned).

- testing under controlled conditions where faults could be instigated in RTUs and the response of the SMDS measured to understand the sensitivity of detection and the impacts that should be expected.

Results from testing on small samples must not be misinterpreted as representing performance of a technology when applied more broadly to the buildings sector; use of larger samples is critical to reaching such conclusions.

\section{Other Lessons Learned}

The SMDS demonstration project provided many other lessons related to the performance of similar projects, which are identified in this section. These lessons relate to the hardware, software, and the logistics associated with interactions with demonstration partners.

- The enthusiasm and interest of site personnel are critical: During the SMDS demonstration, there were several times when PNNL had to communicate with the site personnel to investigate hardware and/or software issues. This sometimes required troubleshooting, photographing equipment, meticulous attention to communications. The enthusiasm and interest of site personnel was crucial in accomplishing the tasks required to complete a successful demonstration.

- Hardware needs to be durable: During shipment of the SMDS hardware, damage occurred to one of the radio cards and one of the outdoor-air temperature sensor housings. Hardware must be designed to withstand conditions during shipping, and packing must be adequate to prevent damage.

- Measurement equipment must meet equipment specifications: During the initial site selection process, consideration was not given to the RTU power requirements with respect to the hardware design. During one of the initial site installations, site staff could not secure the current transducers on the individual power components of the RTU. The result was a failed installation, and modification to the current transducer specifications.

- Outdoor-air temperature sensor shielding and location is critical: Because the SMDS is always on the rooftop, solar gain can be an issue. Clear, concise directions for SMDS placement on the south side of the RTU should be listed. In addition, the sensor housing should be modified from gray to white, to reduce solar gain in cases where natural sunlight cannot be avoided.

- User interface design is the most critical component for building owners: The feedback from the demonstration partners was that they were very excited about the technology. However, after review of the user interface, both partners had questions regarding the information presented. More consideration and resources should be dedicated to initial interface design, to appeal to users both aesthetically and technically. Conveying technical 
information in a way that is understandable to all users of the technology will increase the market adoption of the technology.

- Hardware installation procedures must be simple if end user staff are installing. The installations at the Hardware SMDS test sites took between 4 hours and several days before confirmation that all equipment was communicating successfully was received. This required constant communication and support between NorthWrite and the site. The feedback was that the installation was too complex and time-consuming despite the equipment being designed for quick, easy installation. Most installation problems were associated with verification and maintenance of wireless communication and changes required to software. 


\section{Appendices}

\section{A. SMDS Demonstration Installation Guide}

Packing List -

Indoors - Each Building will have:

- 1 - Gateway device with Extended Antenna \& Power Supply

- 1 - Ethernet Cable

- 1 - Zigbee Repeater with Power Supply

- 1 - Cell Modem with Sprint SIM

Rooftop - Each unit will have:

- 1 - SMDS RTU Monitor

- 1 - Set of 3 Current Transformers wired to multi connector

- 1 - 4 Wire Power Cable wired to SMDS RTU Monitor

These units have been preconfigured to communicate. Once properly wired and powered they will connect to each other and begin providing data to our Network Operations Center. It is very important that the device does go into its predestined location (located on the interior label).

Materials needed -

1. 2 - NM/SE knockout connectors for power box. (per rooftop unit (RTU))

Step 1 - Install ISY Gateway and Connect to the Internet

A. Connect Gateway to Power and Cell Modem in an indoor location as close to the rooftop units as possible (e.g., if the building is has 4 floors, connect the Gateway and Cell Modem on the $4^{\text {th }}$ floor).

B. Set Zigbee repeater aside until verification and signal strength has been analyzed by NorthWrite.

Step 2 - Install SMDS on the rooftop unit.

A. Remove power to the RTU. Test to be sure there is no power coming to the circuit breaker.

B. Determine where to mount the SMDS Monitor to the rooftop unit. This will be limited by the length of the CT's wiring harness (7 ft.). Please keep in mind that we want to avoid direct sunlight as much as possible to get the best temperature data that we can (you will notice the heat shield protecting the temperature probe on the base of the unit).

C. Open up the device and perform a quick examination for any damage caused in shipping, any disconnected wires etc.). If you find any problems or have any questions call NorthWrite customer Service@1-800-743-4232

D. Mount the SMDS Monitor using the enclosed sheet metal screws. Take this time to also Earth Ground the device using the Green Ground Wire coming from the SMDS Monitor.

E. Determine power configuration of the rooftop unit being monitored. You will need to use the number of CT's and power leads that correspond with your specific configuration. Here is an example:

3 phase RTU Power Lead Neutral (GREEN), CT \# 1 (BLACK), CT \# 2 (RED), CT \#3 (WHITE)

There is only one order to wire this:

Green $=$ Neutral

Field Testing and Demonstration of the Smart Monitoring and Diagnostics System (SMDS)

for Packaged Air Conditioners and Heat Pumps 
Black $=$ Phase 1

Red $=$ Phase 2

White $=$ Phase 3

F. Make sure the rooftop unit is powered down. Punch a medium sized knockout from the box where the unit gets its power and pull the CT's through the opening, the connecter first. You will need to secure these knockouts with a NM/SE connector (not provided because size varies). Punch a smaller knockout in the box and pull the power lead into the box.

G. Connect the power lead to the unit by securing the Green Lead to the neutral buss and the correct power (see above) lines into the breaker itself.

H. Attach necessary CT's to power feed to the rooftop unit. Make sure that the load arrows on the CT's are pointing in the direction of the RTU. (Each phase is numbered and must be connected to the feed from the same line as its voltage).

IE - BLACK wire connected to Phase \# 1 and CT \# 1 on feed to the rooftop unit.

Red wire connected to Phase \#2 and CT \#2 on feed to the rooftop unit.

White wire connected to Phase \#3 and CT \#3 on feed to the rooftop unit.

**If the unit is a 3-phase unit, then all three CT's WILL BE USED. However, if the unit is only single phase or split phase, 1 or 2 CT's will be used, in which case use included zip ties to secure extras CT out of the way, and clean up your wiring.

I. Insert Blue CT and Red CT Connectors into their respective ports on the bottom of the SMDS Monitor.

** Once you have completed the install, and you get everything closed up, please use a dab of silicone sealant on both of these connectors to ensure their water shedding abilities.

J. Repower the rooftop unit and open up the SMDS Monitor Box. Once connected, you should see a blue light and a green light alternately blinking.

Repeat the steps above for each RTU being monitored. Once this is completed, please contact NorthWrite Customer Service @ 1-800-743-4232 to go over the installation details, verification of radio signal strength, and data moving to our Network Operations Center. If the signal strength is too low, we will instruct you on how and where to hook up the Zigbee repeater.

\section{SMDS Install Guide Photos}

Here are some images that will help to understand each of the parts of this system. 


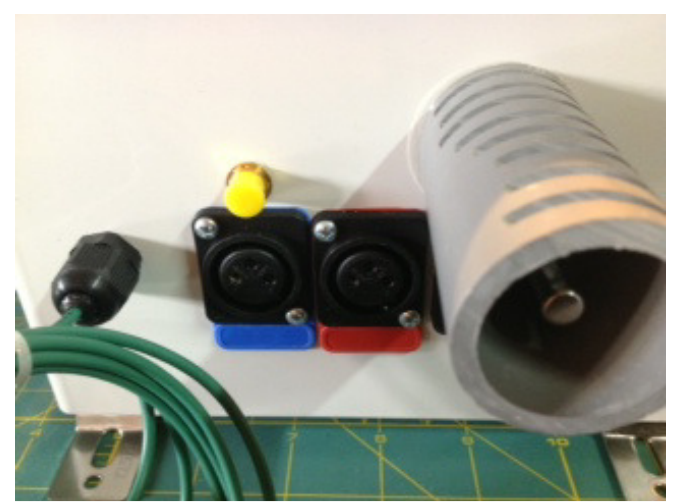

Notice Green Ground Wire

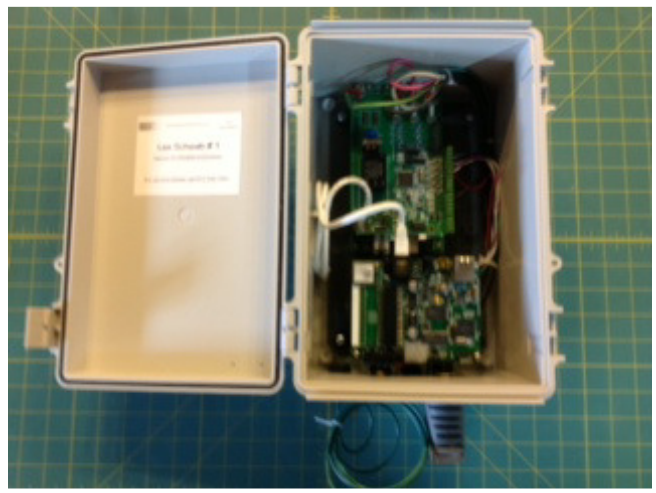

SMDS Monitor

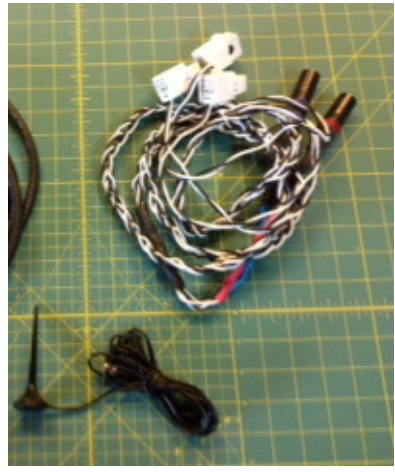

Contents of Cable Bag (CT's and Zigbee Antenna) 


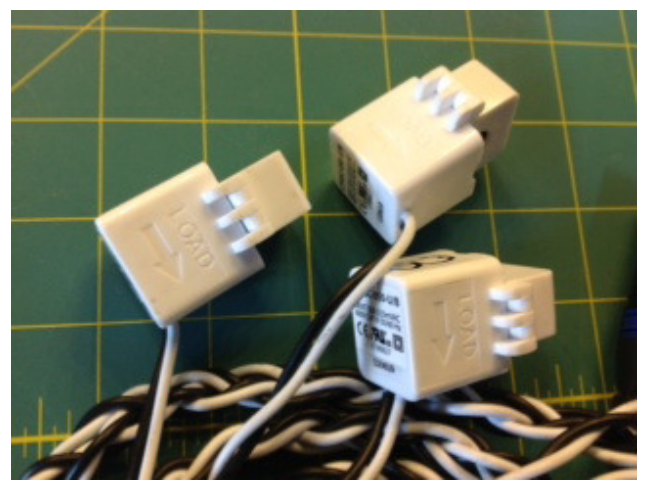

Notice the Load Direction arrows on CT's

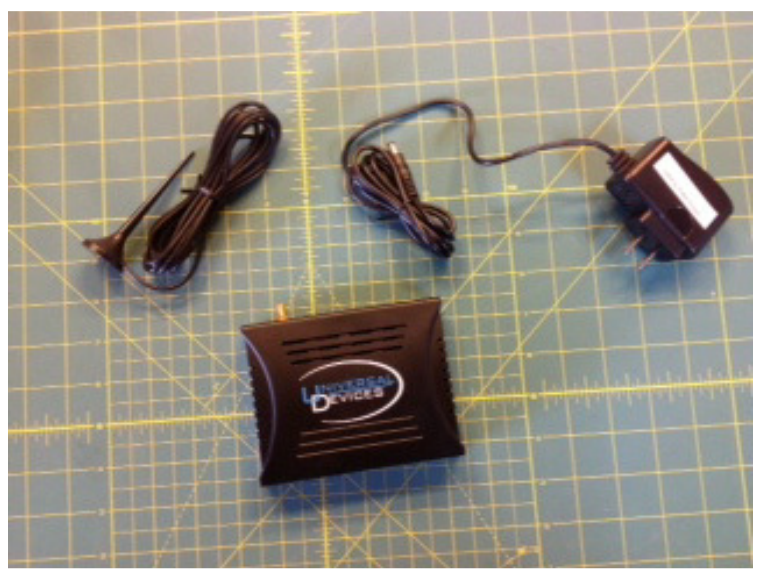

ISY Gateway, Antenna and Power Supply

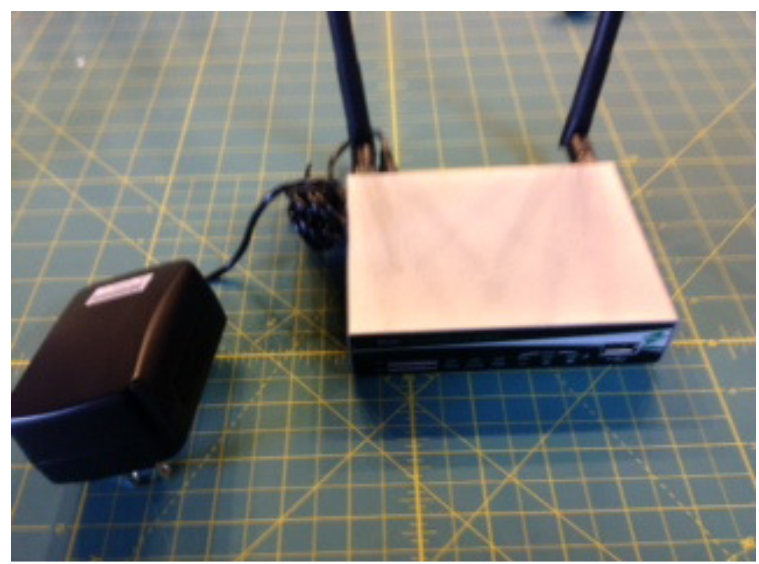

Cell Modem \& Antennas with Power Supply 


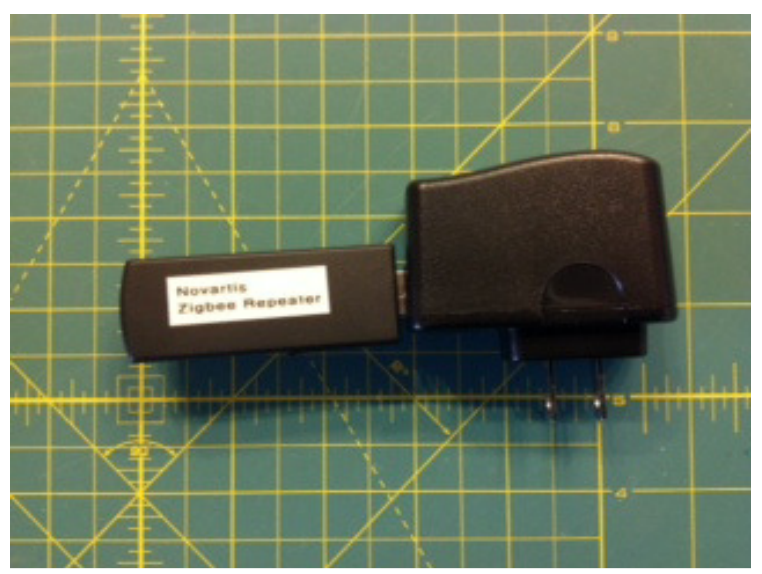

Zigbee Repeater with Power Supply

\section{B. Degradation Detection Methodology Improvement - Use of Smaller Data Sets}

In cases when all criteria are satisfied for determining performance curves, the SMDS methodology still requires 6 weeks of data (3 weeks of 1-minute data for the baseline and 3 weeks for the first postbaseline period) before the performance degradation detection process can execute. After the SMDS successfully establishes the first set of post-baseline performance curves and the detection process is run, the execution of the detection process repeats weekly. The oldest week of data in the previous monitoring period is removed and is replacing by the current week of data collected. Thus, a sliding time window three weeks long is used to define the data set for each execution of the degradation detection process.

Reducing the number of data points required for establishing the baseline and for subsequent processing for degradation detection because results could be obtained earlier. For example, decreasing the number of required data points from 30,240 (3 weeks) to 20,160 (2 weeks) for each processing would enable the SMDS to provide the first degradation detection results after 4 weeks of data collection rather than the 6 weeks, and decreasing the number of points required per degradation detection processing to 10,080 (1 week) would enable SMDS to provide the first results in 2 weeks. Users are generally anxious to see initial results; therefore, reducing the time to the first results has value in meeting user expectations. Furthermore, shorter data sets for processes would also provide more weeks of analysis in testing efforts like the one in this project.

The use of shorter data sets was therefore examined using the field test data for the Hardware SMDS. The software was modified to use both 2-week and 1-week data sets. The criteria described in Section III, requiring a minimum number of cooling cycles and a specified range of outdoor-air temperatures, were also modified for reasonable compatibility with the smaller data sets. The minimum outdoor-air temperature requirement was changed from $20^{\circ} \mathrm{F}$ to $10^{\circ} \mathrm{F}$, and the required minimum number of cycle points was modified from 50 to 30 .

Table VIII.1 and Table VIII.2 show the results from the SMDS performance degradation detection process with these smaller data sets corresponding to 2 weeks of data points and 1 week, respectively. 
Table VIII.1 SMDS performance degradation results for all RTUs in the Hardware SMDS field test, using 2-week data sets

\begin{tabular}{|c|c|c|c|c|c|c|}
\hline \multirow{2}{*}{ Location } & RTU & $\begin{array}{c}\text { Baseline } \\
\text { Performance } \\
\text { Curves } \\
\text { Established } \\
\text { (Yes/No) }\end{array}$ & $\begin{array}{c}\text { Total Number } \\
\text { of Weeks after } \\
\text { Baseline } \\
\text { Establishment }\end{array}$ & $\begin{array}{c}\text { Degradation } \\
\text { Detected } \\
\text { (Yes/No) }\end{array}$ & $\begin{array}{c}\text { Fraction of } \\
\text { Weeks with } \\
\text { Detected } \\
\text { Degradation }\end{array}$ & $\begin{array}{c}\text { Estimated } \\
\text { Cumulative } \\
\text { Cost of } \\
\text { Degradation } \\
\mathbf{( \$ )}\end{array}$ \\
\hline \multirow{3}{*}{$\begin{array}{c}\text { Test Site } \\
\text { A }\end{array}$} & RTU1 & Yes & 19 & Yes & $14 / 19$ & $\$ 451$ \\
\cline { 2 - 7 } & RTU2 & Yes & 24 & No & $0 / 24$ & ---- \\
\cline { 2 - 7 } & RTU3 & Yes & 11 & Yes & $3 / 11$ & $\$ 1$ \\
\hline \multirow{2}{*}{$\begin{array}{c}\text { Test Site } \\
\text { B }\end{array}$} & RTU1 & Yes & 6 & Yes & $3 / 6$ & $-\$ 31$ \\
\cline { 2 - 7 } & RTU2 & Yes & 8 & No & $0 / 8$ & --- \\
\cline { 2 - 7 } & RTU3 & No & N/A* & N/A* & N/A* & N/A* \\
\hline
\end{tabular}

${ }^{*} \mathrm{~N} / \mathrm{A}=$ Not Applicable: SMDS did not establish baseline performance curves; therefore not able to detect degradation.

Table VIII.2 SMDS performance degradation results for all RTUs in the field test, using the 1-week data collection methodology approach

\begin{tabular}{|c|c|c|c|c|c|c|}
\hline Location & RTU & $\begin{array}{c}\text { Baseline } \\
\text { Performance } \\
\text { Curves } \\
\text { Established } \\
(\text { Yes/No) } \\
\end{array}$ & $\begin{array}{c}\text { Total Number } \\
\text { of Weeks after } \\
\text { Baseline } \\
\text { Establishment }\end{array}$ & $\begin{array}{c}\text { Degradation } \\
\text { Detected } \\
(\text { Yes/No) }\end{array}$ & $\begin{array}{c}\text { Fraction of } \\
\text { Weeks with } \\
\text { Detected } \\
\text { Degradation }\end{array}$ & $\begin{array}{c}\text { Estimated } \\
\text { Cumulative } \\
\text { Cost of } \\
\text { Degradation } \\
(\$)\end{array}$ \\
\hline \multirow{3}{*}{$\begin{array}{c}\text { Test Site } \\
\text { A }\end{array}$} & RTU1 & Yes & 19 & Yes & $15 / 19$ & $\$ 574$ \\
\hline & RTU2 & Yes & 18 & No & $0 / 18$ & ---- \\
\hline & RTU3 & Yes & 8 & Yes & $2 / 8$ & $\$ 0$ \\
\hline \multirow{3}{*}{$\begin{array}{c}\text { Test Site } \\
\text { B }\end{array}$} & RTU1 & Yes & 8 & Yes & $4 / 8$ & $-\$ 19$ \\
\hline & RTU2 & Yes & 6 & No & $0 / 6$ & ---- \\
\hline & RTU3 & No & $\mathrm{N} / \mathrm{A}^{*}$ & $\mathrm{~N} / \mathrm{A}^{*}$ & $\mathrm{~N} / \mathrm{A}^{*}$ & $\mathrm{~N} / \mathrm{A}^{*}$ \\
\hline
\end{tabular}

$* \mathrm{~N} / \mathrm{A}=$ Not Applicable: SMDS did not establish baseline performance curves; therefore not able to detect degradation.

Comparing the results obtained using the 3-week data sets (see Table 4 in Section VE) with the results using 1-week and 2-week data sets reveals that a baseline was established for an addition RTU, RTU2 at Test Site B. This additional baseline was obtained not from using a smaller data set but because the temperature range required in these analyses was decreased to $10^{\circ} \mathrm{F}$ from the $20^{\circ} \mathrm{F}$ required in degradation analysis of the 3-week data. Still, no degradation was detected for this unit.

Performance degradation was only detected for one RTU, RTU1 at Test Site A, for all three sizes of data sets. Detection of the degradation persisted over about the same number of weeks, 15 out of 19 total weeks after establishment of the baseline for analysis with the 3-week and 1-week data sets and 14 out of 19 weeks for the 2 -week data sets, as indicated by the fraction of weeks with degradation detected. The cumulative cost of degradation relative to the estimate of $\$ 456$ for analysis using the 3- 
week data sets was $\$ 5$ less $(\$ 451)$ in the results for 2 -week data sets and $\$ 118$ greater $(\$ 574)$ for the 1 week data sets.

Satisfying the criteria on the number of cycle data points and temperature range of the cycle data for establishing a baseline was difficult when using the 1-week data sets, thus requiring continuation of data collection (beyond the 10,080 points corresponding to 1 week) to satisfy these criteria.

The total number of weeks after baseline establishment increased in all but one unit (RTU3 at Test Site A) for the 2-week data sets compared to the total number of weeks after establishing a baseline for the 3-week data sets. For the 1-week data sets, the number of weeks after establishing the baseline increased for 2 RTUs and decreased for 2 RTUs compared to the results when using 3-week data sets. Although various factors other than the nominal time for data collection (e.g., differences in the criteria on data for proceeding with the degradation detection analysis and the relationship between the number of cooling cycles and the length of the nominal data collection period) contribute to the observed differences in results, the 2 -week data sets with less stringent criteria for proceeding with the performance degradation detection analysis yielded results more consistent with the results from the 3 -week data sets than did the 1 -week data sets. Based on this limited evidence, the authors conclude that use of 2-week data sets shows promise for use in place of the 3-week data sets in the SMDS but testing on more RTUs is needed.

\section{Acronyms}

ASHRAE

BTO

CBM

CT

DOE

EIA

HVAC

$\mathrm{NM} / \mathrm{SE}$

NOC

NYSERDA

OAT
American Society of Heating, Refrigerating, and Air-Conditioning Engineers

U.S. Department of Energy, Building Technologies Office

Condition-based maintenance

Current transducer

U.S. Department of Energy

Energy Information Administration

Heating, ventilating and air conditioning

Non-metallic, service entrance

Network operations center

New York Energy Research and Development Administration

Outdoor-air temperature

Field Testing and Demonstration of the Smart Monitoring and Diagnostics System (SMDS) 
$\begin{array}{ll}\text { PNNL } & \text { Pacific Northwest National Laboratory } \\ \text { PVC } & \text { Polyvinyl chloride } \\ \text { RTU } & \text { Rooftop unit, packaged air conditioners and heat pumps } \\ \text { SMDS } & \text { Smart Monitoring and Diagnostic System } \\ \text { UI } & \text { User interface }\end{array}$

\section{References}

ASHRAE. 2012. ASHRAE Standard 180-2012: Standard Practice for Inspection and Maintenance of Commercial Building HV AC Systems. American Society of Heating, Refrigerating and Air-

Conditioning Engineers Inc., Atlanta, GA.

ASHRAE. 2010. ASHRAE Standard 62.1-2010: Ventilation for Acceptable Indoor Air Quality. American Society of Heating, Refrigerating and Air-Conditioning Engineers Inc., Atlanta, GA.

U.S. Department of Energy (DOE). 2014. "Install units produced by the High Performance Rooftop Unit Challenge that meet the high performance rooftop unit specification." Web page at http://www4.eere.energy.gov/alliance/activities/technology-solutions-teams/spaceconditioning/rtu, last accessed on November 23, 2014.

Energy Information Administration (EIA). 2006. 2003 Commercial Buildings Energy Consumption Survey. U.S. Department of Energy, Washington, D.C. Last accessed in September 2014 at http://www.eia.doe.gov/emeu/cbecs/contents.html. 